\title{
Criticality Safety Envelope for Receipt, Handling, and Storage of Transuranic Waste
}

by

A. M. Vincent

Westinghouse Savannah River Company

Savannah River Site

Aiken, South Carolina 29808

K. E.

Hammer

This paper was prepared in connection with work done under the above contract number with the U.S. Department of Energy. By acceptance of this paper, the publisher and/or recipient acknowledges the U. S. Government's right to retain a nonexclusive, royalty-free license in and to any copyright covering this paper, along with the right to reproduce and to authorize others to reproduce all or part of the copyrighted paper. 


\section{DISCLAIMER}

This report was prepared as an account of work sponsored by an agency of the United States Government. Neither the United States Government nor any agency thereof, nor any of their employees, makes any warranty, express or implied, or assumes any legal liability or responsibility for the accuracy, completeness, or usefulness of any information, apparatus, product, or process disclosed, or represents that its use would not infringe privately owned rights. Reference herein to any specific commercial product, process, or service by trade name, trademark, manufacturer, or otherwise does not necessarily constitute or imply its endorsement, recommendation, or favoring by the United States Government or any agency thereof. The views and opinions of authors expressed herein do not necessarily state or reflect those of the United States Government or any agency thereof.

This report has been reproduced directly from the best available copy.

Available to DOE and DOE contractors from the Office of Scientific and Technical Information, P. O. Box 62, Oak Ridge, TN 37831; prices available from (423) 576-8401.

Available to the public from the National Technical Information Service, U. S. Department of Commerce, 5285 Port Royal Road, Springfield, VA 22161. 


\section{DISCLAIMER}

Portions of this document may be illegible in electronic image products. Images are produced from the best available original document. 
WESTINGHOUSE SAFETY MANAGEMENT SOLUTIONS

CRITICALITY AND RADIATION TRANSPORT SERVICES

CRITICALITY SAFETY SERVICES

6 November 97

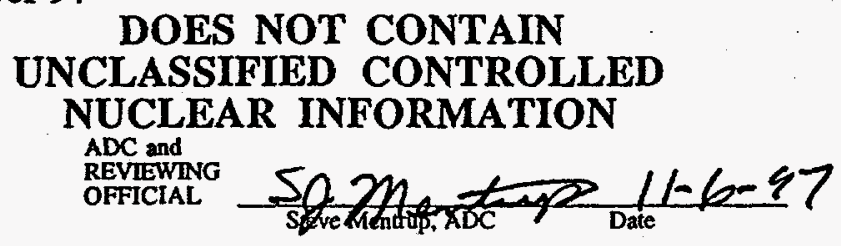

N-NCS-E-00008

Rev. 0

Page 1 of 71

KEYWORDS:

TRU Waste

Technical

Safety Margins

Criticality

MCNP4A

RETENTION:

LIFETIME

\section{Nuclear Criticality Safety Evaluation:}

CRITICALITY SAFETY ENVELOPE FOR RECEIPT, HANDLING, AND STORAGE OF TRANSURANIC WASTE (U)

APPROVAL

Author

Criticality Safety Services

Technical Reviewer

Criticality Technology Services

Manager

Criticality Safety Services

Manager

Solid Waste Safety Compliance
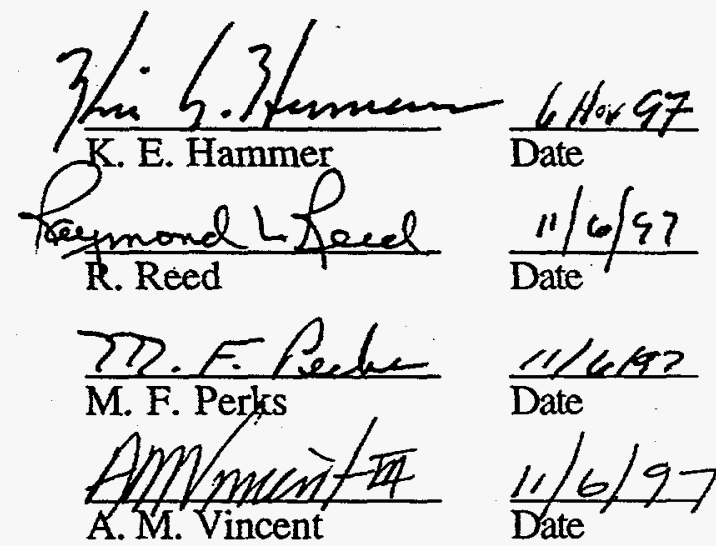

DISTRIBUTION

F. Beranek,

C. E. Apperson

M. F. Perks

J. R. Chandler

J. Brotherton

R. L. Reed

K. E. Hammer

A. Q. Goslen

J. L. Kelly

WSMS Files
$\mathrm{CCC} 3 / 16$

$\mathrm{CCC} 3 / 31$

706-F/114

$\mathrm{CCC} 3 / 7$

$\mathrm{CCC} 3 / 9$

$\mathrm{CCC} 3 / 33$

642-E

$704-2 \mathrm{H} / 187$

$724-21 \mathrm{E}$

$\mathrm{CCC} 3$
R. M. Seaborn

W. T. Goldston

A. M. Vincent

J. A. Blankenhorn

W. A. Morrison

D. W. Zimmerman

J. A. D'amelio

S. J. Mentrup

A. Gibbs

Records Management
705-3C

705-3C

$724-21 \mathrm{E}$

$724-9 \mathrm{E}$

724-7E

724-7E

705-3C

705-3C

724-21E

730-B 


\section{Table of Contents}

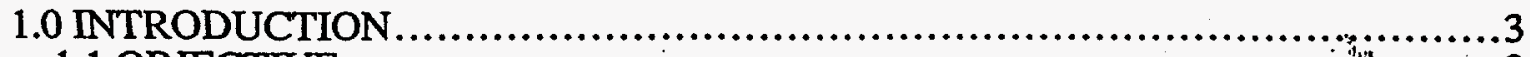

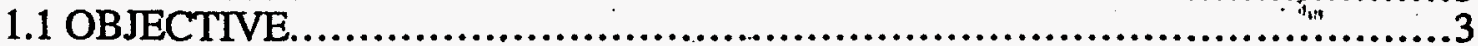

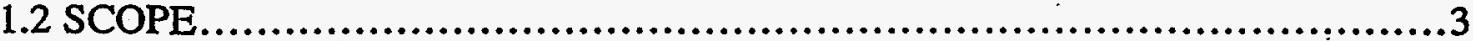

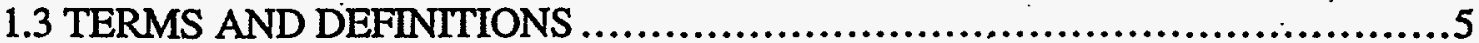

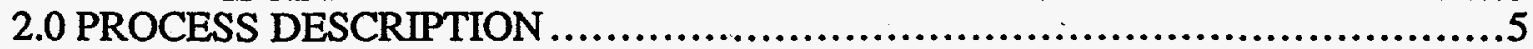

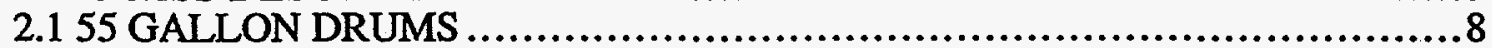

2.2 POL YETHYLENE BOXES............................................................. 10

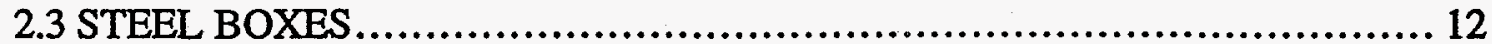

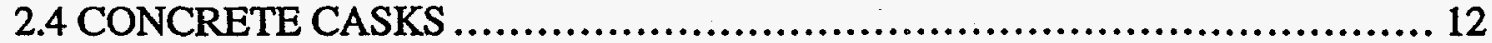

2.5 CONCRETE CULVERTS...................................................... 13

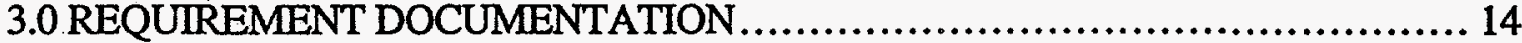

4.0 METHODOLOGY ............................................................. 15

5.0 EVALUATIONS............................................................... 18

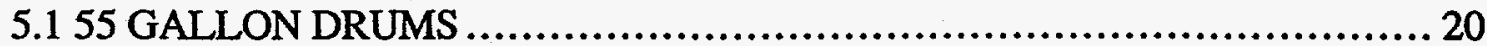

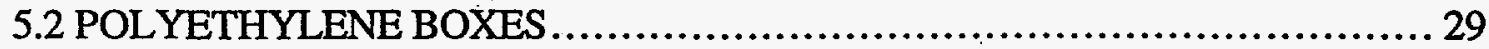

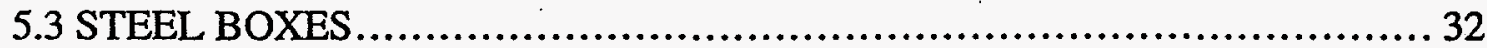

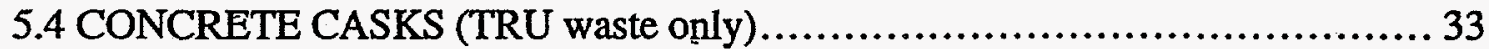

5.5 CONCRETE CULVERTS................................................. 34

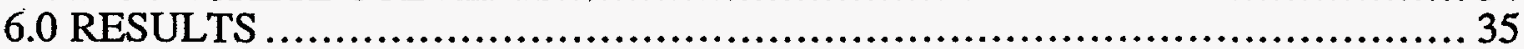

7.0 DESIGN FEATURES (ACTIVE AND PASSIVE) AND ADMINISTRATIVE

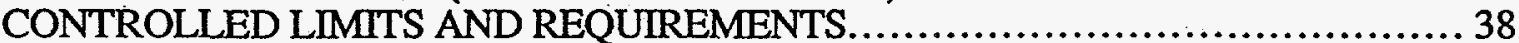

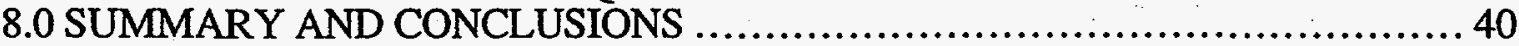

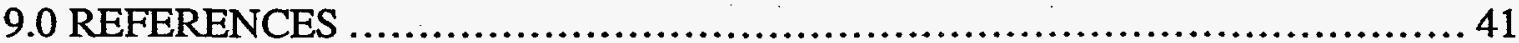

10.0 APPENDIX A - MCNP4A DRUM MODELS $\ldots \ldots \ldots \ldots \ldots \ldots \ldots \ldots \ldots \ldots \ldots . . .44$

11.0 APPENDIX B - HEPA FILTER CHARACTERISTICS $\ldots \ldots \ldots \ldots \ldots \ldots \ldots \ldots \ldots . \ldots \ldots$ 


\subsection{INTRODUCTION}

Current criticality safety limits for Solid Waste Management Facility (SWMF) Transuranic (TRU) Waste Storage Pads are based on analysis of systems where mass is the only independent parameter and all other parameters are assumed at their most reactive values (Ref. 1). These limits result in administrative controls (i.e., limit stacking of containers, coordination of drums for culvert storage based on individual drum fissile inventories, and mass limits for accumulation of polyethylene boxes in culverts) which can only be met by redundant SWMF administrative controls. These analyses did not credit the nature of the waste generator process that would provide bounding limits on the other parameters (i.e. less than optimal moderation and configurations within packages (containers)). They also did not indicate the margin of safety associated with operating to these mass limits. However, by crediting the waste generator processes (and maintaining such process assumptions via controls in the criteria for waste acceptance) sufficient margin of safety can be demonstrated to justify continued SWMF TRU pad operation with fewer administrative controls than specified in the Double Contingency Analysis (DCA) (Ref. 1).

\subsection{OBJECTIVE}

This NCSE will justify a reduced set of criticality safety controls for receipt, handling, and storage activities for the Transuranic (TRU) waste based on credit taken for the nature of containerized TRU waste. The new criticality safety controls will continue to control (limit) container inventory, but will rely on the lack of excess moderating material in the container and credible physical limitations on fissile configurations within the container. This NCSE will demonstrate that under normal and credible abnormal conditions both the container fissile inventory limit and at least one of the bounding assumptions must be exceeded to result in a critical configuration.

This NCSE is presented in four parts. The process description provides the reader with a description of the types of waste and the process by which waste is packaged by the waste generators (normal conditions). The evaluation section outlines the thought process by which normal conditions are combined with credible upset scenarios to identify the most reactive configurations. Each configuration is evaluated to determined the scenario's impact on reactivity and safety of the upset conditions. The results section indicates the margin of safety by which SWMF TRU waste storage pads are operated. The design features and administrative controls section identifies the waste acceptance criticality safety controls credited by this NCSE and the existing handling/storage controls that are no longer required for criticality safety.

\subsection{SCOPE}

This NCSE applies to receipt, handling, and storage of TRU waste on the Solid Waste Management Facility (SWMF) TRU waste storage pads. This includes drums, polyethylene boxes, steel boxes, concrete culverts, and concrete casks. This NCSE considered all TRU waste generators (Ref. 2). It covers both existing waste on the TRU pads and continuing waste receipt provided the waste generator practices upon which the NCSE is predicated are maintained. The NCSE covers both normal and credible abnormal conditions. 
This NCSE is predicated on the following waste generation practices used by waste generators

* No increases in current container fissile inventory limits as prescribed by thè Waste Acceptance Criteria (WAC) 3.06 (Ref. 3). This is a key assumption used in determining the frequencies of criticality related conditions and configurations on the TRU pads (Ref. 4). Drums, polyethylene boxes, concrete casks, and steel boxes are limited to $195 \mathrm{~g}$ FGE Pu-239. Concrete culverts are limited to $390 \mathrm{~g}$ FGE Pu-239 unless the culvert is filled with drums or polyethylene boxes to which $195 \mathrm{~g} \mathrm{Pu}-239$ for each drum or box applies.

* The current practices, the same as those used in the past, of recovering usable fissile material and decontamination ensuring surface contamination is well attached and not easily dislodged will continue to be practiced in the future.

* Waste generation process and packaging practices that "by their nature" limit polyethylene (or equivalent) to less than $30 \%$ by volume inside the container.

* Fissile material contaminated waste is randomly distributed within waste containers. This is a key assumption used in determining the frequencies of criticality related conditions and configurations on the TRU pads (Ref. 4).

* Concrete culvert walls/bases are at least 5" thick providing 4 hours of protection from external fires and have an internal volume of $4.8 \mathrm{~m} * * 3$ or less limiting internal fires as used in the Fire Estimate (Ref. 5).

Containers which can be exempted from these assumptions will have applicable criticality safety evaluations prepared and controls determined demonstrating their safety in Solid Waste configurations prior to receipt, handling, and storage in a Solid Waste Facility. In the past, exemptions have been granted for following waste receipts:

- HEPA filters in polyethylene boxes that have been overloaded due to known pre-filter failure (Ref. 6), but that were within the inventory limit for a culvert;

- Standard Waste Boxes (Ref. 7) that were not approved containers at the time of receipt but were within the inventory limit for a culvert (Ref. 8);

- Naval Fuels waste whose configuration was justified by a specific NCSE (Ref. 9); and

- FB-Line Special Big Black Steel Boxes (Ref. 10).

This NCSE does not cover SWMF waste configurations with specific NCSE justifications (Naval Fuels and FB-Line Special Big Black Steel Boxes). These configurations are legacy waste whose safety has been determined by previous NCSEs. These configurations are closed to further waste handling activities and the Double Contingency requirements protecting them (posted signs and exclusionary fencing) were identified in the Solid Waste Double Contingency Analysis (Ref. 1). These specific Double Contingency Analysis (DCA) requirements are implemented via the SWMF Technical Safety Requirements (Ref. 11) and are verified for DCA compliance (Ref. 12). 
This NCSE also does not cover receipt, handling, and storage of containers that are not approved (Ref. 8) or containers exceeding inventory limits (Ref. 6), unless they have been overpacked in other approved containers (i.e., containers identified in this NCSE) with higher inventory limits. Justification for acceptance includes an engineering evaluation, possibly including an NCSE, demonstrating the overpack container is bounded by the assumptions and limits identified by this NCSE. Receipt, handling, and storage is performed to the limits and controls of the overpack container.

\subsection{TERMS AND DEFINITIONS}

Credible Event - an event that has a frequency of occurrence of larger than 1.0E-6 occurrences per year.

Hydrogenous Waste - waste containing high concentrations of hydrogen, primarily polyethylene and water, or other materials with good moderating properties.

K-effective - Multiplication factor for a finite system.

$\underline{\mathrm{K} \text {-safe }}$ - Value of $\mathrm{K}$-effective that is considered to be always safe, considering the appropriate bias, bias uncertainty, area of applicability margin, and minimum suberiticality margin.

Red Pails - 5 gallon pails (painted red) that are used only for handling waste contaminated with fissionable material. The pails are critically safe for any waste that can fit inside the pail provided proper separation is maintained between pails.

SWMF - Solid Waste Management Facility

USQE - Unreviewed Safety Question Evaluation.

WAC - Waste Acceptance Criteria, referring to the SRS Site 1S Manual

Waste Cut - Quantity and type of items that have been contaminated from being used inside the process line where fissile material is regularly handled and processed,

WIPP - Waste Isolation Pilot Project

TRU - Transuranic isotopes with atomic number of 92 or higher.

\subsection{PROCESS DESCRIPTION}

This section provides the reader with an overview of waste generator processes related to the characterization and packaging of solid waste. This discussion will provide the nominal characteristics and internal configuration of waste in waste containers. These nominal configurations will be used as normal conditions for the discussion of contingencies and evaluation of safety margins.

SWMF receives, handles, and stores fissile-contaminated waste packaged in approved containers. The waste is generated by various site processes and packaged by the waste generators in accordance with their procedures. The waste is packaged and shipped to SWMF in accordance with the Manual IS Waste Acceptance Criteria (Ref. 3). The waste generator procedures contain sufficient controls to ensure the waste packaging and :associated documentation complies with the requirements imposed by the Waste 
Acceptance Criteria and the Double Contingency Principle (Ref. 2). Facilities packaging waste are reviewed prior to shipment and periodically monitored for compliance with the Waste Acceptance Criteria and Double Contingency Principle (Ref. 3). Frequently waste generator procedures impose more restrictive fissile content limits on containers than specified in the WAC (e.g., FB-Line generally imposes a $150 \mathrm{~g}$ FGE limit versus the $195 \mathrm{~g}$ FGE limit specified in the WAC for waste drums).

Current criticality safety limits, their basis, and the associated criticality safety controls are identified in the SWMF DCA (Ref. 1). The limits are summarized in Chapter 6 of the SWMF SAR (Ref. 13) and are presented in Table 1.

Table 1 - Waste Storage Pad Mass and Configuration limits

\begin{tabular}{|c|c|c|}
\hline Waste Receipt Classification & Mass Limit & Configuration Limit \\
\hline Handling of 55 Gallon Drums & $<195 \mathrm{~g} \mathrm{Pu}-239 \mathrm{FGE}$ & Single Planar Array \\
\hline Handling of 55 Gallon Drums & $\begin{array}{l}<130 \text { g Pu-239 FGE, exception } 3 \\
\text { Drums }>130 \text {, but }<195 \text { g Pu-239 FGE }\end{array}$ & Up To Two Tier Stacking \\
\hline $\begin{array}{l}\text { Drums containing } 1 / 2 \mathrm{Ci} \text { or Less } \\
\text { Excluding } \mathrm{Cm}-245, \mathrm{Cm}-246, \mathrm{Cm}- \\
247, \mathrm{U}-235, \mathrm{U}-236 \text {, and U-238 }\end{array}$ & None & Up To 3 Tier Stacking \\
\hline $\begin{array}{l}\text { Drums containing } 1 / 2 \mathrm{Ci} \text { or Less } \\
\text { Including } \mathrm{Cm}-245, \mathrm{Cm}-246, \mathrm{Cm}- \\
247, \mathrm{U}-235, \mathrm{U}-236, \text { and } \mathrm{U}-238\end{array}$ & Engineering Evaluation & Engineering Evaluation \\
\hline Steel Boxes with more than $1 / 2 \mathrm{Ci}$ & $<195$ g Pu-239 FGE per Box & Single Planar Array \\
\hline $\begin{array}{l}\text { Concrete Casks with more than } 1 / 2 \\
\mathrm{Ci}\end{array}$ & $<195$ g Pu-239 FGE per Casks & Single Planar Array \\
\hline $\begin{array}{l}\text { Concrete Culverts with more than } \\
1 / 2 \mathrm{Ci}\end{array}$ & $<390$ g Pu-239 FGE per Culvert & Single Planar Array \\
\hline Drums in Culverts & $\begin{array}{l}3 \text { Drums }>130 \text {, but }<195 \mathrm{~g} \text { Pu-239 } \\
\text { FGE, } 11 \text { Drums }<130 \mathrm{~g} \mathrm{Pu-239} \mathrm{FGE,} \\
\text { Max. Culvert Total } 2015 \mathrm{~g} \mathrm{Pu-239} \\
\text { FGE }\end{array}$ & Two Tier Stacking \\
\hline $\begin{array}{l}\text { Handling Polyethylene Boxes } \\
\text { container HEPA or Roughing Filters } \\
\text { with more than } 1 / 2 \mathrm{Ci} \text { Outside } \\
\text { Culverts }\end{array}$ & $<195$ g Pu-239 FGE per Box & Single Planar Array \\
\hline Polyethylene boxes Inside Culverts & $<390$ g Pu-239 FGE per culvert & Two Tier Stacking \\
\hline
\end{tabular}

It should be noted that SWMF has implemented inventory limits for drums and polyethylene boxes that are more restrictive than the WAC limits based on past NCSEs. The past NCSEs used the more conservative approach of not crediting limited availability of moderation and credible distributions of fissile material within the container. Stacking limits are implemented for all containers. In Table 1, engineering evaluations refer to a safety analysis, including criticality safety, performed prior to receipt that determines the safety of handling/storage of the waste and ensures that proper procedures have been implemented. 
The Savannah River Site (SRS) has multiple TRU waste generators that send waste to SWMF as well as the potential for off-site receipt of TRU waste (Ref. 2). The following SRS facilities have in the past shipped TRU waste to SWMF.

- FB-Line

- SRTC

- 772-F Laboratory

- HB-Line

- 235-F

Each facility may have multiple waste streams. Although the waste streams have many individual characteristics, there are two important characteristics that apply to all waste streams:

- differences between job control waste and process waste, and

- difference in the type of container in to which the waste is packaged.

\section{JOB CONTROL WASTE VERSUS PROCESS WASTE}

The first characteristic that distinguishes waste streams is whether the waste is process waste or job control waste. Process waste comes from the process line where fissile materials are handled and job control waste comes from work areas surrounding the process lines. Job control waste has low fissile content, on the order of a few grams per container (drum), but contains large amounts of moderating material like polyethylene. Process waste has a higher fissile content than job control waste, but has lesser amounts of moderating material.

Process waste normally doesn't contain excessive amounts of fissile because of nuclear material accountability, ALARA, waste minimization, and container inventory restrictions imposed on the waste generators. Material accountability practices require that waste cuts removed from the process and that are indicating 100 or more grams fissile are returned to the process line for recovery (Ref. 2). ALARA practices strive to reduce exposure by decontamination of waste prior to handling. Waste minimization strives to reduce the volume of TRU waste, subsequently TRU contamination is minimized. The Site Waste Acceptance Criteria sets the site limits for container inventories of $\mathrm{Pu}-239$ or equivalent based on the type of container.

A probability risk assessment has been performed to evaluate the likelihood of intermingling the process waste and the job control waste (Ref. 14). The PRA documented the incredibility of these two types of waste streams becoming mixed. The PRA credited waste generator procedures that maintain the separation of job control and process waste streams.

There have been cases where process waste containers were mixed with job control waste containers (Ref. 15). These cases have been attributed to waste burial slips (Ref. 16) incorrectly indicating zero fissile material content; assays of the waste containers determined the fissile material content recorded on the slips to be incorrect (Ref. 15). 


\section{CONTANER TYPE}

The second characteristic that distinguishes waste streams is the type of container.

Approved containers for packaging waste included 55 gallon drums, polyethylene boxes, steel boxes, concrete casks, and concrete culverts. Table 2 indicates container materials and dimensions.

Table 2 - Approved Container Nominal Dimension and Materials

\begin{tabular}{|c|c|c|c|c|c|}
\hline Container Type & $\begin{array}{c}\text { Inside } \\
\text { Dimensions }\end{array}$ & $\begin{array}{c}\text { Wall } \\
\text { Thickness }\end{array}$ & $\begin{array}{c}\text { Wall } \\
\text { Material }\end{array}$ & $\begin{array}{l}\text { Internal } \\
\text { Liners }\end{array}$ & Reference \\
\hline $\begin{array}{l}55 \text { Gallon } \\
\text { Drums }\end{array}$ & $\begin{array}{l}\text { Diameter } 221 / 2^{\prime \prime} \\
\text { Height } 333 / 16^{\prime \prime}\end{array}$ & 16 Gauge & $\begin{array}{c}\text { Low Carbon } \\
\text { Steel }\end{array}$ & Polyethylene & 17 \\
\hline $\begin{array}{l}\text { Polyethylene } \\
\text { Boxes }\end{array}$ & $\begin{array}{c}\text { Base } 163 / 4^{\prime \prime} \times \\
291 / 4^{\prime \prime} \\
\text { Height } 301 / 4 "\end{array}$ & $1 / 8^{\prime \prime}$ & Polyethylene & None & 18 \\
\hline Concrete Casks & $\begin{array}{c}\text { Base } 311 / 2 " \text { by } \\
311 / 2 " \\
\text { Height } 441 / 4 "\end{array}$ & $4-6^{\prime \prime}$ & Concrete & 3/8" Steel & 19 \\
\hline Steel Boxes & $\begin{array}{c}\text { Base } 12^{\prime} \times 18^{\prime} \\
\text { Height } 7^{\prime} \\
\text { or } \\
\text { Fitted to } \\
\text { Equipment }\end{array}$ & $3 / 8^{\prime \prime}$ & Steel & $\begin{array}{c}\text { 3/4" } \\
\text { plywood } \\
\text { Internal } \\
\text { Containers }\end{array}$ & 20 \\
\hline $\begin{array}{l}\text { Concrete } \\
\text { Culverts }\end{array}$ & $\begin{array}{c}\text { Diameter } 6^{\prime} \\
\text { Height } 6^{\prime}\end{array}$ & $6 "$ & Concrete & None & 21 \\
\hline
\end{tabular}

\subsection{GALLON DRUMS}

This section provides a description of the waste generator process by which drums are loaded with waste. The description includes all types of drum waste and the nominal configuration/content associated with the waste type. These nominal drum configurations will be used as the starting point for the evaluation section to be presented later in this NCSE.

Waste placed in drums includes tools, vessels, lead lined gloves, glove box HEPA filters, plastic bottles containing swipes used to clean out cabinets, and job control waste. Job control waste are items used outside the process lines that have become contaminated because of the trace amounts of fissile material. The other items have been surfacecontaminated from being used inside the process line where fissile material is regularly handled and processed. Each item is removed separately and referred to as a waste cut. Thus, waste placed in drums is characterized as job control waste and surface contaminated, atomic swipes, and glove box HEPA filters process waste.

The SRS approved 55 gallon drums are described briefly in Table 2 and in detail in reference 17.

\section{JOB CONTROL WASTE}

Job control waste is generated by work performed outside the process line. Levels of fissile material contamination outside the process are maintained as low as reasonably possible to minimize worker exposure. However, waste generated in these areas can become contaminated with fissile material. This waste is collected into drums kept separate from the waste removed from the process line (Ref. 14). Drums are scanned to determine 
the level of alpha contamination. At just a few grams of fissile material per drum, drums filled with job control waste are not a criticality concern.

\section{SURFACE-CONTAMINATED PROCESS WASTE}

Surface-contaminated process wastes are typically tools, vessels, and lead lined gloves used within the process line that must be changed out. These items are thoroughly decontaminated before being removed from the process line: thus any fissile contamination is affixed to surfaces and would take considerable effort to remove. These items are wrapped in polyethylene bags to limit the spread of contamination and removed via the bagout ports as waste cuts. Fissile material surface-contamination can be in contact with polyethylene, but fissile material is attached to the waste and cannot mix with the polyethylene (mixed together in the sense that the polyethylene and fissile material cannot form an optimal fissile/moderator ratio). As they are removed, waste cuts are surveyed using a hand held neutron counter to estimate the amount of fissile material. Waste cuts with excessive amounts of fissile material are returned to the process line for further decontamination. "Excessive amounts of fissile material" is currently set at $100 \mathrm{~g} \mathrm{Pu}-239$ based on the Criticality Safety Limit in the room containing the assay instruments (Ref. 2). Typical surface contaminated process waste contains on the order of gram quantities of $\mathrm{Pu}$ 239 and waste volumes are generally less than 0.5 liters. The majority of the waste cuts fit into red pails (Ref. 2) and are assayed to obtain an accurate account of the fissile material in the waste (Ref. 2). When sufficient waste cuts have been collected to fill one or more drums, operations determines which waste cuts are to be placed in each drum and initiates the drum filling process (typical of FB-Line). When waste cuts have filled a drum, the drum is closed and assayed (final portable far field gamma assay (Ref. 2)) to confirm the results of the waste cut scans. Larger waste cuts can't be assayed. Their fissile material content is determined using a portable far field gamma assay. Both survey and assay methods have been characterized and calibrated to meet the requirements of the Waste Acceptance Criteria and to ensure fissile inventories are conservatively estimated (Ref. 2).

Typically, 16 to 20 waste cuts may be placed in a drum. The waste cuts are not placed in the drum in any preferred order. The total accumulation of fissile material in the drum may not exceed the operating limits of the drum (150 g Pu-239, Ref. 2). Free space is minimized to reduce the number of TRU containers, but waste is not forced into the drum to prevent the spread of contamination. Operating limits for the drums are less than the Nuclear Criticality Safety Limits for drum fissile inventory (Ref. 2).

\section{ATOMIC SWIPE PROCESS WASTE}

Atomic Swipes (Ref. 22) are used to clean out wet and dry cabinets in the process line. The clean out process results in the swipes becoming thoroughly contaminated with fissile material.

In wet cabinets, fissile bearing liquids are soaked into the swipe. The amount of fissile material is dependent on the concentration in the cabinet and the volume of the swipe. However, wet cabinets have administrative criticality safety controls limiting the concentration to always safe levels (less than $7.3 \mathrm{~g}$ per liter, ANS 8.1 (Ref. 23)). Thus, the amount of fissile material in the wet swipes is limited by the volume of the swipes. Used swipes are placed in 1-liter plastic bottles (Ref. 24).

In dry cabinets, fissile material dust is collected with the swipe. The amount of fissile material is dependent on the amount of dust that can be collected and the volume of the swipe. Dry cabinets are not concentration limited. The swipes contain an unknown amount of fissile material, possibly more than $100 \mathrm{~g} \mathrm{Pu}-239$. Clean out procedures treat them as 
potentially unsafe. Clean out procedures have procedural criticality safety control steps that limit no more than 6 swipes in one bottle, no more than two bottles in one cabinet, and 3 foot separation between bottles (Ref. 22).

All bottles are wrapped in polyethylene bags, removed via the bagout ports, neutron counter surveyed, and placed in red pails. As is the case with surface contaminated process waste, excessive waste cuts (greater than $100 \mathrm{~g} \mathrm{Pu}-239$ ) are returned to the process line to reclaim excess fissile material. All of these waste cuts, as 1 liter bottles, are assayed and fissile content conservatively estimated (Ref. 2). These wrapped waste cuts are placed in drums with surface contaminated process waste. No preferred order is used during placement. The drum inventory limit is not exceeded.

\section{GLOVE BOX FILTER PROCESS WASTE}

Glove box filters are small HEPA filters (small enough to fit in a red pail) attached to glove boxes. These filters are sometimes referred to as pre-filters or cabinet filters. These filters protect the larger ventilation HEPA filters from becoming highly contaminated. The filter material is N007 filter grade media as specified in AG-1 (Ref. 25). The filter medium is made of B-type borosilicate glass and traps (i.e., release of contamination takes considerable effort) contamination by diffusion of the particulate into the material, The filter medium is folded such that air flows into the filter parallel to the medium and contamination is uniformly distributed throughout the filter (see Ventilation HEPA Filters Section 2.2). The filter medium is designed to withstand extreme conditions. The medium doesn't support combustion, and melting occurs only at high temperatures (1000 degree C).

These filters are replaced on a regular schedule or when the pressure differential across the filter indicates the filter is saturated. The filters are wrapped in polyethylene bags, removed via the bagout ports, surveyed by a neutron counter, and placed in red pails. As is the case with surface contaminated process waste, excessive waste cuts (greater than $100 \mathrm{~g} \mathrm{Pu}-239$ ) are returned to the process line to reclaim excess fissile material (Ref. 2). All of these waste cuts are assayed and fissile content conservatively estimated (Ref. 2). These wrapped waste cuts are placed in drums with surface contaminated process waste. No preferred order is used during placement in the drum. The drum inventory limit is not exceeded.

\subsection{POLYETHYLENE BOXES}

This section provides a description of the waste generator process by which polyethylene boxes are loaded with waste. The description includes all types of polyethylene box waste and the nominal configuration/content associated with the waste type. These nominal polyethylene box configurations will be used as the starting point for the evaluation section to be presented later in this NCSE.

The SRS approved polyethylene boxes are briefly described in Table 2 and in detail in reference 18 .

Polyethylene boxes are used for short term confinement of contaminated waste. However, polyethylene boxes will melt and burn during a fire. Polyethylene has a melting point of 120 - 135 degree C (Ref. 26). Polyethylene will flash burn at 340 degree C (Ref. 26). Polyethylene will burn, but it will hardly support combustion (Ref. 27). 
SWMF has approved the receipt of roughing filters and ventilation HEPA filters in polyethylene boxes. Restrictions limiting waste types in polyethylene boxes are specified in the Waste Acceptance Criteria (Ref. 3).

Other types of waste placed in polyethylene boxes include, for example, cabinet panels, but in these cases the polyethylene boxes are placed in other containers (i.e., steel boxes). Polyethylene boxes are considered waste in the other containers.

\section{ROUGHING FILTERS}

Roughing filters are used in the ventilation system to filter air before passing through the ventilation HEPA filter. The roughing filters are similar to those used in home heating systems. The roughing filters strip out particles larger than 1 micron. Fissile contamination particles are generally smaller than 1 micron, ranging from 0.2 to 0.7 microns, and generally pass through the roughing filter. Thus, roughing filters have significantly less fissile contamination than HEPA filters. These filters are replaced on a regular schedule or when the pressure differential across the filter indicates the filter is saturated. These filters are individually triple bagged and placed 8 roughing filters to a polyethylene box. These filters are too large to fit in a red pail. Fissile content is determined by portable far field gamma assay and documented dose-to-curie calculations (Ref. 2).

\section{VENTILATION HEPA FIL TERS}

Ventilation HEPA filters are large HEPA filters (24" x 24" x 11.5") that remove small particle contamination from the ventilation system. These filters are protected by cabinet (glovebox) and roughing filters, thus they generally do not accumulate large amounts of fissile material. The filter material is N007 filter grade media as specified in AG-1 (Ref. 25). The filter material is designed not to burn (limited to $7 \%$ by mass loss on ignition of organic binders at 360 degree $C$ for 45 minutes (Ref. 25)). However, the material will char and melt, but only under extreme conditions (more than one hour exposure to 1000 degree $\mathrm{C}$ (Ref. 25). The filter media is glued to steel frames. The frames are at least 11.5" deep. In contrast, the glove box filters have cardboard frames.

The filter medium is a continuous sheet of folded filter paper. Folds are required by the specification to be 8 to 11.5 " in length. The medium is made of B-type borosilicate glass (Ref. 25). The filter medium is folded such that air flows into the filter parallel to the medium and contamination uniformly diffuses into the filter medium (Ref. 28). Van der Waals forces trap $99 \%$ of Pu-239 contamination caught by the filter medium (Ref. 28). Fires cause the media fibers to melt together and further trap the fissile material in the filter medium (see Appendix B). Melting of HEPA filter fibers eliminates voids and reduces the filter medium volume. (see Appendix B). Thus, it is assumed that the fissile material received with the HEPA filter remains attached to the HEPA filter medium even after a fire.

The fissile material is uniformly loaded over the surface of the filter because the folded design has a large effective flow area that is needed for high mass flow rate and low pressure drops across the filter (see Appendix B). The ventilation HEPA filter must maintain high flow rate $(1000 \mathrm{ft} * * 3 / \mathrm{min})$ with low pressure drop ( 1 inch of water). To ensure this condition, large flow areas must be used. Thus, contaminated air must flow through the entire flow area of the filter (i.e., across the folds) of the filter.

The folded medium incorporates considerable void into the filter volume (24" $x 24$ " $\mathrm{x}$ 11.5"). Based on minimum manufacturer specifications ( $280 \mathrm{sq}$. ft at 16.5 mils thick, Ref. 29) the 108 liter filter volume is occupied by 10.9 liters of filter medium. 
These filters are replaced on a regular schedule or when the pressure differential across the filter indicates the filter is saturated. The filter is triple bagged and placed one filter to a polyethylene box. The filter is too large to fit in a red pail. Fissile content is determined by portable far field gamma assay and documented dose-to-curie calculations (Ref. 2).

\subsection{STEEL BOXES}

This section provides a description of the waste generator process by which steel boxes are loaded with waste. The description includes all types of steel box waste and the nominal configuration/content associated with the waste type. These nominal steel box configurations will be used as the starting point for the discussion of evaluations to be presented later in this NCSE.

The SRS approved steel boxes are briefly described in Table 2 and in detail in reference 20 .

Steel Boxes are constructed to contain retired equipment from the process lines. Dimensions of the boxes vary depending on the size of the equipment. Typical boxes have been $18^{\prime}$ long by $12^{\prime}$ wide by $7^{\prime}$ tall, containing a decontaminated glove box. Steel boxes have been given a variety of names in the past including Big Black Steel Boxes, Engineered Steel Boxes, and Miscellaneous Steel Boxes. Steel boxes are stored on concrete pads or in concrete culverts based on radiation levels.

When a piece of equipment is retired from the process line, it is first decontaminated. The item is often highly contaminated and requires extensive decontamination before it is separated from the line. Decontamination includes both chemical and mechanical methods. Hand surveys, sensing at micro-curie levels, are performed to ensure all reclaimable materials have been removed. Decontamination practices eliminate loose or easily detached fissile contamination from the waste. The remaining fissile contamination is generally minor and is securely attached to surfaces.

The item is separated from the process line after decontamination. Job control waste is placed inside the item to effectively use the space. The item is wrapped in polyethylene (perhaps a polyethylene box) and placed inside a plywood box. As the item is moved out through successively cleaner areas, more polyethylene is wrapped around the item. When the item reaches the clean area, a steel box is constructed around the item. The box is constructed with thick ( $3 / 8$ inch) steel walls with side vents that allow gases to escape, but prevent rain from entering.

Steel boxes are hand scanned after construction and fissile content is conservatively estimated using documented dose-to-curie calculations (Ref. 2).

\subsection{CONCRETE CASKS}

This section provides a description of the waste generator process by which concrete casks are loaded with waste. The description includes all types of concrete cask waste and the nominal configuration/content associated with the waste type. These nominal concrete cask configurations will be used as the starting point for the evaluation section to be presented later in this NCSE.

The SRS approved concrete casks are briefly described in Table 2 and in detail in reference 19.

Waste placed in concrete casks is generally surface-contaminated associated laboratory equipment. Associated laboratory equipment includes some polyethylene and other 
hydrogenous material, but free liquids are prohibited. Small shavings of fissile material may be present, but do not represent a significant amount of fissile material (i.e., less than $15 \mathrm{~g} \mathrm{FGE} \mathrm{Pu-239}$ per SCD-3, Ref. 30). Available fissile material is reclaimed for mass accountability prior to disposal. Fissile material content for each waste cut is determined by mass balance before and after the waste is generated. Waste items are placed inside steel cask liners and compacted with a $1000 \mathrm{lb}$. weight. When the steel liner/box is full, it is closed, removed from the shielded cell, and placed in a concrete cask. Fissile material content of the cask is determined by the waste cut data records. Fissile material is generally distributed throughout the container, but is not necessarily homogeneous.

\subsection{CONCRETE CULVERTS}

This section provides a description of the waste generator process by which concrete culverts are loaded with waste. The description includes all types of concrete culvert waste and the nominal configuration/content associated with the waste type. These nominal concrete culvert configurations will be used as the starting point for the evaluation section to be presented later in this NCSE.

The SRS approved concrete culverts are briefly described in Table 2 and in detail in reference 21 .

Concrete culverts are used to shield waste pad personnel from high alpha contaminated drums and polyethylene boxes.

Concrete culverts are also used as waste containers for special cases. In each case, the waste is evaluated to document the actual configuration and content of the waste. Receipt of Standard Waste Boxes (Ref. 8) is one example where culverts were used to receive waste. In this case, the Standard Waste Boxes had not been documented as approved containers for SWMF receipt, but could be accepted as waste in a culvert. 


\subsection{REQUIREMENT DOCUMENTATION}

This NCSE fulfills the requirements of DOE Order 5820.2A (Ref. 31) mandating that criticality safety evaluations be performed on all DOE waste management facilities.'

This NCSE was performed to the requirements of the SRS Nuclear Criticality Safety Manual (Ref. 30). 


\subsection{METHODOLOGY}

This NCSE does not set new criticality safety limits, but provides an evaluation of criticality safety margins given past and current packaging practices, including in'ventory limits.

This NCSE compares nominal operating conditions to credible upset conditions to demonstrate the margin of safety in SWMF operations.

Normal operating conditions for this NCSE are based on the following assumptions.

* Container fissile material inventories are at their maximum allowed by the Site Waste Acceptance Criteria (Ref. 3). In reality, most packages have fissile material content much less than the limits.

* Maximum moderation content is less than $30 \%$ of the waste volume based on the "nature of the waste generation and packaging process", and

* Placement of waste cuts/waste materials is randomly distributed within the container based on documented process knowledge and procedures lacking specific instructions to distribute waste cuts.

Credible upset conditions for this NCSE refer to mass errors, operator placement of waste cuts in the most reactive configuration (within containers) when containers are stacked next to each other, flooding of containers with water, degradation of internal waste cut segmentation, and fires.

Normal waste configurations within individual containers are identified in the process description section of this NCSE. No credit is taken for SWMF handling and storage of containers. The worst possible array stacking is assumed as a normal condition. Credible abnormal conditions, including hypothetical fires and flooding, are identified in the evaluation section of this NCSE. Container dimensions used in this NCSE were obtained from approved design specifications (Ref. 17, 18, 19, 20, 21).

Container inventories, $\mathrm{Pu}-239$ mass per container, are treated as the independent variable. Credible mass errors are bounded by frequency analysis of past inventory errors (Ref. 4).

The safety of identified conditions, both nominal and upset, will be evaluated based on ANS standards, existing NCSEs, and analyses performed using MCNP4A running on an IBM RS6000 workstation on the WSRC AFS network (Ref. 32). Configurations and dimensions are listed in the MCNP4A input models provided in Appendix A. Material atom densities and cross sections used in the MCNP4A calculations are listed in Table 3. Mixtures of materials were based on volume fractions (Ref. 33). Fissile material was assumed to be $100 \% \mathrm{Pu}-239$ (a conservative assumption for TRU waste). 
TABLE 3 - Material Atom Densities

\begin{tabular}{||c|c|c|c||}
\hline Material & cross-section File & Nuclide & Atom/bn-cm \\
\hline Carbon Steel & $6012.50 c$ & Carbon & $3.921 \mathrm{e}+03$ \\
\hline & $26000.50 c$ & Iron & $8.3491 \mathrm{e}-02$ \\
\hline Air (at STP) & $7014.50 c$ & Nitrogen & $4.25 \mathrm{e}-05$ \\
\hline & $8016.50 c$ & Oxygen & $1.13 \mathrm{e}-05$ \\
\hline Polyethylene (100\%) & $1001.50 c$ & Hydrogen & $7.95868 \mathrm{e}-02$ \\
\hline & $6012.50 c$ & Carbon & $3.95211 \mathrm{e}-02$ \\
\hline Standard Concrete & $26000.50 \mathrm{c}$ & Iron & $3.474 \mathrm{e}-04$ \\
\hline & $1001.50 c$ & Hydrogen & $1.3846 \mathrm{e}-02$ \\
\hline & $8016.50 c$ & Oxygen & $4.57783 \mathrm{e}-02$ \\
\hline & $20000.50 c$ & Calcium & $1.5231 \mathrm{e}-03$ \\
\hline & $14000.50 c$ & Silicon & $1.66646 \mathrm{e}-02$ \\
\hline & $19000.50 \mathrm{c}$ & Potassium & $4.615 \mathrm{e}-04$ \\
\hline & $13027.50 \mathrm{c}$ & Aluminum & $1.7436 \mathrm{e}-03$ \\
\hline & $6012.50 \mathrm{c}$ & Carbon & $1.154 \mathrm{e}-04$ \\
\hline & $12000.50 c$ & Magnesium & $1.14 \mathrm{e}-04$ \\
\hline & $1001.50 \mathrm{c}$ & Hydrogen & $6.68499 \mathrm{e}-02$ \\
\hline & $8016.50 \mathrm{c}$ & Oxygen & $.3 .34249 \mathrm{e}-02$ \\
\hline
\end{tabular}

All calculations in this NCSE were based on drum arrays since average fissile densities for drums and drum arrays are greater than any other waste containers. Thus, mass limits for drum arrays are conservatively applicable to all other container arrays.

For all models, the $\mathrm{Pu}-239$ atom densities were specified to get the desired amount of $\mathrm{Pu}$ 239 in the fissile lump.

For models that required fissile/moderator material lumps with fixed volume, Pu-239 atom densities were adjusted to obtain a variety of Pu-239 masses. Lump volumes were modeled as the intersection of the drum cylinder and a sphere of given radius (Ref. 34). Lumps intersecting the base or top plane of the drum required larger radii to have the same volume. Thus, lumps at the midplane of the drum used a lump radius of $10 \mathrm{~cm}$, but lumps at the bottom of the drum used $13 \mathrm{~cm}$. The Pu-239 atom densities used in the models are listed in Table 4.

Table 4 - Pu-239 Number Densities (Atoms/barn-cm) Used in MCNP4A Drum Array Calculations.

\begin{tabular}{|c|c|c|}
\hline Lump Radius (cm) & 13 & 10 \\
\hline Lump Volume (cm**3) & 2103 & 1956 \\
\hline $195 \mathrm{~g} \mathrm{Pu}-239$ & 0.0002336 & 0.0002511 \\
\hline $300 \mathrm{~g} \mathrm{Pu}-239$ & 0.0003594 & 0.0003864 \\
\hline $390 \mathrm{~g} \mathrm{Pu}-239$ & 0.0004672 & 0.0005023 \\
\hline $510 \mathrm{~g} \mathrm{Pu}-239$ & 0.0006109 & 0.0006568 \\
\hline $728 \mathrm{~g} \mathrm{Pu}-239$ & 0.0008721 & 0.0009376 \\
\hline $970 \mathrm{~g} \mathrm{Pu}-239$ & 0.0011620 & 0.0012493 \\
\hline
\end{tabular}

Fissile lumps were modeled as a mixture of $\mathrm{Pu}-239$, polyethylene, water, and air. For dry conditions, a 30/5/65 volume percent mixture of polyethylene, water, and air, respectively, was assumed. This moderator mixture was used to bound the moderating properties of the 
low density wood fiber used to make swipes. For wet conditions, a 30/70 volume percent mixture of polyethylene and water was assumed. The remainder of the drum was filled with polyethylene, water, and air based on whether dry or wet conditions are being modeled.

Calculations were run for a sufficient number of histories to ensure variations in the solution were small compared to the standard deviation of the result. Results reported in this NCSE include both the K-effective of the system and the standard deviation. A system is considered criticality safe if calculated $\mathrm{K}$-effective plus two standard deviations is less than K-safe.

$\mathrm{K}$-safe used in this NCSE is 0.96. The nominal and upset conditions identified in this NCSE are the same as those covered by a previous NCSE (Ref. 33 and 35) which established an appropriate bias, bias uncertainty, area of applicability margin, and minimum subcriticality margin for SWMF TRU waste activities resulting in a K-safe of 0.96 for MCNP4A calculations using the ENDF/B-V continuous energy cross section library. 


\subsection{EVALUATIONS}

The following discussion will demonstrate that SWMF waste container configurations remain safely subcritical under normal and credible abnormal conditions (most reactive) taking credit for standard practices of packaging the waste. Discussion of contingencies is an integral part of demonstrating these conditions.

Waste container types and typical contents were identified in section 2.0. However, interaction between containers is dependent on how containers are stacked together.

Normal stacking of containers is based on the type of container and container inventory (see Table 1). Steel boxes, concrete casks, and concrete culverts are normally stacked 1 high in square pitched arrays independent of container inventory. Drums with less than $1 / 2$ $\mathrm{Ci}$ of alpha contamination (equivalent of less than $8 \mathrm{~g} \mathrm{Pu}-239$ ) can be banded 4 drums to a pallet and stacked 3 high in square pitched arrays on the waste storage pad. Drums with more than $1 / 2 \mathrm{Ci}$ must be placed inside a culvert to reduce worker exposure. Inside the culvert, the drums are stacked 2 high in a triangular pitch array with 11 of the drums limited to less than $130 \mathrm{~g} \mathrm{Pu}-239$. Polyethylene boxes are stacked two high when stored in culverts and the culvert inventory is limited $390 \mathrm{~g}$ Pu-239. All containers are handled assuming they contain their maximum fissile material inventory and are restricted to 1 high stacking. In this evaluation, stacking of all containers will be considered a credible upset condition to demonstrate that containers meeting the WAC inventory limits can be handled in any configuration.

Initiating events, leading to abnormal configurations, were limited to credible initiating events that would have a credible impact on criticality safety. Credible initiating events are those that would occur on a frequency greater than once in a million years. Credible events for this NCSE included operator/machinery errors, rain (flooding of container), fires, radiolytic decomposition of plastic containers, tornadoes, and high winds, but didn't include plane crashes and meteors. Those events having a credible impact on criticality safety would result in configurations that are more reactive than the normal configurations. Thus, operator/machinery error, flooding, fires, radiolytic decomposition could effect a reactivity increase, but tornadoes and high winds would disperse containers. The resulting upsets that were identified included stacking/spacing of containers, operator distribution of waste within the container, exceeding container fissile inventory limits, exceeding hydrogenous waste content, flooding of the container, aging/radiolytic decomposition of internal plastic containers, and fires.

These upsets will be discussed from two points of view. First, each upset is considered generically providing some background on the scenario and describing the effects the upset could have on content and configuration. In some cases, the generic description provides the justification for eliminating the upset from further consideration. Second, each of the upset scenarios are addressed in relation to the process description in section 2.0 .

- Stacking - Current criticality safety limits limit some container stacking to single planar arrays (see Table 1). The intention of this NCSE is to demonstrate that stacking restrictions are not needed. Thus, this evaluation will consider stacking containers 2 or more high as an upset condition.

- Spacing - The error is SWMF places containers closer together than they are placed during normal operations. For example, pad stored drums are normally placed in square arrays with rolling rims touching. A spacing error would be placing the grums 
in a triangular array with the rolling rims overlapping. This applies to drums which can be placed in either triangular or square pitched arrays and have rolling rims that can be mistakenly overlapped. The result is fissile material lumps within the container being placed closer to lumps in neighboring containers.

- Operator Loading - The error is a waste generator operator mal-distributes several high fissile content lumps, without exceeding drum inventory limits, in each of several containers such that these containers could be configured with the fissile lumps collocated. A review of Waste Generator procedures (Ref. 2) did not identify procedural steps that excluded the operator from preferentially placing waste cuts, potentially producing sections of the container with higher than nominal concentration of fissile material. The analysis of mass errors (Ref. 4) assumes lumps were randomly placed in the container and included the probability of collocation in the determination of credible mass errors.

- Container Fissile Inventory - The error is the amount of fissile material in a container has exceeded the limit due to operator or machinery errors and SWMF is not notified. This is referred to as a double batch when the fissile mass exceeds twice the limit (Ref. 30). An evaluation of past burial records and waste cut data (Ref. 4) has determined credible (i.e., frequency of once in a million years) mass errors for waste containers received by SWMF. The review identified credible single/multiple container mass errors.

- Hydrogenous Waste - The error is the waste generator has packaged more hydrogenous waste in a container than normal. A previous study (Ref. 36) has bounded the normal and credible abnormal polyethylene content for current SRS waste generation operations at less than $30 \%$ by volume. All calculations will bound hydrogenous waste errors by assuming the waste volume always contain $30 \%$ polyethylene.

- Container Flooding - The error is a container becomes flooded with water. The container's normal condition is to be dry. Disposal of free liquid is not acceptable per the WAC (Ref. 3). Containers are vented and SWMF has experienced ingress of water into vented drums that were exposed to the environment (Ref. 37). However, SWMF has changed practices by storing vented drums on covered pads. Fire fighting could be a source of flooding; however, SWMF operating practice allows fires to burn themselves out unless the fire is causing significant radioactive releases (Ref. 1).

- Aging of Internal Segmentation - The error is that radiolytic decomposition of plastic (i.e., polyethylene bottles or wrappings) within the container compromises structural integrity of internal segmentation which changes the configuration of fissile material. Gravity is the only force acting on the fissile material to cause migration to the bottom of the container (Ref. 4). Movement and reconfiguration is dependent on whether the fissile material is attached to or detached from the waste form. If attached to the waste form, the fissile material will be compacted with the other waste in the container. If detached from the waste form, the fissile material may gradually be driven to the bottom of the drum by gravity and dispersed ( $\mathrm{x}-\mathrm{y}$ dimension) when sifted through the other waste in the drum (Ref. 4).

- Fires - The error is a fire that changes the distribution and concentration of fissile/moderator inside the container. However, fires inside containers are oxygen limited and will not spread to other nearby containers (Ref. 13). Fires outside the 
container would cook the contents, however, combustible materials are not readily available where containers are handled and stored (i.e., only vehicles used for delivery and handling will contain burnable fuel that could spill and ignite).

The following sections provide discussion of specific upset conditions and configurations for the drums, polyethylene boxes, steel boxes, concrete casks, and concrete culverts.

\subsection{GALLON DRUMS}

Drums containing plastic bottles filled with dry atomic swipe waste are considered to bound drums with other waste forms because of the potentially higher concentration of fissile material in the dry atomic swipe waste in the bottles (see section 2.1). Other wastes packaged in drums have lower concentrations than plastic bottles. The surface contaminated waste contains on the order of a few grams per waste cut with at most 20 waste cuts per drum. Glove box filter loadings are also on the order of a few grams; a few have been recorded as high as 16 grams $\mathrm{Pu}-239$. Pu-239 concentrations within the cabinet filters are less than dry atomic swipe waste because of the large volume of the filters $(<7.3$ $\mathrm{g}$ per bottle). In contrast, the dry swipe bottles can contain more than $100 \mathrm{~g} \mathrm{Pu}-239$ in a single one liter bottle.

A single drum is not a criticality concern under any condition for the following reasons. Inventory limits per drum are less than the always safe ANS 8.1 limit of $450 \mathrm{~g} \mathrm{Pu}-239$ and the SRS limit of $390 \mathrm{~g} \mathrm{Pu}-239$. An operational inventory limit of $195 \mathrm{~g} \mathrm{Pu}-239$ per drum is required by the Waste Acceptance Criteria. In the past, some drums have exceeded the $195 \mathrm{~g}$ limit (due to operator or machinery errors) and it is anticipated that some will exceed $195 \mathrm{~g}$ in the future. An analysis of past and current operations, as well as burial records for all TRU waste containers, has determined the frequency with which over-loaded drums could be anticipated (Ref. 4). The study determined that no drums have been received with more than $220 \mathrm{~g} \mathrm{Pu}-239$ and only 5 drums out of more than 19000 exceeded the $195 \mathrm{~g}$ limit. The study concluded that the credible maximum fissile mass in a single drum would be $245 \mathrm{~g} \mathrm{Pu}-239$ and the maximum for 3 drums together to be $242 \mathrm{~g}$ in each drum. The amount of historical data would not support conclusions for more than three drums. Thus, a single drum by itself is not a concern. However, multiple drums warrant more consideration.

Multiple drums are a concern when the fissile material in each of the drums has been localized such that fissile lumps can interact, perhaps as a single lump. Localization can be caused by either operator placement or aging of the waste.

\section{LOCALIZATION BY OPERATOR PLACEMENT}

Localization is dependent on the operator including plastic bottles with other wastes in each of three drums such that when the three drums are placed together the bottles are collocated. All waste the size of plastic bottles is placed into drums according to bag out procedures (Ref. 2). The scenario is the operator places bottles together at the middle plane and to the outside of drum. The operator does this for several drums. This increases the chances, while handling and storing the drums, that the bottles come together and interact as a single lump.

A frequency study has been performed that determined configurations and fissile content that would be credible in the three drum cases (Ref. 4). The study determined the frequency of $1.13 \mathrm{E}-6$ events per year for the occurrence of 3 drums each containing $242 \mathrm{~g}$ 
Pu-239. The study determined a probability of $4.22 \mathrm{E}-2$ for a 3 drum combination having . masses adjacent within a $30 \mathrm{~cm}$ radius sphere. The combined probability of this configuration is $4.77 \mathrm{E}-8$.

The configuration predicted by the frequency study is not the most reactive (see Figure 1). The study predicts bottles are distributed along the surface of the $30 \mathrm{~cm}$ sphere (radius of adjacent masses). Bottles are equally spaced. A more reactive configuration would be to bring the bottles to the surface of the drum. This configuration was modeled as spheres intersected by cylinders with radii of $10 \mathrm{~cm}$ extending inward from the surface of the drum (Ref. 34). The study determined a probability of $2.15 \mathrm{E}-6$ for a 3 drum combination having masses adjacent within a $10 \mathrm{~cm}$ radius sphere (a combined probability of $2.42 \mathrm{E}-12$ ).

\section{Figure 1 - Comparison of Drum Model Simplifications}

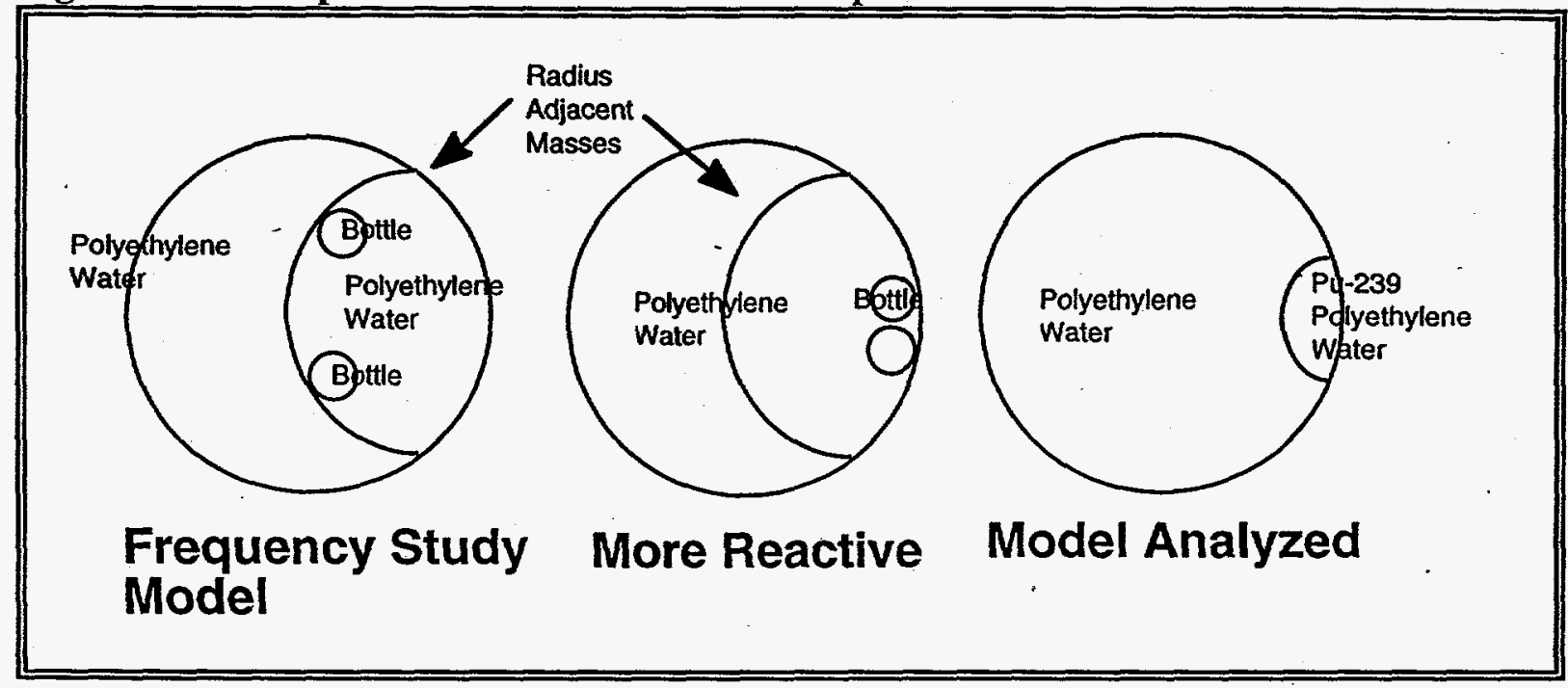

This analysis considered cases of 3 drums arranged in an infinite planar array. Each drum contained the equivalent of 2 plastic bottles containing swipe waste (total volume of 2 liters) modeled as a partial sphere of radius 10 or $13 \mathrm{~cm}$ based on the whether the lump is at the base of the drum or at the drum's mid-plane. Lumps were placed as close as possible to lumps in the adjacent drums. Each lump contained a mixture of fissile material and moderator. The amount of Fissile material changed from case to case to test the affects of exceeding the WAC inventory limits (i.e., $195 \mathrm{~g}$ PU-239 per drum). Moderator was assumed to be a 30/5/65 percent volume mixture of polyethylene, water, and air, respectively ( $\mathrm{Pu}-239$ volume was neglected). This moderator mixture was used to bound the moderating properties of the low density wood fiber used to make the swipes. The remainder of the drum was filled with the moderator mixture. Drums were placed in a triangular pitched array separated by the lid diameter of the drum. Spectral reflection on a triangular cell was used to model an infinite planar array (See Figure A.1). 
For the 3 drum cases, bottles were placed at the midplane of the drum or the base of drum to consider the effects of concrete reflection.

Table 5 - Comparison K-effective +/- One Standard Deviation depending on Fissile Lump Elevation in an infinite array of 3 Drum Trios (1-High) Configured with Two One-Liter Bottles containing Pu-239 and Dry Polyethylene/Water/Air Mixture.

\begin{tabular}{|r|c|c|}
\hline Cases & TELEAB[1-7] & TELBP[0-6] \\
\hline Fissile Loc & mid-plane & bottom \\
\hline Lump Radius (cm) & 10 & 13 \\
\hline Lump Volume (cm $\left.{ }^{* * 3}\right)$ & 1956 & 2103 \\
\hline $195 \mathrm{~g} \mathrm{Pu}-239$ & $0.79150+/-0.00313$ & $0.79461+/-0.00207$ \\
\hline $242 \mathrm{~g} \mathrm{Pu}-239$ & $0.79579+/-0.00288$ & $0.80859+/-0.00208$ \\
\hline $300 \mathrm{~g} \mathrm{Pu}-239$ & $0.80861+/-0.00298$ & $0.82011+/-0.00194$ \\
\hline $390 \mathrm{~g} \mathrm{Pu}-239$ & $0.82397+/-0.00286$ & $0.83237+/-0.00198$ \\
\hline $510 \mathrm{~g} \mathrm{Pu}-239$ & $0.83506+/-0.00292$ & $0.84795+/-0.00219$ \\
\hline $728 \mathrm{~g} \mathrm{Pu}-239$ & $0.86542+/-0.00262$ & $0.87462+/-0.00191$ \\
\hline $970 \mathrm{~g} \mathrm{Pu}-239$ & $0.88161+/-0.00304$ & $0.89448+/-0.00230$ \\
\hline
\end{tabular}

The difference between the two sets of results is due to the reflective properties of the concrete slab at the base of drums. Cases with the lumps at the top of the drum were not performed, but would have been less reactive because of leakage out the top of the drum. The results in Table 5 show that the a one-high planar arrays of drums stacked one high with plastic bottles collocated between three drums could be safe for loadings of $970 \mathrm{~g} \mathrm{Pu}$ 239 FGE in each drum under dry conditions.

\section{FLOODING}

Flooding inside the drums would decrease reactivity because the polyethylene bottles keep the water from mixing with the $\mathrm{Pu}-239$ and the water surrounding the bottles would isolate the bottles. Bottle failure due to radiolytic decomposition or a fire releases the fissilebearing waste and is expected to result in the fissile waste/polyethylene mixture falling or dripping to the bottom of the drum forming a layer of fissile waste/polyethylene on the bottom of the drum (Ref. 4). The K-effective of such conditions is discussed, for dry and wet conditions, in the next section.

\section{RADIOLYTIC DECOMPOSITION}

Radiolytic decomposition (aging) of the waste could affect the structural integrity of the plastic bottles and polyethylene wrapping around waste cuts. The resulting configuration of the fissile material is dependent on whether the fissile material is attached to the waste or detached.

\section{Fissile Material Attached to Waste Form}

Fissile material attached to the waste form would generally retain it's shape and move as the other waste in the drum settles. The worst case scenario would be having bottles left in the bottom of the drum and decomposing in place. This scenario is equivalent to cases TELBP listing in Table 5. However, the fissile material could become wetted which is not covered by the previous results. This situation was analyzed using a two high stacked array of 
drums with the fissile lumps left at the bottom of the drums. The dry polyethylene/water/air mixture was replaced with a wet mixture of polyethylene ( 30 volume $\%)$ and water (70 volume \%). The results are listed in Table 6.

Table 6 - Effects of Wetting Dry Swipes in Compromised Plastic Bottles (Bottles at Bottom of Drum and Drums Stacked Two High) on K-effective $+/-1$ Standard Deviation.

\begin{tabular}{|c|c|}
\hline Cases & TESGW[1-7] \\
\hline Lump Radius (cm) & 13 \\
\hline Lump Volume (cm $\left.{ }^{* * 3}\right)$ & 2103 \\
\hline $195 \mathrm{~g} \mathrm{Pu}-239$ & $0.72635+1-0.00260$ \\
\hline $242 \mathrm{~g} \mathrm{Pu}-239$ & $0.74268+1-0.00314$ \\
\hline $300 \mathrm{~g} \mathrm{Pu}-239$ & $0.75828+1-0.00326$ \\
\hline $390 \mathrm{~g} \mathrm{Pu}-239$ & $0.77438+1-0.00306$ \\
\hline $510 \mathrm{~g} \mathrm{Pu}-239$ & $0.79679+1-0.00291$ \\
\hline $728 \mathrm{~g} \mathrm{Pu}-239$ & $0.81825+1-0.00301$ \\
\hline $970 \mathrm{~g} \mathrm{Pu}-239$ & $0.83107+1-0.00273$ \\
\hline
\end{tabular}

Comparing these results to a similar dry configuration (cases TELBP) in Table 5 shows that wetting decreases the K-effective of the system. The decrease is due to the shielding effects of the water.

Fissile Material Detached from the Waste Form

Fissile material detached from the waste form would generally sift to the bottom of the drum due to gravity. Handling of the drum may cause some redistribution other than to the bottom of the drum; however, this is unlikely because most handling occurs when the drummed waste is new and significant radiolytic decomposition has not occurred. The fissile material will generally become more dispersed ( $x-y$ dimension) as it sifts to the bottom. Thus, the likely configuration is a layer of fissile material spread across the bottom of the drum.

The safety of this configuration was analyzed using a repeated arrangement of 3 drums with the fissile/moderator mixture forming a disk in the bottom of each drum. Both dry and wet conditions were analyzed for various amounts of fissile material using the most reactive mixture of fissile material to moderator. Dry conditions were modeled as a 30/5/65 volume percent mixture of polyethylene, water, and air, respectively. Wet conditions were modeled as a 30/70 volume percent mixture of polyethylene and water. The mixture bounds the moderator mixture after a fire because a fire would have burned away the polyethylene that would be replaced with water during flooding. Polyethylene is a better moderator than water (Ref. 34). The Pu-239 density was maintained at $0.037 \mathrm{~g} / \mathrm{cc} \mathrm{Pu-239}$ for both wet and dry cases. The corresponding $\mathrm{H} / \mathrm{Pu}$ is 740 at dry conditions. To test the effect of exceeding the WAC inventory limits (i.e., $195 \mathrm{~g} \mathrm{PU-239}$ per drum), the disk thickness (determines the amount of fissile material) was varied. 
Table 7 - Comparison of K-effective +/- 1 Standard Deviation for Dry and Wet Conditions after Radiolytic Decomposition of Internal Plastic Bottles and wrappers (One high stacking of drum trio in an infinite array).

\begin{tabular}{|c|c|c|c|}
\hline & & DRY AGED WASTE & AGED FLOODED WASTE \\
\hline Pu-239 mass & Layer Thickness & TDSAX[1-5] & TDSX[1-5] \\
\hline $194 \mathrm{~g}$ & $5.17 \mathrm{~cm}$ & $0.40774+1-0.00182$ & $0.50464+/-0.00166$ \\
\hline $291 \mathrm{~g}$ & $7.75 \mathrm{~cm}$ & $0.52349+1-0.00242$ & $0.65526+1-0.00203$ \\
\hline $388 \mathrm{~g}$ & $10.33 \mathrm{~cm}$ & $0.62170+1-0.00286$ & $0.76449+1-0.00205$ \\
\hline $485 \mathrm{~g}$ & $12.91 \mathrm{~cm}$ & $0.70691+1-0.00273$ & $0.84790+1-0.00222$ \\
\hline $728 \mathrm{~g}$ & $19.37 \mathrm{~cm}$ & $0.86891+/-0.00181$ & $0.98715+1-0.00194$ \\
\hline
\end{tabular}

Comparison of Table 7 with Table 5 cases TELBP and Table 6 shows that spreading fissile material over the bottom of a drum decreases K-effective for low masses (1-2 times WAC limit), but increases K-effective for larger masses. The difference is due to the thickness of the fissile layer. The thick layers have less neutron leakage than the thin layers. The flooded cases are more reactive than the dry due to increased moderation and decreased leakage (due to increased reflection). The increased moderation and flooding increases reactivity such that aged flooded cases exceed K-safe for a mass less than $728 \mathrm{~g} \mathrm{Pu}-239$, but more than $485 \mathrm{~g}$. However, the $485 \mathrm{~g}$ mass is still much greater than the credible mass of $242 \mathrm{~g}$ for each drum in a 3 drum configuration.

\section{SOLID WASTE OPERATOR OVERLAPPING DRUM RIMS}

The 55 gallon drums used to store waste have rolling rims and lids that extend beyond the side of the drum. The lid extends out 0.54 inches and the rolling rim 0.62 inches. The operator could overlap the rims causing the drums to be closer together.

Hypothetical, most reactive, configurations were used to ensure this evaluation of drum . separation would bound all other configurations. However, the resulting configurations are beyond incredible and are being used to demonstrate the relative importance of drum rolling rim separation.

In this evaluation, the fissile lumps in the drum trios were positioned in the top of the drums. A second set of drums were placed on top. The fissile lumps in the second set were positioned in the bottom of the drums. Thus, six lumps are positioned together and could interact as a single lump. The chances of this configuration occurring was determined to be incredible by the frequency study (Ref. 4). However, it was used because it was the most reactive and it had been used in previous analysis (Ref. 38). The reactivity was further increased by extending the fissile lump beyond the confines of the plastic bottle to obtain an optimal $\mathrm{H} / \mathrm{Pu}$ of 740 (Ref. 33). This configuration would require five one-liter bottles (in each of six drums) come together at the common edge (closest to other five drums) with $39 \mathrm{~g} \mathrm{Pu}-239$ mixed with polyethylene (30\% of volume) and water in each bottle. This is a total of 30 bottles and $1170 \mathrm{~g} \mathrm{Pu}-239$ that must come together. It is doubtful that all this will happen at the same time.

The effect of rolling rims overlap is demonstrated by changing the center to center separation between drums. Cases TE2TF[1-2] used the drum lid diameter $(60.1663 \mathrm{~cm})$ for separating the drums. Cases TE2TFC[1-2] used the actual rolling rim diameter $(60.5631 \mathrm{~cm})$. These two cases demonstrate the significance of using the lid diameter in place of the rolling rim diameter. Cases TE2TFO[1-2] used the rolling rim diametefless 
the thickness of the rim $(59.0085 \mathrm{~cm})$. Cases TE2TFC[1-2] and TE2TFO[1-2] demonstrate the significance of overlapping rolling rims while placing drums.

Table 8 - K-effective $+/-1$ Standard Deviation of
Hypothetical Five Bottle per Drum Double-Stacked Drum
Trios with Six Collocated Fissile Lumps Separated by
Various Rolling Rim Thickness.
\begin{tabular}{|r|c|c|c|}
\hline & LD DIAMETER & ROLLING RIM (CORRECT) & OVERLAPPING \\
\hline Cases & TE2TF[1-2] & TE2TFC[1-2] & TE2TFO[1-2] \\
\hline Center-to-Center & $60.1663 \mathrm{~cm}$ & $60.5631 \mathrm{~cm}$ & $59.0085 \mathrm{~cm}$ \\
\hline $94 \mathrm{~g}$ Pu-239 & $0.75045+1-0.00182$ & $0.74036+1-0.00176$ & $0.77201+1-0.00169$ \\
\hline $194 \mathrm{~g}$ Pu-239 & $0.94483+1-0.00180$ & $0.94241+1-0.00188$ & $0.97047+1-0.00175$ \\
\hline
\end{tabular}

The results demonstrate that using the correct rolling rim diameter (as compared to lid diameter) decreases calculated $\mathrm{K}$-effective of the normal (rolling rims in contact) planar array by between 0.002 and 0.010 . Overall, K-effective of a planar array of drums with overlapping rolling rims is larger than $\mathrm{K}$-effective of a planar array of drums with rolling rims in contact by 0.028 to 0.032 .

The cases reported in this NCSE, other than the TE2TFC and TE2TFO cases referenced in Table 8, used the lid diameter to determine drum spacing rather than the rolling rim.

This is not a concern because using the smaller diameter lends additional conservatism based on the results in Table 8 . However, the results demonstrate that overlapping the rolling rims does have a significant affect on K-effective. The following equation will be used to determine K-effective for evaluating the margin of safety.

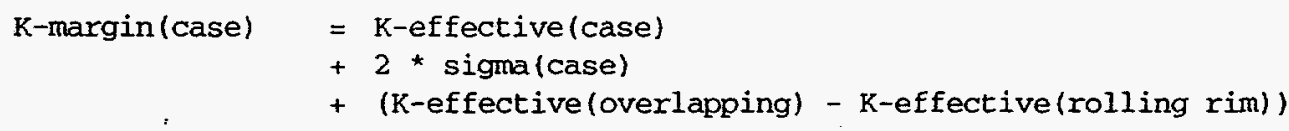

where
$\mathrm{K}$-margin
case
K-effective() is the
is the
is the
adjusted $\mathrm{K}$-effective used to evaluate margin of safety.
specific case being evaluated.
value obtained from MCNP for the given case, the case
with overlapping rims, or the case where the rolling rim diameter was used.
sigma()
is the
standard deviation for the particular case obtained from MCNP.
overlapping is the
case where the rolling rim diameter was reduced by the thickness of the rolling rim to simulate overlapping.
rolling rim is the
case where the rolling rim diameter was used to define the separation between drum rather the lid diameter.

The results in Table 8 supports bounding of overlapping rolling rims by 0.032 increase in K-effective.

\section{SQUARE VERSUS TRIANGULAR PITCHED DRUM PLACEMENT}

Normally SWMF operations stores drums on concrete pads (drums with low enough alpha contamination to be stored outside a culvert) in a square pitched array. However, drums 
can be placed in a triangular array where fissile/moderator lumps inside the drums could be brought closer together.

Three hypothetical configurations were analyzed to determine the reactivity affects of square versus triangular pitched arrays of drums. The planar drum arrays were considered with 2, 3, and 4 collocated fissile/moderation lumps in 2,3, or 4 drums (see Figure 2). This analysis assumed the most reactive geometry of partial spheres and concentrations of

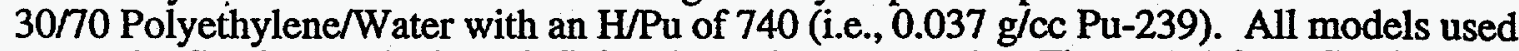
spectral reflection to obtain an infinite planar drum arrays (see Figure A.1 for reflective cell used for triangular pitched drum array).

Figure 2 - Configurations Used to Demonstration Importance of Triangular versus Square Pitched Arrays

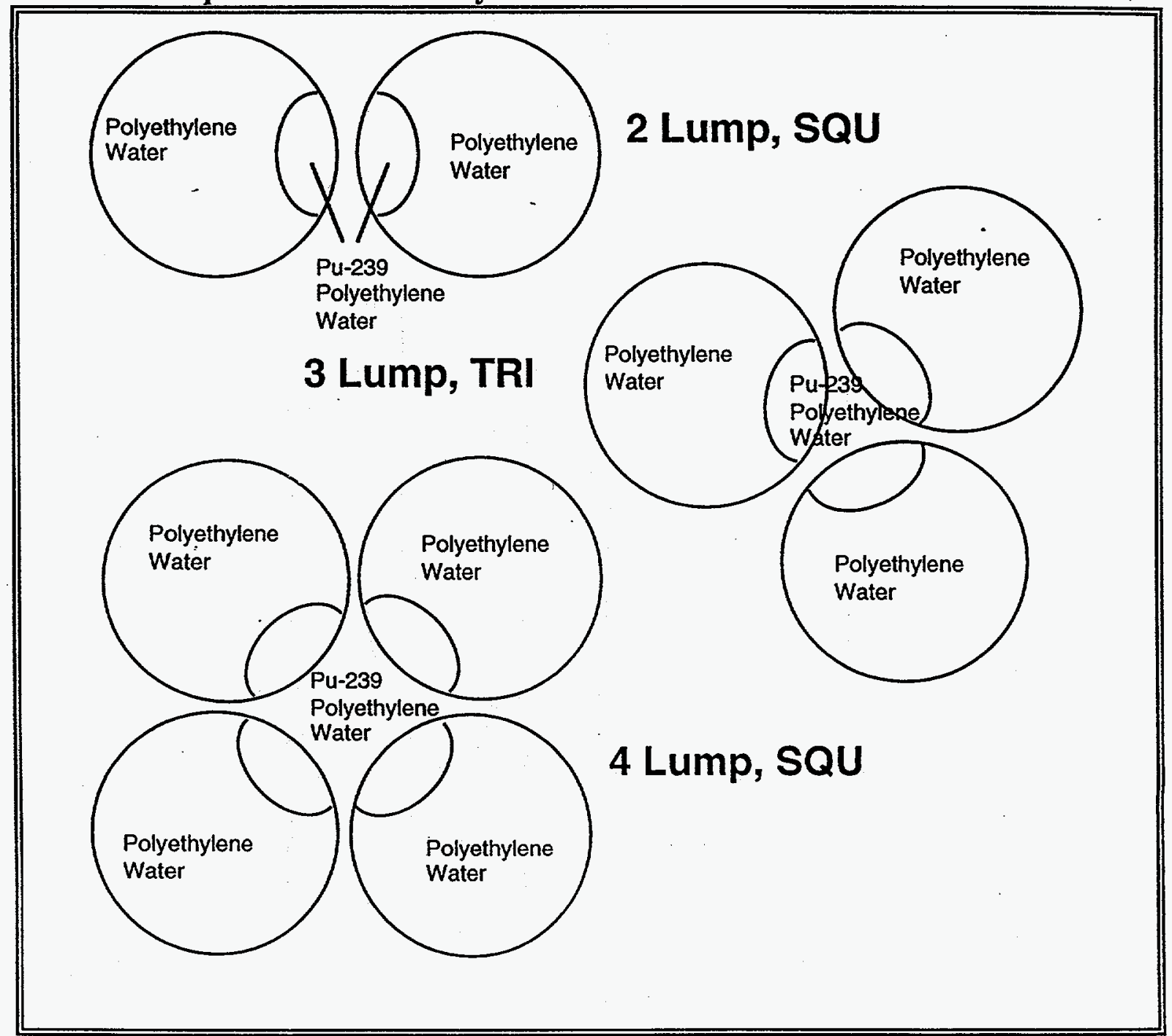

The first configuration is a triangular pitched drum array with the fissile lumps (partial sphere centered on drum wall) located closest to it's two other neighbors (3 LUMPS, TRI). $\mathrm{H} / \mathrm{Pu}$ concentration is fixed and lump volume is increased to place more fissile material in the lump. Drums are separated by touching lid diameters rather than using the drum's rolling rim diameter. The reactivities of this configuration for a series of masses are 
reported in Table 9 as cases TELSO[0-5]. The amount of fissile material changed from case to case to test the affects of exceeding the WAC inventory limits (i.e., $195 \mathrm{~g}$ PU-239 per drum).

The second configuration is a square pitched array of drums with fissile lumps located next to another fissile lump (2 LUMPS, SQU). H/Pu concentration is fixed and lump volume is increased to place more fissile material in the lump. Drum spacing was modeled using the lid diameter. The reactivities of this configuration for a series of masses are reported in Table 9 as cases E2LS[0-5].

The final configuration is a modification of the 2 LUMPS, SQU model (E2LS[0-5]) by rotating the drum container such that fissile lumps are.closest to their 3 neighbors (4 LUMPS, SQU). The reactivity of this configuration for a series of mass errors are reported in Table 9 as cases EALS[0-5].

Table 9 - MCNP4A Calculated K-effective +/-1 Standard Deviation Comparing Models with Triangular and Square Pitch with 2, 3, And 4 Fissile Lumps Collocated.

\begin{tabular}{|c|c|c|c|c|c|}
\hline mass & rádius & volume & 3 LUMPS, TRI & 2 LUMPS, SQU & 4 LUMPS, SQU \\
\hline g Pu-239 & $\mathrm{cm}$ & $\mathrm{cm}^{* * 3}$ & cases - TELSO[0-5] & cases - E2LS[0-5] & cases - E4LSS[0-5] \\
\hline 94 & 13.81 & 2506 & $0.64840+1-0.00247$ & $0.63634+1-0.00180$ & $0.59905+1-0.00193$ \\
\hline 195 & 17.72 & 5143 & $0.83953+1-0.00295$ & $0.81441+/-0.00192$ & $0.79735+1-0.00185$ \\
\hline 241 & 19.09 & 6363 & $0.90009+1-0.00254$ & $0.86823+1-0.00185$ & $0.85460+1-0.00171$ \\
\hline 299 & 20.61 & 7913 & $0.95691+1-0.00252$ & $0.92320+1-0.00191$ & $0.91244+1-0.00189$ \\
\hline 390 & 22.62 & 10296 & $1.01832+/-0.00299$ & $0.98545+1-0.00176$ & $0.98236+1-0.00188$ \\
\hline 510 & 24.89 & 13466 & $1.07749+1-0.00208$ & $1.05369+1-0.00211$ & $1.05631+/-0.00187$ \\
\hline
\end{tabular}

The results demonstrate that triangular pitched drums are more reactive than square pitched drums and the 2 lump square pitch array is more reactive than the 4 lump square pitched array. The 4 lump square pitched array is the least reactive because of the air space separating the fissile material lumps. The 2 lump configuration is more reactive because the fissile material lumps are brought closer together. The 3 lump configuration does not bring the fissile material lumps closer than the 2 lump model. However, the 3 lump model, like the 4 lump model, form a nearly complete sphere which minimizes the amount of leakage and results in the highest reactivity.

All results in this NCSE, with the exception of E2LS[0-5] and E4LS[0-5], were modeled using a triangular pitch. Triangular versus square pitched arrays represents an increase in reactivity of approximately 0.01 to $0.03 \mathrm{~K}$-effective.

\section{STACKING CONTAINERS}

Past NCSEs have used overly conservative models of fissile material geometry and moderator inventory within drums (Ref. 38). The results of these NCSEs caused SWMF to restrict stacking of some drums (see Table 1, section 2).

The configuration used in past NCSEs (Ref. 38) has been determined to be incredible by the frequency study reported in reference 4 . The past NCSE assumed the fissile material from six drums came together at the common edge. The equivalent cases for plastic bottles containing swipe waste would be 12 bottles together at the common edge. The probability of a 6-Drum combination having masses adjacent is the 3-Drum combination squared (i.e. 
Figure A.5 - (Continue Case tesfaa1)

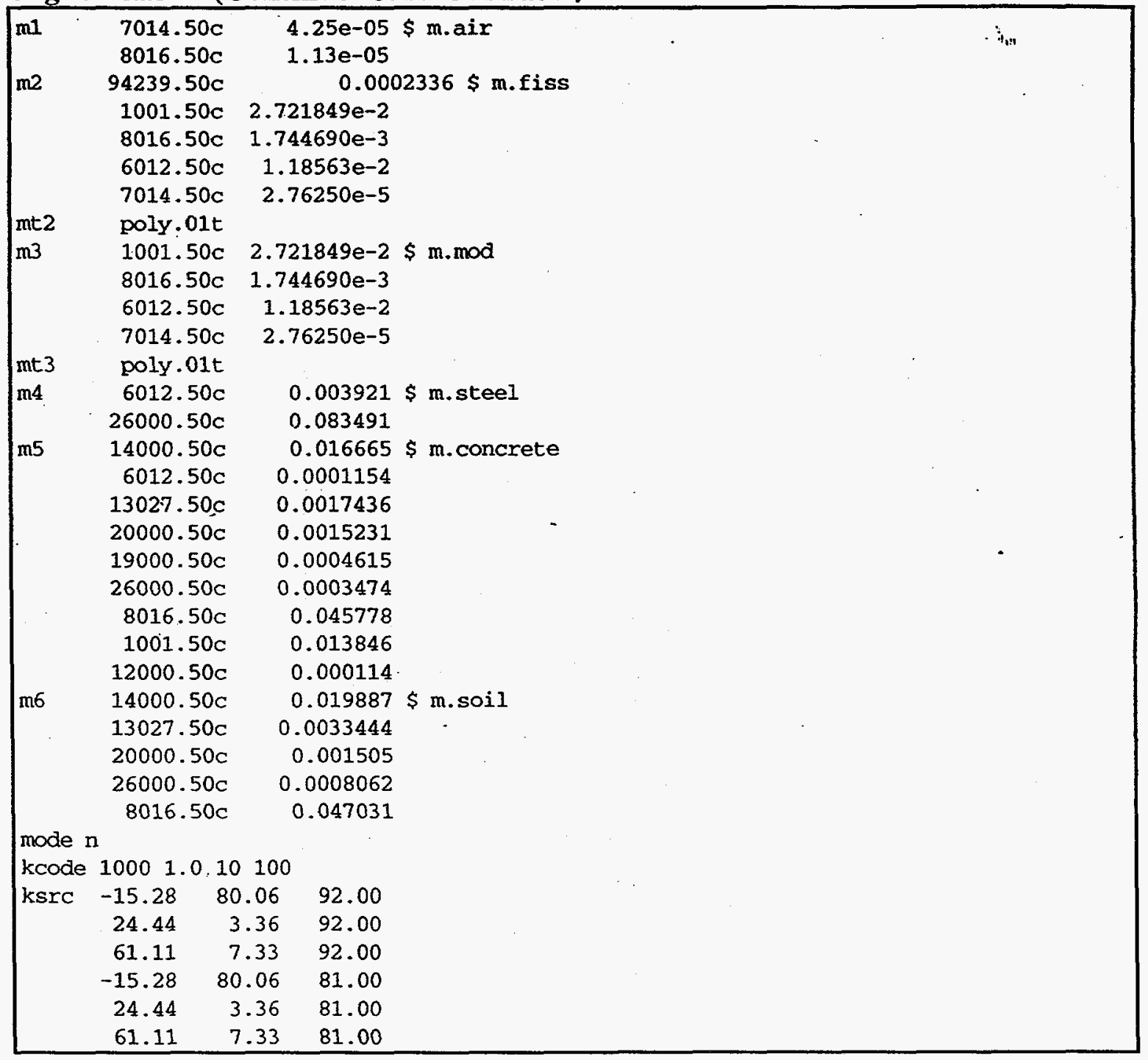


inventory limits and the waste is randomly placed in each drum. The difference between K-effective of the stacked arrays (TESGA cases) and K-effective of the unstacked arrays (TELBP cases) are less than the associated statistical error. The small differences in Keffective indicate that the fissile lumps in top and bottom drums are not significantly interacting. Isolation is attributed to the separation distance and waste material between the two fissile material lumps. The separation distance between the fissile lumps is credited because of the random nature with which waste cuts are placed into drums. Adding a 3rd or 4th layer of drums is not expected to statistically affect $\mathrm{K}$-effective because with the fissile material in the new drums comes waste that provides isolation for the new layer of drums. Thus, stacking drums is not considered a criticality concern provided the WAC container inventory limits are met and the waste was randomly placed in the drum.

\subsection{POLYETHYLENE BOXES}

The following qualitative discussion demonstrates the safety of waste stored in polyethylene boxes (HEPA filters and roughing filters).

Polyethylene boxes containing HEPA filters (as discussed in section 2.2) contain more fissile material than roughing filter waste. Pu-239 contamination particle size $(0.3-0.7$ microns) is too small to be stopped by the roughing filter and passes through to the HEPA filter.

Past NCSEs have set the polyethylene/HEPA mass inventory limit at $195 \mathrm{~g} \mathrm{Pu}-239$ assuming an overly conservative model of the fissile material lumped at the walls and away from the corners of box. Interaction was limited to two boxes based on the horizontal dimensions of the polyethylene boxes, but not in the vertical dimension (Ref. 39). Thus, polyethylene boxes have been limited to single tier stacking because of the short interaction distance between the bottom and the top of polyethylene boxes.

Under normal conditions, HEPA filters are safe because fissile material is somewhat uniformly distributed over the volume of the filter and lack of moderation material in the filter medium. A polyethylene box can hold one HEPA filter. The filter occupies a volume of 108 liters filled with about 10.9 liters of filter media. A polyethylene box has $195 \mathrm{~g} \mathrm{Pu}$ 239 mass limit per the WAC (Ref. 3). The polyethylene boxes are keeping the HEPA filters separated from each other as well as isolated from other materials (i.e., water or other hydrogenous wastes).

\section{SPACING AND STACKING}

Past normal operations stored eight Polyethylene boxes stacked inside a culvert and the culvert limited to $390 \mathrm{~g} \mathrm{Pu}-239$. This analysis assumes each polyethylene box contains $195 \mathrm{~g} \mathrm{Pu}-239$, the whole culvert contains $1560 \mathrm{~g} \mathrm{Pu}-239$. However, frequency analysis of HEPA filter burial records has determined eight filters each with $195 \mathrm{~g} \mathrm{Pu}-239$ is incredible (Ref. 4). The study determined the maximum credible HEPA filter loading to be two HEPA filters totaling $310 \mathrm{~g} \mathrm{Pu}-239$ and $6 \mathrm{HEPA}$ filters each with $100 \mathrm{~g}$, for a culvert total of $910 \mathrm{~g} \mathrm{Pu}-239$. However, both configurations are safe because of low fissile material concentration and lack of moderation.

A filter filled with $195 \mathrm{~g} \mathrm{Pu}-239$, maximum Pu-239 inventory based on the WAC (Ref. 3), has a concentration of about $1.8 \mathrm{~g} / \mathrm{l}$ (grams of $\mathrm{Pu}-239 \mathrm{per}$ liter of filter medium). The ANS 8.1 always safe concentration is $7.3 \mathrm{~g} / \mathrm{l}$ assuming full water moderation and reflection. The $7.3 \mathrm{~g} / \mathrm{l}$ applies to an infinite homogenous system that implies no leakage. The culvert with eight polyethylene boxes is a limited system and does have leakage; thus 
the needed concentration is greater than $7.3 \mathrm{~g} / \mathrm{l}$ and $7.3 \mathrm{~g} / \mathrm{l}$ can be used to bound this system.

The HEPA filter is safe because of it's low Pu-239 concentration and the lack of moderating material in the filter medium. Thus, three things must occur for a credible upset condition:

- increase fissile material inventory,

- decrease the volume within which the fissile material is concentrated, and

- increase the amount of moderating material.

Spacing and stacking of polyethylene boxes together will create configurations with larger amounts of fissile material (assuming $195 \mathrm{~g} \mathrm{Pu}-239 \mathrm{box}$ ) and larger volumes (108 liters per filter) than a single polyethylene box. However, each box has the same concentration of fissile material and the intact boxes are keeping water separate from the fissile material. Thus, spacing and stacking of intact polyethylene boxes does not represent a credible criticality safety concern.

\section{CONTAINER FISSILE INVENTORY்}

Container fissile inventory and operator loading are interrelated. It is the operator who is responsible for removing the HEPA filter from the ventilation system (Ref: 2 ). If the operator fails to follow procedures, the filter cold become overloaded with fissile inventory.

A review of past HEPA filter burial records has bounded credible HEPA fissile material masses (Ref. 4). The study identified two sets of HEPA fissile material inventories. The majority of HEPA inventories were due to normal operation of the HEPA filters. The second set of inventories included 5 cases exceeding the WAC mass limits because of prefilter failures.

Normal HEPA filter inventories ranged from 5 to 95 grams. Considering just these inventories, the frequency study (Ref. 4) indicates the credible maximum single HEPA filter inventory would be $195 \mathrm{~g} \mathrm{Pu}-239$ and the credible maximum double HEPA inventory would be $310 \mathrm{~g} \mathrm{Pu}-239$ (for both HEPA filters together). The study determined that assuming HEPA filter fissile inventory of $100 \mathrm{~g} \mathrm{Pu}-239$ per filter would bound $99.2 \%$ of HEPA filter receipts.

The five abnormal HEPA filters had inventories ranging from 242 to $333 \mathrm{~g} \mathrm{Pu}-239 \mathrm{per}$ filter. However, these high content HEPA filters were recognized prior to shipment and special precautions were taken to place them in culverts with total culvert fissile mass inventory limited to $390 \mathrm{~g} \mathrm{Pu}-239$ (Ref. 6). Future shipment requests that must exceed the WAC limits are covered by the WAC exemption procedure (Ref. 40). Thus, per the scope of this NCSE, these five HEPA filters are considered culvert waste and not considered as polyethylene box waste.

\section{HYDROGENOUS WASTE}

Hydrogenous waste included in the polyethylene box with the HEPA filter is limited to the polyethylene wrappers surrounding the HEPA filter.

The polyethylene in the wraps and in the box walls represent a significant source of . moderating material. However, the Pu-239 is trapped within the HEPA filter medium and 
can't mix with the polyethylene. Thus, the moderating properties do not affect the reactivity of the system.

Polyethylene is also a good reflector of neutron and the presence of polyethylene surrounding the HEPA would affect reactivity. However, other factors outweigh the affects of reflection. First, comparing the HEPA filter fissile concentration (1.8 g/1) to the ANS 8.1 limit $(7.3 \mathrm{~g} / 1)$ implies that infinite systems are being compared. The HEPA filter is a limited system and leakage of neutrons outweighs the affects of reflection. Second, the thickness of polyethylene is on the order of millimeters whereas good polyethylene reflectors must be more than several centimeters thick (Ref. 41 and 42).

\section{CONTAINER FLOODING}

In the event that a culvert fills with water including inside the polyethylene boxes, fissile material in the culvert would become fully moderated. Assuming all of the HEPA filters contained $100 \mathrm{~g} \mathrm{Pu}-239$, then the culvert would contain $800 \mathrm{~g} \mathrm{Pu}-239$. However, the Pu239 is distributed throughout the volume of the HEPA filters. The Pu-239 is attached to the filter media fibers (see section 2.2) and will not move around when the filter is flooded. Each HEPA filter has a volume of 108 liters. At a $100 \mathrm{~g}$ loading, the HEPA filter would have a Pu-239 concentration of $0.9 \mathrm{~g} / \mathrm{l}$. Assuming the maximum credible fissile material inventory of $910 \mathrm{~g} \mathrm{Pu}-239$, two HEPA filters would have a concentration of $1.4 \mathrm{~g} / 1$ and the remaining $6 \mathrm{HEPA}$ filters would have a concentration of $0.9 \mathrm{~g} / \mathrm{l}$. In both cases, the concentration is less than the ANS 8.1 safe concentration of $7.3 \mathrm{~g} / \mathrm{l}$.

\section{RADIOLYTIC DECOMPOSITION OF POLYETHYLENE BOXES}

Radiolytic decomposition will break down the walls of the polyethylene boxes. The result will be polyethylene dust that settles around the area where the HEPA filters are stored. Polyethylene boxes are stored eight to a culvert. The culvert makes a good container for keeping the polyethylene dust mounded around the HEPA filters. However, the dust is still outside of the filter medium and does not penetrate into the filter medium unless air is flowing through the filter. However, even if the dust could mix into the filter medium, the worst case concentration of the Pu-239 is between 0.9 and $1.4 \mathrm{~g} / \mathrm{l}$. ANS 8.1 concentration limits (7.3 g/l Pu-239 in water moderated and water reflected) can be applied to this situation because polyethylene moderator strength is conservatively $30 \%$ better than water (Ref. 43).

\section{FIRES}

A fire estimate of HEPA filters in polyethylene boxes stored in culverts has been performed for SWMF TRU waste storage pads (Ref. 5). The estimate considered effects of external and internal fires on the contents of the culvert. Effects of an external fire were mitigated by 5 " concrete walls of the culvert. An internal fire results in a maximum temperature increase of 139 degree $C$ (Ref. 5). It is expected that the inside of the culvert would reach 162 degree $C$. This temperature would cause some localized melting of the polyethylene boxes, but little charring/melting of the HEPA filter. The HEPA filter remains intact and maintains the fissile material within the filter.

Melted polyethylene is assumed (worst case) to mix with the HEPA filters. Without gross melting of the HEPA filter, the maximum Pu-239 concentration could be $1.8 \mathrm{~g} / \mathrm{l}$ for a single HEPA filter containing $195 \mathrm{~g} \mathrm{Pu}-239$ and less for other HEPA filter containing lesser $\mathrm{Pu}-$ 239 inventories. As discussed in radiolytic decomposition section, mixing of the polyethylene and $\mathrm{Pu}-239$ at this concentration is not a criticality concern. 


\section{FIRES, THEN FLOODING}

A fire will expose the HEPA filters and enhance mixing of melted polyethylene into the HEPA filter (Ref. 5). Subsequent flooding will allow mixing of water into the HEPA filter. Mixing of melted polyethylene and water will not occur. The resulting Pu-239 concentration would be the same as during container flooding because fire impact on the HEPA filter is limited to localized char/melting at the edges of the filter. Thus, fires and flooding are not a credible criticality concern because Pu-239 concentrations will not exceed the ANS 8.1 limits.

\subsection{STEEL BOXES}

The following qualitative discussion demonstrates the safety of waste stored in steel boxes.

Steel boxes contain process equipment that have become surface contaminated with fissile material. As discussed in section 2.3, surface contamination is well attached to the discarded process equipment because of the actions taken to decontaminate the equipment.

Under normal conditions, the steel box contains process equipment that is stuffed with job control waste. The equipment is wrapped in plastic, a wooden box is built around the waste, and more plastic is wrapped around the box.

\section{SPACING}

A previous analysis (Ref. 33) has shown steel boxes can be safely placed next to each other with $195 \mathrm{~g} \mathrm{Pu}-239$ in each box. The WAC limit for steel boxes is $195 \mathrm{~g} \mathrm{Pu}-239$ (Ref. 3). The frequency study (Ref. 4) reported that over loading of steel boxes has only occurred under anticipated circumstances where special analyses and procedures were implemented to ensure the safety of receiving, handling, and storage.

\section{STACKING}

Steel boxes can be safely stacked based on the height of the boxes and the distribution of fissile material within the waste. The box height is greater than the height of drums. The height of the container determines the separation of fissile lumps in top and bottom containers. Stacking of drums does not significantly increase the K-effective of the system. This conclusion is valid if lumps have not been preferentially placed in the bottom of top containers and the top of bottom containers. The criticality safety of containers with larger heights are bounded by containers with smaller heights. Decontamination practices; as discussed in section 2.3 , justify assuming the fissile material is attached to the process equipment and can't collect in the corners of the steel box.

\section{OPERATOR LOADING AND CONTAINER FISSILE INVENTORY}

Operator loading and container fissile inventory errors will not render steel boxes unsafe based on past operating history (Ref. 4) and decontamination practices.

A frequency study of past steel box burial records has determined the majority of steel boxes contain on the order of $5 \mathrm{~g} \mathrm{Pu}-239$. A few boxes that contain much more than $5 \mathrm{~g}$ $\mathrm{Pu}-239$ have been identified to be the result of special waste generator campaigns (Ref. 4). These containers were recognized prior to receipt as exceeding the container limits and an exemption was requested (Ref. 10). Special analysis (including NCSEs), controls, and procedures were implemented to ensure containers could be handled and placed safely. 
Decontamination practices maintain low fissile inventories in steel boxes. As discussed in section 2.3, decontamination reduces the radioactive contaminate present and likewise removes the excess fissile material.

Decontamination practices can also be credited to maintain a distribution of fissile material such that fissile material is not likely to be loaded into the corner of the box. Maldistribution of fissile contamination would result in hot spots that would be detected while surveying the equipment. Additional effort would be taken when hot spots are identified to ensure contamination is reduced.

Thus, it is reasonable to assume that inventory errors may reach 10 to $20 \mathrm{~g} \mathrm{Pu}-239 \mathrm{per}$ box, but exceeding the $195 \mathrm{~g}$ limit is unlikely because the level of contamination present would trigger considerable decontamination effort. In addition, decontamination practices provide a reasonable assurance that fissile material is not concentrated at comers of the steel box.

\section{HYDROGENOUS WASTE}

Normal packaging of steel boxes includes large amounts of hydrogenous materials as discussed in section 2.3. However, this is not considered a criticality concern because fissile contamination is attached to the surfaces of the discarded equipment and can not mix with the hydrogenous material.

\section{CONTAINER FLOODING}

Flooding is not considered a criticality safety concern because the fissile contamination is attached to the surfaces of the discarded equipment and can not mix with the water flooding the container.

\section{RADIOLYTIC DECOMPOSITION OF POLYETHYLENE WASTE}

Radiolytic decomposition of polyethylene waste is not considered a criticality safety concern because breakdown of the polyethylene will not enhance the chances that the polyethylene will mix with the fissile material attached to the surfaces of the discarded equipment.

\section{FIRES}

Fires could release some fissile contamination; however, amounts would be small based on the decontamination practices used to clean out the equipment (see section 2.3). Fires would be limited to a single container (Ref. 13) and the fissile material inventory limit for a single container (195 g Pu-239) is less than the safe mass limit of $450 \mathrm{~g}$ Pu-239 (Ref. 23).

\subsection{CONCRETE CASKS (TRU waste only)}

The following qualitative discussion demonstrates the safety of waste stored in concrete casks is bounded by the safety of drums (see section 5.1). The fissile material inventory limit for concrete casks is $195 \mathrm{~g} \mathrm{Pu}-239$ (Ref. 3). The safety of concrete casks are bounded by the safety of drums for the following reasons.

- Concrete casks contain surface contaminated waste as discussed in section 2.1. Thus, since drum surface contaminated waste is bounded by atomic swipe waste, then surface 
contaminated waste in concrete casks is bounded by atomic swipe fissile material concentrations.

- Concrete casks contain primarily low level or intermediate level waste that contain sufficient transuranics to be considered Transuranic waste. An analysis of past burial records indicate that 6 casks with fissile content as high as $49 \mathrm{~g} \mathrm{Pu}-239$ have been sent to SWMF (Ref. 4).

- Concrete casks are thick walled containers with approximately 6" of separation between the outside boundary of the container and the container's inside surface. The separation is large enough that fissile material lumped into the inside corners of 4 casks would be no closer together than if the fissile material had been placed in 4 drums.

\subsection{CONCRETE CULVERTS}

Concrete culverts serve two purposes on SWMF waste storage pads:

- radiation shielding to reduce the radiation fields on the waste storage pads; and

- waste container approved for storing fissile material contaminated waste.

Concrete culverts are used to store drums and polyethylene boxes that meet the limits of the WAC (Ref. 3). The walls of the culvert provide shielding for waste pad workers. The criticality safety of the stacked array of containers within the culvert is bounded by an infinite array of like containers outside the culvert.

Concrete culverts are only used as approved primary containers under special circumstances. Concrete culverts used as approved containers have a mass limit of $390 \mathrm{~g}$ $\mathrm{Pu}-239$ (Ref. 39). Examples of such special circumstances include receipt of several high fissile content HEPA filters (Ref. 6) and receipt of Standard Waste boxes from SRTC (Ref. 8). As a part of these circumstances, evaluations are performed and procedures created, including criticality safety, to ensure sufficient controls maintain the criticality safety of the configured waste. 


\subsection{RESULTS}

This section demonstrates the margin of criticality safety by which SWMF receives, handles, and stores TRU waste containers when credit is taken for waste form characteristics and waste generator packaging practices (including presence of procedures requiring conformance with WAC mass limits). The margin of criticality safety for these results is defined as the difference between $\mathrm{K}$-safe and the $\mathrm{K}$-effective of SWMF TRU waste configurations. K-safe for SWMF configurations was determined in a previous NCSE (Ref. 33) to be 0.96 . The range of configurations includes normal and credible abnormal conditions. Normal SWMF TRU operating configurations are identified in section 2.0 and requirements on Waste Generators are listed in section 1.2. Credible abnormal conditions are based on frequency studies of past burial records (Ref. 4) and justifications provided in section 5.0.

The SWMF storage configuration bounds receiving and handling configurations. The stored arrays are larger than receiving and handling arrays. Typically containers are received by the truck load, but are usually handled one at a time.

Arrays of drums containing two plastic bottles filled with atomic swipe waste (encompassing the fissile mass in the drum) were used as the bounding configuration for determining safety margins. Drums containing bottles of atomic swipe waste were found to have the most reactive configuration of fissile mass, moderator, and geometry under normal and credible abnormal operating conditions (Section 5.1 Drums).

This demonstration of safety margins includes waste generator loading errors. As demonstrated in Figure 1 and discussed in section 5.1, placement of plastic bottle within the drum is important to the reactivity of the configuration. Configurations used in the calculations had the plastic bottles placed at the outside wall of the drum to increase interaction with bottles in adjacent drums.

The K-effective values presented in Tables $11,12,13$, and 14 include calculated statistical uncertainties and the $0.032 \mathrm{~K}$-effective correction for overlapping of drum rolling rims as discussed in section 5.1 .

\section{SAFE MASSES FOR NOMINAL CONDITIONS}

Results of analyzing normal conditions of stored drums containing intact plastic bottles indicated the Pu-239 mass can be as high as $970 \mathrm{~g}$ (4.9 times $195 \mathrm{~g} \mathrm{WAC} \mathrm{limit)} \mathrm{and}$ maintain criticality safety. A summary of drum/bottle results are presented in Table 11.

Table 11 - K-effective of Fissile Mass Inventories for Normal Drum/Plastic Bottle Configurations for Dry Conditions with Bottles at Drum Bottom.

\begin{tabular}{|c|c|c|}
\hline $\begin{array}{c}\text { Fissile Mass } \\
(\mathrm{g} \text { Pu-239) }\end{array}$ & $\begin{array}{c}\text { K-effective } \\
\text { (cases TELBP) }\end{array}$ & $\begin{array}{c}\text { Credibility of Fissile Mass } \\
\text { (occurrence frequency) }\end{array}$ \\
\hline 970 & 0.93 & Incredible (<<1.00e-6) \\
\hline 242 & 0.85 & Upper Bounds of Credibility (1.13e-6) \\
\hline 195 & 0.83 & Operating Limit (1.24e-2) \\
\hline$<150$ & $\sim 0.81$ & Anticipated (1.0) \\
\hline
\end{tabular}


Credibility of fissile mass has been provided to demonstrate that the maximum'safe fissile mass can exceed the credible fissile mass. The boundary between credible and incredible is the occurrence frequency of $1.0 \mathrm{E}-6$ events per year.

\section{SAFE MASSES FOR FLOODED CONDITIONS}

Safe masses for flooded conditions are bounded by the masses determined for nominal conditions. Flooding, without failure of the plastic bottles, will fill the spaces between bottles and reduce interaction.

\section{SAFE MASSES FOR AGED CONDITIONS}

Results of analyzing aged conditions of stored drums that initially contained plastic bottles, but now contain fissile material deposited in the bottom of the drum (both as a flat layer and mounded at edge), indicate the Pu-239 mass can be as high as $728 \mathrm{~g}$ (3.7 times $195 \mathrm{~g}$ WAC limit) and maintain criticality safety. A summary of aged drum results are presented in Table 12.

Table 12 - K-effective of Fissile Mass Inventories for Aged Drum/Plastic Bottle Configurations under Dry Conditions

\begin{tabular}{|c|c|c|c|}
\hline $\begin{array}{c}\text { Fissile Mass } \\
(\mathrm{g} \text { Pu-239) }\end{array}$ & $\begin{array}{c}\text { K-effective Dry } \\
\text { Layer at Drum } \\
\text { Bottom (cases } \\
\text { TDSAX) }\end{array}$ & $\begin{array}{c}\text { K-effective Dry } \\
\text { Lump at Drum } \\
\text { Bottom Edge (cases } \\
\text { TELBP) }\end{array}$ & $\begin{array}{c}\text { Credibility of Fissile } \\
\text { Mass (occurrence } \\
\text { frequency) }\end{array}$ \\
\hline 728 & 0.90 & 0.91 & Incredible $(\ll<1.00 \mathrm{e}-6)$ \\
\hline 195 & 0.44 & 0.83 & Operating Limit (1.24e-2) \\
\hline
\end{tabular}

The $\mathrm{K}$-effective of the aged conditions is significantly different from the normal conditions (Table 11) because of changes in geometry. For normal conditions, fissile material is modeled in the shape of a sphere of 30/5/65 volume percent polyethylene/water/air moderated fissile material, but for aged conditions the fissile material is likely to form a layer of fissile material at the bottom of the drum (Ref. 4). Neutron leakage in the collapsed configuration reduces the K-effective compared to the nominal configuration for many amounts of fissile mass near the waste generator mass limit (195 g) (see Table 13). However, as more fissile mass is added, the fissile layer thickness is increased and leakage effects are reduced (See section 5.1).

Table 13 - Comparison of K-effective using Spherical and Slab Fissile/Moderator Lump Models

\begin{tabular}{|c|c|c|c|}
\hline $\begin{array}{c}\text { Fissile Mass } \\
\text { (g Pu-239) }\end{array}$ & $\begin{array}{c}\text { K-effective Dry } \\
\text { Spherical Lump } \\
\text { (cases TELBP) }\end{array}$ & $\begin{array}{c}\text { K-effective Dry } \\
\text { Layer Drum Bottom } \\
\text { (cases TDSAX ) }\end{array}$ & $\begin{array}{c}\text { K-effective Wet } \\
\text { Layer Drum Bottom } \\
\text { (cases TDSX) }\end{array}$ \\
\hline 195 & 0.83 & 0.44 & 0.54 \\
\hline 300 & 0.86 & 0.56 & 0.69 \\
\hline 390 & 0.87 & 0.66 & 0.80 \\
\hline 485 & Not Calculated & 0.74 & 0.88 \\
\hline 510 & 0.88 & Not Calculated & Not Calculated \\
\hline 728 & 0.91 & 0.90 & 1.02 \\
\hline
\end{tabular}

The credibility of mass inventory has not changed because the frequency of occurrenge for aging is assumed to be 1.0 . 


\section{SAFE MASSES FOR AGED-FLOODED CONDITIONS}

Results of analyzing aged and flooded conditions of stored drums that initially contained plastic bottles, but now contain fissile material deposited in the bottom of the drum (flat and mounded), indicate Pu-239 mass inventory can be as high as $485 \mathrm{~g}$ ( 2.5 times $195 \mathrm{~g} \mathrm{WAC}$ limit) and maintain criticality safety. A summary of aged and flooded drum results are presented in Table 14.

Table 14 - K-effective of Fissile Mass Inventories for Aged and Flooded Drum/Plastic Bottle Configurations

\begin{tabular}{|c|c|c|c|}
\hline $\begin{array}{c}\text { Fissile Mass } \\
\text { (g Pu-239) }\end{array}$ & $\begin{array}{c}\text { K-effective Wet } \\
\text { Layer at Drum } \\
\text { Bottom (cases } \\
\text { TDSX) }\end{array}$ & $\begin{array}{c}\text { K-effective Wet } \\
\text { Lump at Drum } \\
\text { Bottom Edge } \\
\text { (cases TESGW) }\end{array}$ & $\begin{array}{c}\text { Credibility of Fissile } \\
\text { Mass (occurrence } \\
\text { frequency) }\end{array}$ \\
\hline 970 & Not Calculated & 0.87 & Incredible $(<<1.00 \mathrm{e}-6)$ \\
\hline 728 & 1.02 & 0.86 & Incredible $(<<1.00 \mathrm{e}-6)$ \\
\hline 485 & 0.88 & Not Calculated & Incredible $(<<1.00 \mathrm{e}-6)$ \\
\hline 195 & 0.54 & 0.77 & Operating Limit $(1.24 \mathrm{e}-2)$ \\
\hline
\end{tabular}

The K-effective of the flat-layered aged-flooded conditions is significantly increased from the aged conditions (Table 14) because of changes in moderation. However, for the mounded lump conditions, $\mathrm{K}$-effective decreases because of the shielding provided by the water surrounding the lumps. For aged conditions, the fissile material was under moderated, but for aged-flooded conditions the fissile material is optimally moderated.

The credibility of mass inventory has not changed because the frequency of occurrence for aging-flooding is assumed to be 1.0 . 


\subsection{DESIGN FEATURES (ACTIVE AND PASSIVE) AND ADMINISTRATIVE CONTROLLED LIMITS AND REQUIREMENTS}

This NCSE demonstrate criticality safety margins by providing K-effective for several bounding configurations (Tables 11, 12, and 14) for SWMF TRU Waste Storage Pads taking credit for the form of the waste and practices taken by the waste generator. Past analyses didn't take credit for these factors, yielding overly conservative safety margins.

The following assumptions must be ensured by SWMF for the conclusions of this NCSE to be valid. This list is a refinement of the scoping assumptions listed in section 1.2.

* Container fissile inventory limits as stated in WAC procedure 3.06 (Ref. 3) are maintained.

* The current practices, the same as those used in the past, of recovering usable fissile material and decontamination for ALARA will continue to be practiced in the future.

* Waste generation process and packaging practices that "by their nature" limit polyethylene (or equivalent) to less than $30 \%$ by volume inside the container shall be continued.

* Waste packaging practices that randomly place waste into containers are continued. That is the basis of the assumptions used in determining the criticality related frequencies of waste configuration (Ref. 4).

* Waste Characterization includes, but is not limited to, documentation of how fissile material is nominally distributed within the waste form and the extent to which the fissile material is attached to the waste form.

* HEPA filters continue to be qualified to the specification of ASME Code AG-1 (see Sections 2.2 and 5.2).

* Criticality safety evaluations are provided for containers that must be exempted from the above assumptions (Ref. 6). These criticality safety evaluations shall demonstrate the container safety in Solid Waste configurations and shall be prepared and approved along with appropriate procedures (new and upgraded) prior to receipt, handling, and storage of containers in a Solid Waste Facility. The evaluations must specify any special controls required to maintain the safety of those containers in Solid Waste Facilities.

* Four hour rated worth of concrete culvert walls (5" minimum) and base protecting culvert contents for external fires as used in the Fire Estimate (Ref. 5).

* Concrete culvert walls and bases are at least 5" thick providing 4 hours protect from external fires as used in the Fire Estimate (Ref. 5).

* Culvert internal volume of $4.8 \mathrm{~m}^{* *} 3$ or less limiting source of oxygen as used in the Fire Estimate (Ref. 5). 
Past NCSEs, that have overlooked the credits taken in this NCSE, have required SWMF to use container inventory limits in addition to those required by the WAC and limited stacking of some containers to ensure criticality safety (Section 2.0). The existing mass and configurations limits are summarized in Chapter 6 of SWMF SAR (Ref. 13) and included in Table 1 of section 2.0. This NCSE has demonstrated that SWMF can safely continue TRU waste storage pad operations without the additional limits required by those past NCSEs (Section 5 and 6 ). The additional limits that may be eliminated are summarized as follows:

* Single tier (and three tier where applicable) stacking restrictions on steel boxes, concrete culverts, concrete casks, 55 gallon drums, and polyethylene boxes as defined in Appendix A of the SWMF DCA (Ref. 1). This evaluation (section 5.0, all containers) shows stacking limits are not needed.

* Limiting 11 drums to less than $130 \mathrm{~g}$ Pu-239 in configurations of drums greater than $1 / 2 \mathrm{Ci}$ stored in culverts as defined in Appendix A of the SWMF TRU DCA (Ref. 1). This evaluation (section 5.1, Drums) shows drums containing $195 \mathrm{~g} \mathrm{Pu}-239$ and other waste can be safely stacked in an array, 2 or more high, with rolling rims overlapping.

* Limiting culverts to $390 \mathrm{~g} \mathrm{Pu}-239$ for configurations of polyethylene boxes containing HEPA filters or Roughing Filters stored in concrete culverts as defined in Appendix A of the SWMF TRU DCA (Ref. 1). This evaluation (section 5.2, polyethylene boxes) shows polyethylene boxes containing 195 g Pu-239 and other waste can be safely placed together in one culvert.

Specific limits (and the associate controls) in the SWMF DCA (Ref. 1) should be revised per this NCSE. Table 15 lists the reduced set of mass and configuration limits for SWMF TRU waste storage pad operations.

Table 15 - Summary of Reduced Mass and Configuration limits for SWMF Operations of TRU Waste Storage Pads.

\begin{tabular}{|c|c|c|}
\hline Waste Receipt Classification & Mass Limit & Configuration Limit \\
\hline Handling of 55 Gallon Drums & $<195 \mathrm{~g} \mathrm{Pu}-239 \mathrm{FGE}$ per drum & None \\
\hline $\begin{array}{l}\text { Drums containing } 1 / 2 \mathrm{Ci} \text { or Less } \\
\text { Excluding } \mathrm{Cm}-245, \mathrm{Cm}-246, \mathrm{Cm}- \\
247, \mathrm{U}-235, \mathrm{U}-236 \text {, and U-238 }\end{array}$ & None & None \\
\hline $\begin{array}{l}\text { 1/2 Ci or Less Including Cm-245, } \\
\mathrm{Cm}-246, \mathrm{Cm}-247, \mathrm{U}-235, \mathrm{U}-236 \text {, } \\
\text { and } \mathrm{U}-238\end{array}$ & $\begin{array}{l}\text { To be established in a specific } \\
\text { Engineering Evaluation }\end{array}$ & $\begin{array}{l}\text { To be established in a } \\
\text { specific Engineering } \\
\text { Evaluation }\end{array}$ \\
\hline Steel Boxes with more than $1 / 2 \mathrm{Ci}$ & $<195 \mathrm{~g} \mathrm{Pu}-239 \mathrm{FGE}$ per steel box & None \\
\hline $\begin{array}{l}\text { Concrete Casks with more than } 1 / 2 \\
\mathrm{Ci}\end{array}$ & $<195 \mathrm{~g} \mathrm{Pu}-239 \mathrm{FGE}$ per cask & None \\
\hline $\begin{array}{l}\text { Concrete Culverts with more than } \\
1 / 2 \mathrm{Ci}\end{array}$ & $<390$ g Pu-239 FGE per culvert & None \\
\hline Drums in Culverts & $<195 \mathrm{~g} \mathrm{Pu}-239 \mathrm{FGE}$ per drum & None \\
\hline $\begin{array}{l}\text { Handling Polyethylene Boxes } \\
\text { containing HEPA Filters or } \\
\text { Roughing Filters with more than } 1 / 2 \\
\text { Ci Outside Culverts }\end{array}$ & $\begin{array}{l}<195 \text { g Pu-239 FGE per polyethylene } \\
\text { box }\end{array}$ & None \\
\hline $\begin{array}{l}\text { Polyethylene Boxes containing } \\
\text { HEPA Filters or Roughing Filters } \\
\text { Inside Culverts }\end{array}$ & $\begin{array}{l}<195 \text { g Pu-239 FGE per polyethylene } \\
\text { box }\end{array}$ & None \\
\hline
\end{tabular}

Engineering evaluations refer to a safety analysis, including criticality safety, performed prior to receipt that determines the safety of handling/storage of the waste and ensures, that proper procedures have been implemented. 


\subsection{SUMMARY AND CONCLUSIONS}

This NCSE has demonstrated that SWMF can continue receipt, handling, and storage of TRU waste using WAC mass limits ( $195 \mathrm{~g}$ Pu-239 FGE per approved container) and unrestricted stacking configurations (Section 7). Fewer controls are needed because the analyses documented in this NCSE have credited Waste Acceptance Criteria (Ref. 3) controls, bounding moderation characteristics of the waste, and the distribution of waste when placed into containers by the waste generators that were disregarded in previous NCSEs (Section 5 and 6). A process description was provided for all approved containers and the full range of TRU waste types produced by the waste generators (Section 2). Contingencies were identified and evaluations performed to determine the most reactive configurations under credible and limited incredible upset conditions (Section 5). Contingencies included container spacing and stacking, waste operator loading, fissile material inventories, excessive hydrogenous waste, flooding, aging due to radiolytic decomposition, and fires. Safety margins were demonstrated for newly received waste shipments and stored containers considering fissile material inventory, waste generator loading, aging, and flooding upset conditions (Section 6). Finally, assumptions regarding waste characteristics and waste generator actions credited in this NCSE were summarized (Section 7). 


\subsection{REFERENCES}

1. Hammer, K.E., NCSE: Double Contingency Analysis of Solid Waste Management Facility Transuranic Waste Storage Pad Operations (U), N-NCS-E-00005, 4/97.

2. "Waste Generator Actions in Support of the Solid Waste Double Contingency Analysis(U)", A. Q. Goslen, ECS-CRST-97-0026.

3. Procedure 3.06, E-Area, TRU Pads Transuranic Waste Acceptance Criteria, WSRC-1S, Revision No. 3, August 28, 1995.

4. C. Ray Lux, "Criticality Related Frequencies for TRU Pad Operations (U)", SCLC-E-00098.

5. "Fire Estimate for Concrete Culverts on TRU Waste Pads", Mcafee, D., WSMSC97-0007, 27 October 97.

6. "FB-LINE HEPA Filter Disposal", Memorandum, From G.H. Street, To J.W. McClard, 30 June 1988.

7. "Criticality Safety Analysis for Contact Handled Waste at the Waste Isolation Pilot Plant”, DOE/WIPP 88-014, June 1988.

8. “Receipt of Standard Waste Boxes (U)", USQ-SWE-960162, Rev. 0, 10 November 96.

9. "Overpacking, Re-Palletizing, Relocating, and Storing the Naval Fuels Wastes in E-Area", USQ-SWE-96-0024, Rev. 0, 12 June 1996.

10. Nuclear Criticality Safety Analysis 90-1 (U) Nuclear Criticality Safety of the FBLine TRU Waste Burial Boxes, OPS-STD-900008, T.A. Reilly, Westinghouse Savannah River Company, Aiken, SC, April 1990.

11. "Technical Safety Requirements (TSR) Implementation Report Solid Waste Manager Facility", WSRC-IM-97-003, Rev. 0, 3/97.

12. "Actions Needed for Compliance with the TRU Waste Facilities Double Contingency Analysis (U)", A. Q. Goslen, ECS-CSE-97-0003.

13. "Safety Analysis Report Savannah River Site - Solid Waste Management Facility", Rev. 0, WSRC-SA-95-22, February 1996.

14. Lux, R., "Frequency of Receiving Greater Than the Always Safe Mass of Pu-239 in the FB-Line Q-Squared Monitoring Room (U)", N-CLC-F-00209, 10/96.

15. Goslen, A. Q., "Criticality Safety of Solid Waste TRU Operations with Drums Suspected to Contain Significant Quantities of Plutonium (U)", ECS-CRST-970002 , Rev. 2, May 5, 1997.

16. OSR 7-375 and 7-375A, "Radioactive Solid Waste Burial Ground Record" and Instructions (October 31, 1994). 
17. PROCUREMENT SPECIFICATION FOR 55 GALLON PAINTED STEEL DRUMS (U), M-SPS-G-00002, 10/96.

18. Memo J.H. Hershey to P.H. Porter and R.J. Bass, "TRU Waste Packagitrg Requirements Polyethylene Boxes For HEPA Filters", June 8, 1977.

19. Drawings ST5-24224 and ST5-24226.

20. Drawings W734049 and W734050.

21. PROCUREMENT SPECIFICATION FOR CONCRETE STORAGE CONTAINERS (U), M-SPP-G-00250, $5 / 95$.

22. Procedure SOP-221-FB-1477-NS, "Cleaning Cabinet Panels And/Or 410 Jumper Cabinet Sump With Kimwipes (U)", Rev. 3.

23. ANS 8.1, American National Standard for Nuclear Criticality Safety in Operations with Fissionable Materials Outside Reactors, 10/83.

24. Procedure SOP-221-FB-1521-NS, "Cleaning Wet-Cabinet Sumps or Pipe duct Sumps And Neutralizing Sump Waste", Rev. 11.

25. ASME Code AG-1, Section FC.

26. "CIF Solid Waste Container Alternative Materials", Calta, R.F., WSRC-TR-970077, Rev. 0, March 1997, Attachment 3, pp 25-32.

27. "Merch Index", 10th edition, Merck \& co. inc., Rahway, N. J., 1983, p. 1092.

28. "Industrial Ventilation", 20 Edition, American Conference of Government Industrial Hygienists, 1988, ISBN 0-956712-794..

29. Communications from S. D. Klocke to J. F. Mincey, SKA00001.LTR, Flanders Filters, Inc., 3/4/92.

30. "Westinghouse Savannah River Company - Nuclear Criticality Safety Manual (U)”, WSRC-SCD-3, Rev. 2, December 1995.

31. "Radioactive Waste Management", DOE Order 5820.2A, 9/26/88.

32. D. Biswas, MCNP4A Software Management and QA Implementation Package (U), EPD-CTG-950102, September 29, 1995.

33. J. Zino, Nuclear Criticality Safety Evaluation: Mixed Container Types On The TRU Storage Pads In Solid Waste Management Facility (U) , N-NCS-E-00006, December 1996.

34. Williamson, T.G., Baumann, N.P., "Intersecting Volumes - Spheres with Cylinders and Boxes", SRT-CMA-92-0047, 4/21/93.

35. Revolinski, S.M., "MCNP4A Bias Calculation for Plutonuim in TRU Storage Pads in Solid Waste (U)", N-CLC-E-00045. 12/96. 
36. A. Gibbs, Quantity of Plastic in TRU Drums (U), SWE-SWE-96-0495, November $21,1996$.

37. "TRU Drum De-Watering", SR-SWE-93-443, 3/10/93.

38. Nuclear Safety Limits for Various Nuclides in Burial Ground Concrete Culverts, DPSPU-85-272-121, T.A. Reilly, E.I. du Pont de Nemours \& Co., Aiken, SC, November 1985.

39. Forstner, J.L., “Applicability of Bldg. 643-G Nuclear Safety Limits to Two New TRU Waste Containers", DPSPU-82-272-53, 4/29/82.

40. Procedure 5.01, E-Area, Waste Acceptance Criteria Deviations and Exemptions, Revision 1, 25 July 1997.

41. "NCSA 91-02 Nuclear Criticality Safety of the New Special Recovery and the Plutonium Storage Facility", Bullington, J., WSRC-RP-91-101.

42. "NCSE92-06 Nuclear Criticality Safety Limits for the 221-F Vault Button Rack and FL-10 Containers", Bullington, J., NMP-STD-92-0091.

43. Hammer, K.E., "NCSE - Equivalent Water Mass For Polyethylene HEPA Filters (U)", EPD-CTG-94-0003, 3 June 1994. 


\subsection{APPENDIX A - MCNP4A DRUM MODELS}

This analysis of drum arrays relied on MCNP4A spectral reflection on a triangular cell of 3 half drums (see Figure A.1). Spectral reflection surfaces are indicated by asterisk (surfaces 2,3 , and 4). Each drum containers a mixture by volume of $30 \%$ Polyethylene, $5 \%$ Water, and $65 \%$ Air (Cells 16, 20, and 24). Pu-239, of varied amounts, was lumped at the outside of the drum to be collocated next to other drums when spectral reflection is applied (Cells 15, 19, and 23). Lump volume is defined by intersection of interior drum wall, interior drum base or lid if applicable, and a sphere of fixed radii centered on the interior surface of the drum wall. These models ignored the volume of the Pu-239. Steel drum walls are included in the model (Cells 14,18, and 22). Drums are separated by touching lid diameters. Space between drums was filled with air (Cell 12). The drums were placed on a 12" concrete pad (Cell 8, not shown) on top of soil (Cell 9, not shown). Twelve studies were performed analyzing bottles in drums considering single versus double stacking, effects of concrete/soil absorption and reflection, and effects of collocation of fissile lumps at the drum interface versus being at the bottom of both drums. Specific examples of MCNP4A input are provided in figures A.2 through A.13. 
Figure A.1 - XY View of Surfaces and Cells in Tri-Pitched Array of 55 Gallon Drums Model using Spectral Reflection (small letters - surfaces; larger letters - cells; spectral reflection - *)

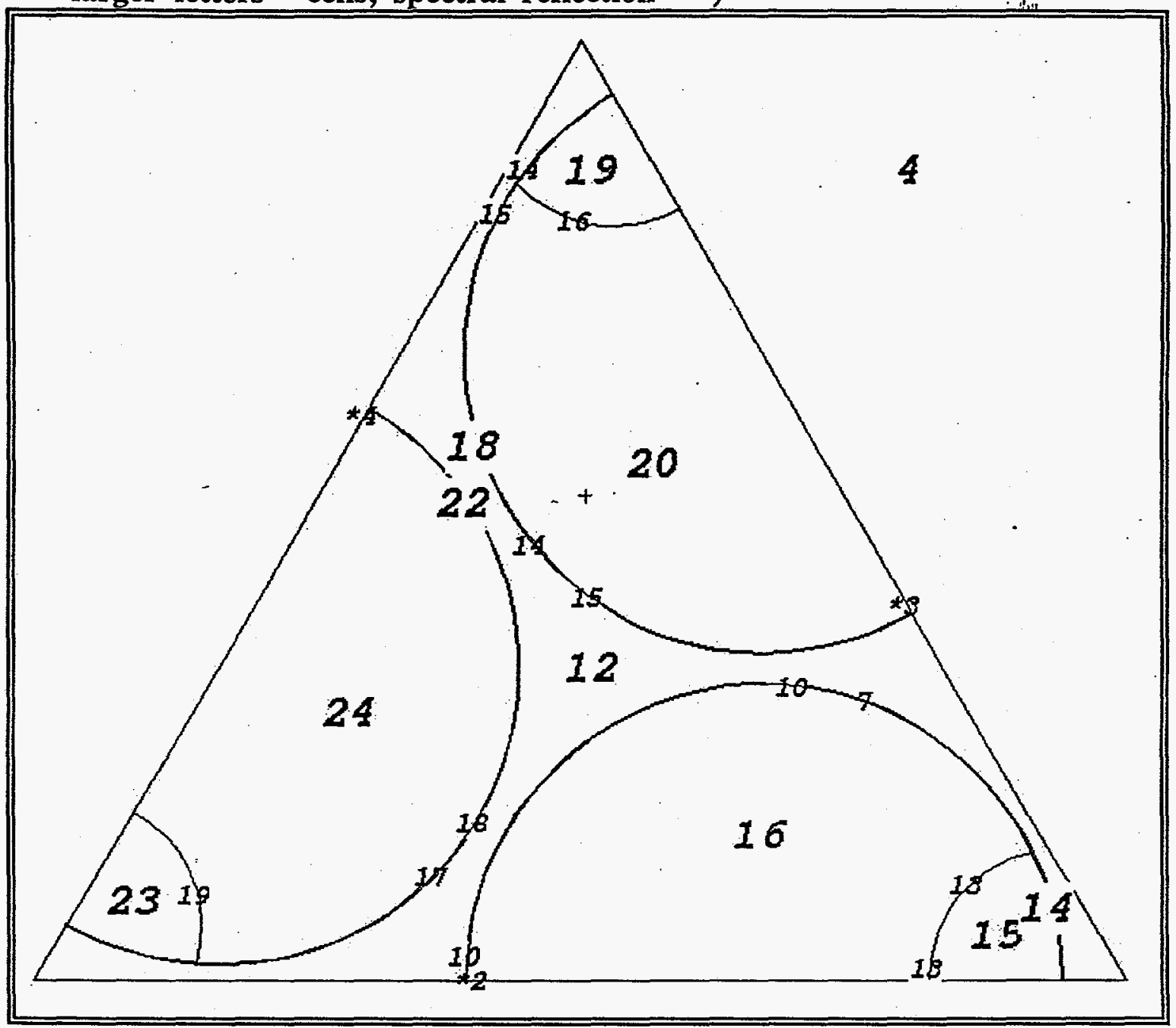


Figure A.2 - MCNP4A Input for Single Planar Array of Drums with $195 \mathrm{~g}$ Pu-239 Lumps Located at the Midplane of the Drum (Case teleab1).

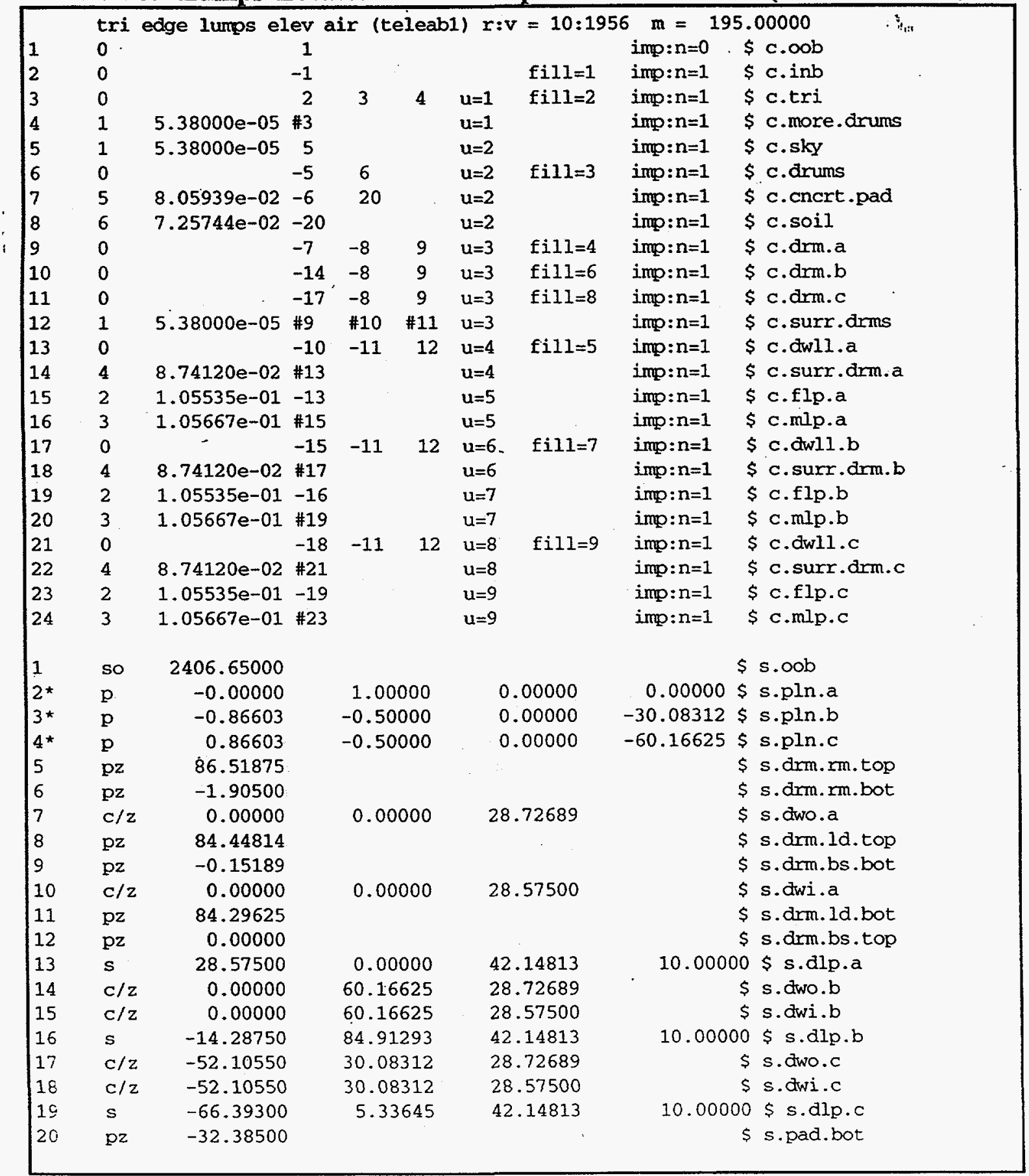


Figure A.2 - (Continue Case teleab1)

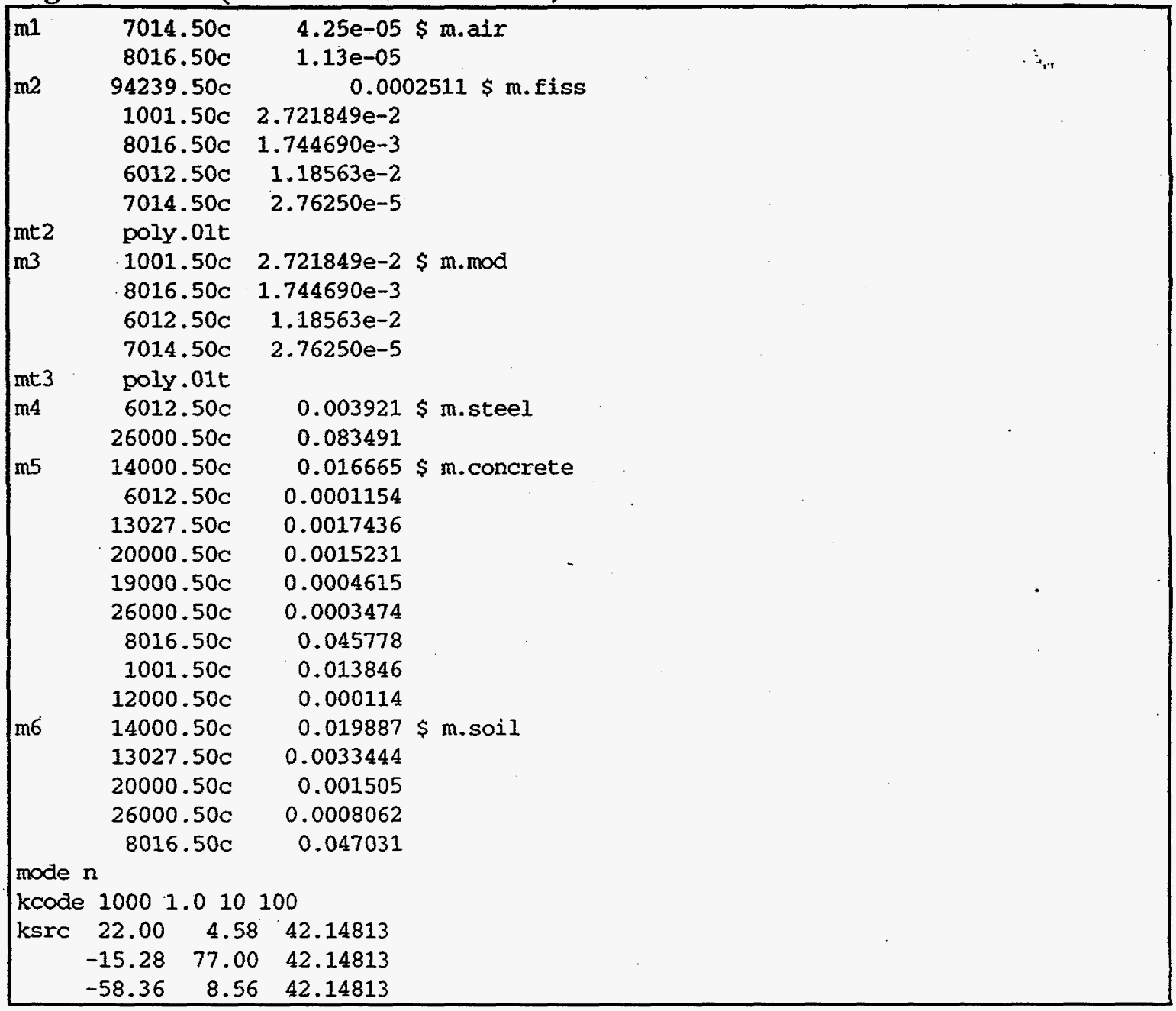


Figure A.3 - MCNP4A Input for Single Planar Array of Drums with $195 \mathrm{~g}$ Pu-239 Lumps Located at the bottom of the Drum (Case teibp 1$)$.

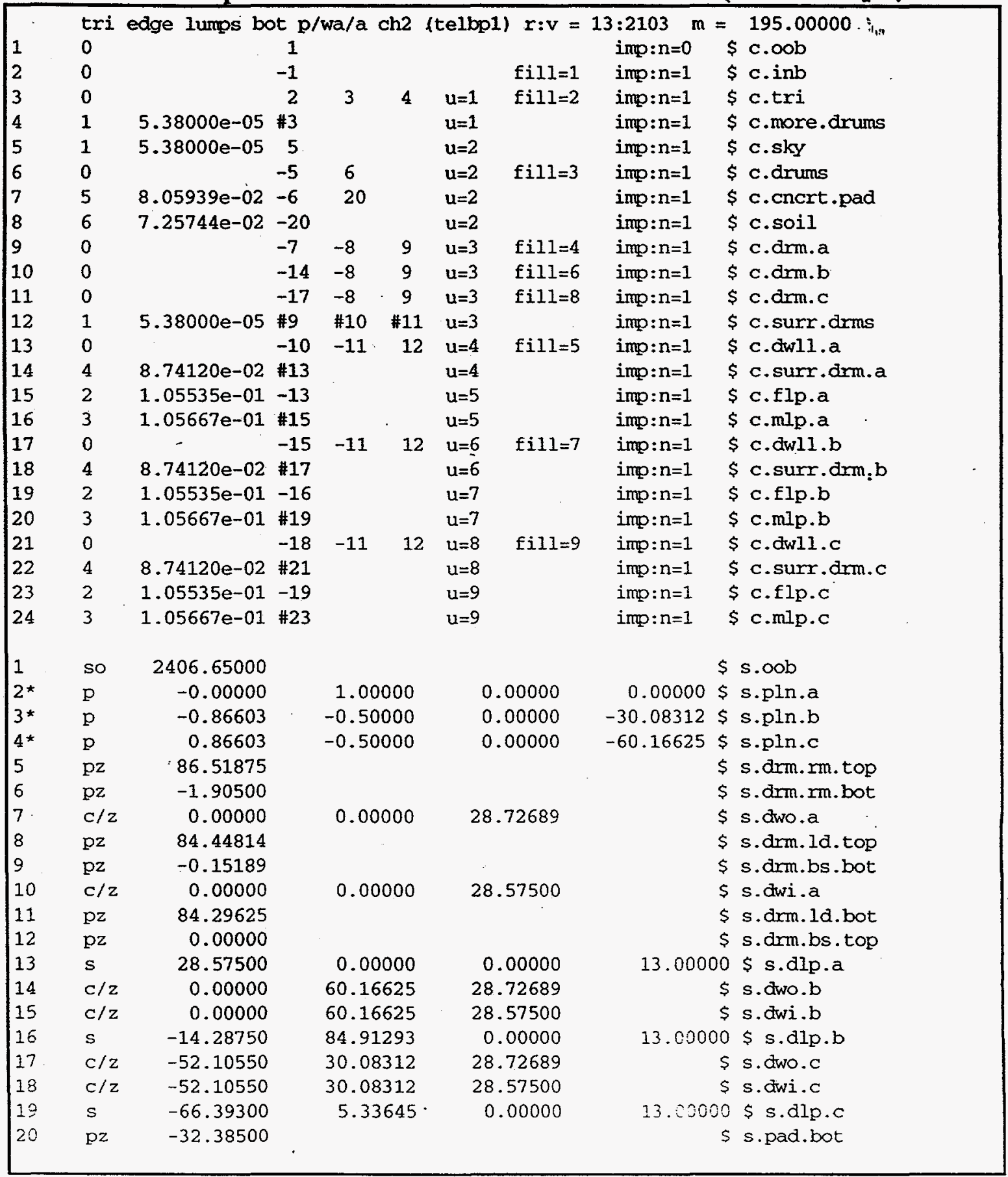


Criticality Safety Envelope for Receipt, Handling, and Storage of Transuranic Waste

Figure A.3 - (Continue Case te 1bp1)

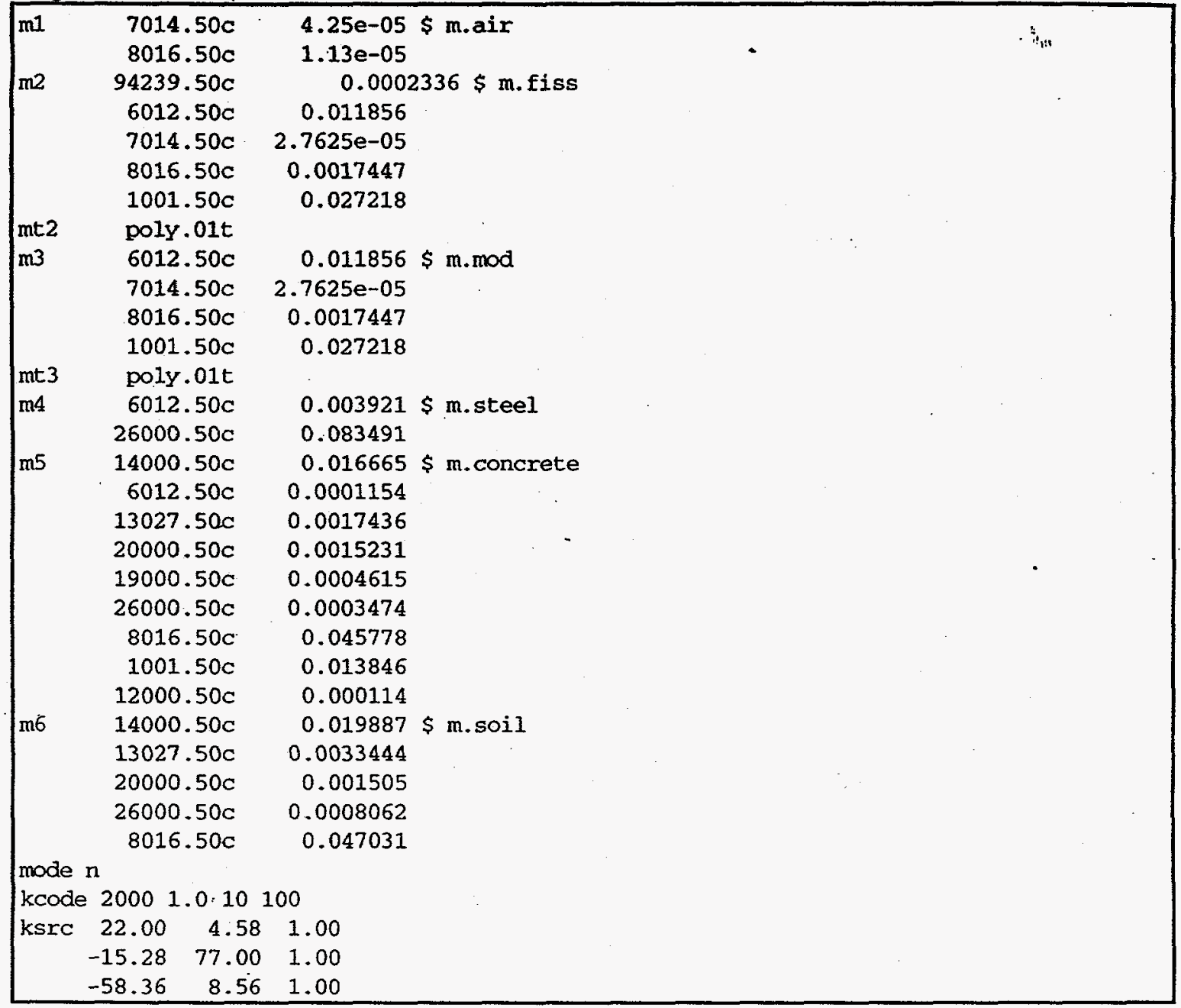


Figure A.4 - MCNP4A Input for Double Planar Array of Drums with $195 \mathrm{~g}$ Pu-239 Lumps Located at the bottom of the Drums (Case tesga1).

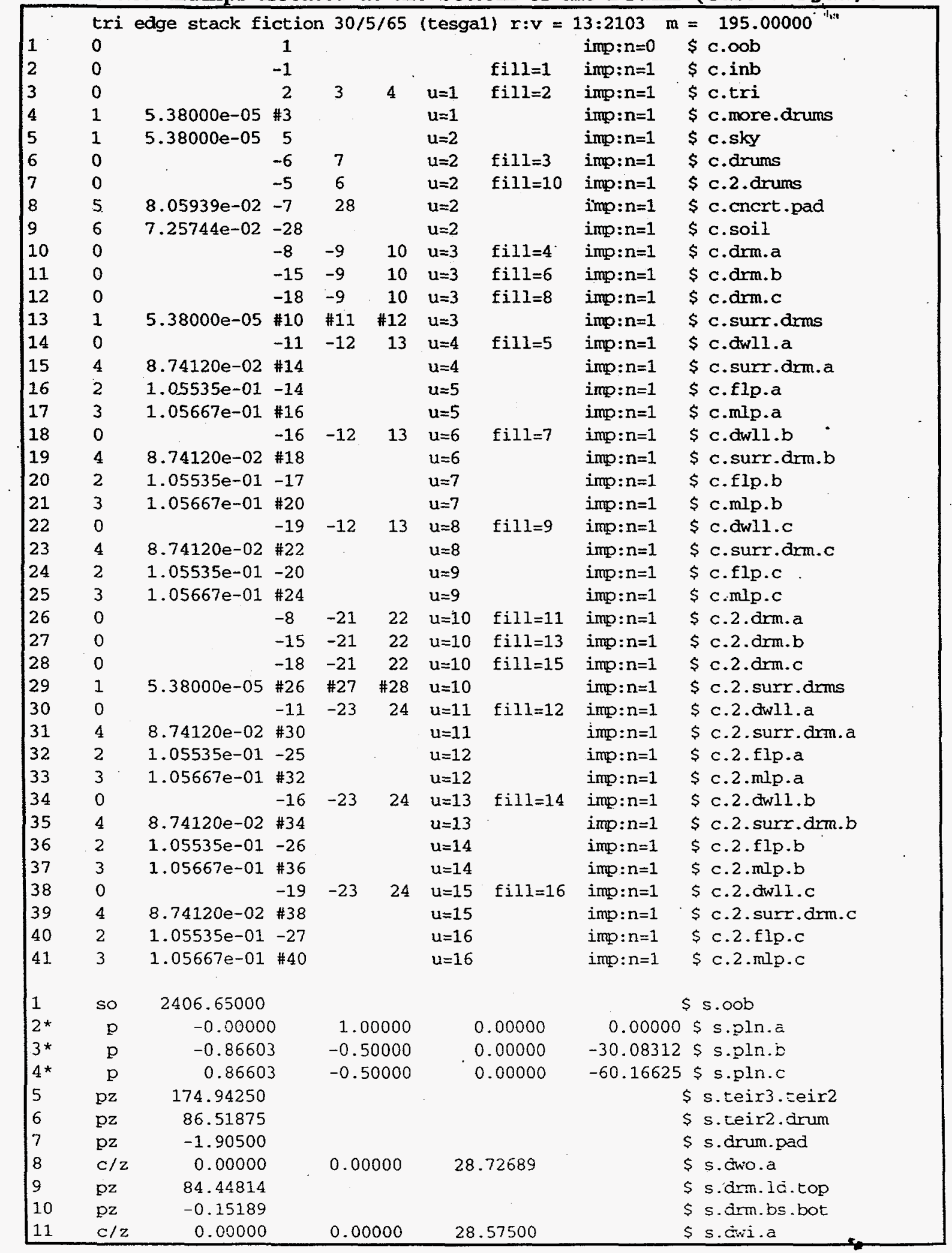


Figure A.4 - (Continue Case tesga1)

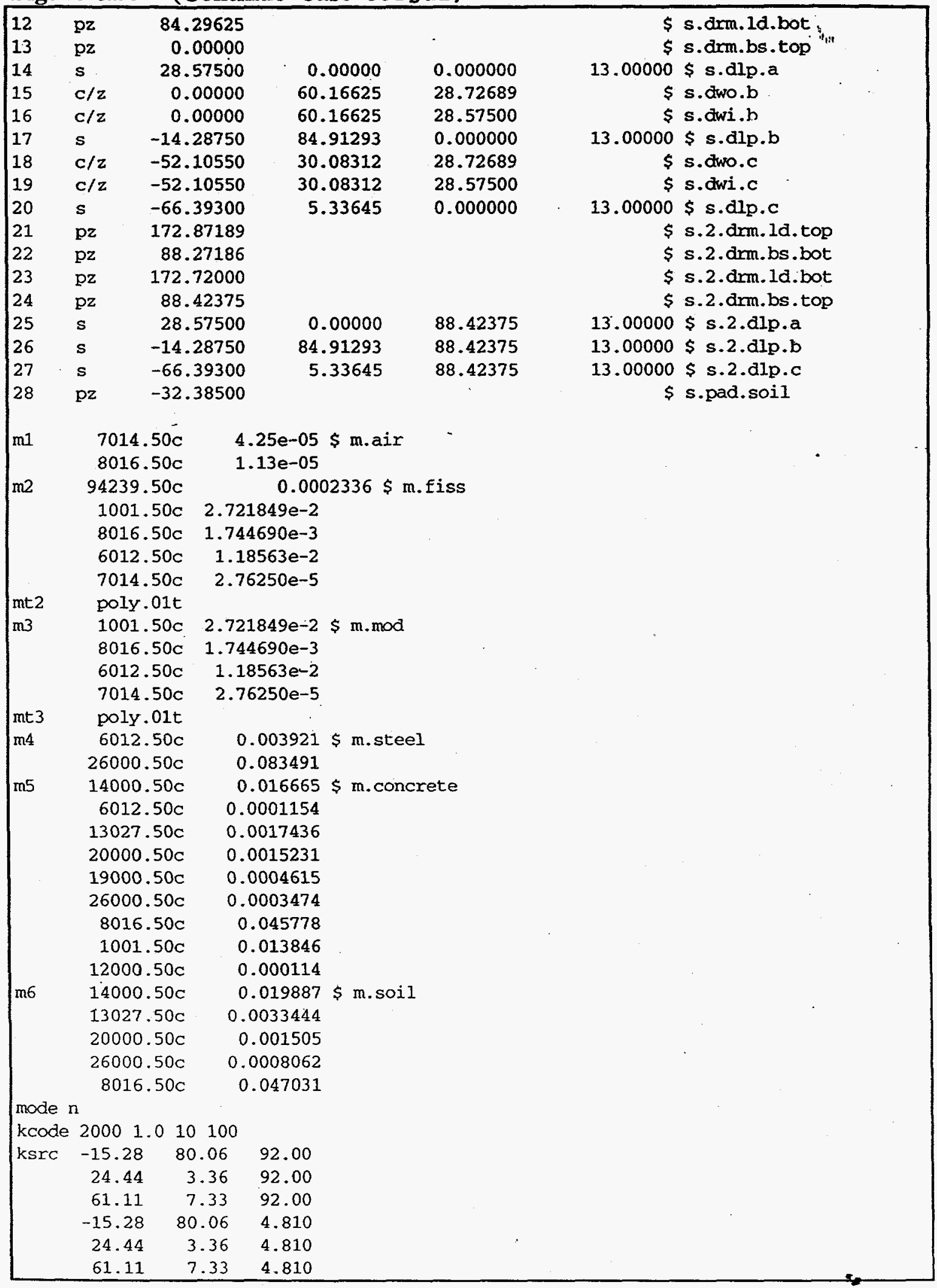


Figure A.5 - MCNP4A Input for Single Planar Array of Drums with $195 \mathrm{~g}$ Pu-239 Lumps Located at the bottom of the Drum (Case tesfaa1).

\begin{tabular}{|c|c|c|c|c|c|c|c|c|c|}
\hline 1 & $\begin{array}{l}\text { tri } \\
0\end{array}$ & edge stack fi & $\begin{array}{c}\text { ictio } \\
1\end{array}$ & n $30 /$ & $5 / 65$ & ltesfa & a1) $r: v=$ & $\begin{array}{l}13: 2103 \\
\text { imp: } n=0\end{array}$ & $\begin{array}{l}m=195.00000^{\circ} \\
\$ c .00 b\end{array}$ \\
\hline 2 & 0 & & -1 & & & & $\operatorname{fi} I 1=1$ & imp: $n=1$ & $\$ c$. inb \\
\hline 3 & 0 & & 2 & 3 & 4 & $u=1$ & fill $=2$ & imp: $n=1$ & \$c.tri \\
\hline 4 & 1 & $5.38000 e-05$ & $\# 3$ & & & $u=1$ & & imp: $n=1$ & \$ c.more.drums \\
\hline 5 & 1 & $5.38000 e-05$ & 5 & & & $u=2$ & & $i m p: n=1$ & \$ c.sky \\
\hline 6 & 0 & & -6 & 7 & & $u=2$ & fill=3 & imp: $n=1$ & $\$ c . d r u m s$ \\
\hline 7 & 0 & & -5 & 6 & & $u=2$ & $\mathrm{fill}=10$ & imp: $n=1$ & $\$ c .2$. drums \\
\hline 8 & 5 & $8.05939 e-02$ & -7 & 28 & & $u=2$ & & imp: $n=1$ & \$ c.cncrt.pad \\
\hline 9 & 6 & $7.25744 \mathrm{e}-02$ & -28 & & & $\mathrm{u}=2$ & & $i m p: n=1$ & \$ c.soil \\
\hline 10 & 0 & & -8 & -9 & 10 & $\mathrm{u}=3$ & $\mathrm{fill}=4$ & imp: $n=1$ & $\$ c . d r m . a$ \\
\hline 11 & 0 & & -15 & -9 & 10 & $u=3$ & $f i 11=6$ & imp: $n=1$ & $\$ c \cdot d r m \cdot b$ \\
\hline 12 & 0 & & -18 & -9 & 10 & $\mathrm{u}=3$ & fill $=8$ & $i m p: n=1$ & $\$ c . d r m . c$ \\
\hline 13 & 1 & $5.38000 e-05$ & $\# 10$ & $\# 11$ & \#12 & $u=3$ & & imp: $n=1$ & $\$ c . s u r r . d r m s$ \\
\hline 14 & 0 & & -11 & -12 & 13 & $\mathrm{u}=4$ & $\mathrm{fill}=5$ & imp: $n=1$ & \$ c.dwll.a \\
\hline 15 & 4 & $8.74120 \mathrm{e}-02$ & $\# 14$ & & & $u=4$ & & imp: $n=1$ & $\$$ c.surr.drm.a \\
\hline 16 & 2 & $1.05535 \mathrm{e}-01$ & -14 & & & $u=5$ & & imp: $n=1$ & \$ c.flp.a \\
\hline 17 & 3 & $1.05667 \mathrm{e}-01$ & $\# 16$ & & & $u=5^{-}$ & & imp: $n=1$ & \$ c.mlp.a \\
\hline 18 & 0 & & -16 & -12 & 13 & $u=6$ & fill $=7$ & imp: $n=1$ & $\$ c . d w 11 . b$ \\
\hline 19 & 4 & $8.74120 e-02$ & $\# 18$ & & & $\mathrm{u}=6$ & & imp: $n=1$ & $\$$ c.surr.drm.b \\
\hline 20 & 2 & $1.05535 \mathrm{e}-01$ & -17 & & & $u=7$ & & imp: $n=1$ & \$ c.flp.b \\
\hline 21 & 3 & $1.05667 e-01$ & $\# 20$ & & & $u=7$ & & $i m p: n=1$ & $\$ c \cdot m l p \cdot b$ \\
\hline 22 & 0 & & -19 & -12 & 13 & $\mathrm{u}=8$ & fill $=9$ & imp: $n=1$ & $\$ c . d w 11 . c$ \\
\hline 23 & 4 & $8.74120 e-02$ & $\# 22$ & & & $\mathrm{u}=8$ & & imp: $n=1$ & $\$ c$. surr.drm.c \\
\hline 24 & 2 & $1.05535 e-01$ & -20 & & & $u=9$ & & imp: $n=1$ & \$ c.flp.c \\
\hline 25 & 3 & $1.05667 e-01$ & $\# 24$ & & & $u=9$ & & $\operatorname{imp}: n=1$ & $\$ c . m l p . c$ \\
\hline 26 & 0 & & -8 & -21 & 22 & $u=10$ & $\mathrm{fill}=11$ & $i m p: n=1$ & $\$ c .2 . d r m . a$ \\
\hline 27 & 0 & & -15 & -21 & 22 & $u=10$ & fill $=13$ & imp: $n=1$ & $\$ c .2 . d r m . b$ \\
\hline 28 & 0 & & -18 & -21 & 22 & $\mathrm{u}=10$ & $\mathrm{fil} 11=15$ & imp: $n=1$ & $\$ c .2 . \mathrm{drm} . \mathrm{c}$ \\
\hline 29 & 1 & $5.38000 e-05$ & $\# 26$ & $\# 27$ & $\# 28$ & $u=10$ & & imp: $n=1$ & $\$ c .2$.surr.drms \\
\hline 30 & 0 & & -11 & -23 & 24 & $u=11$ & fill $=12$ & imp: $n=1$ & $\$ c .2 . d w 11 . a$ \\
\hline 31 & 4 & $8.74120 e-02$ & $\# 30$ & & & $\mathrm{u}=11$ & & $i m p: n=1$ & $\$ c .2$. surr.drm.a \\
\hline 32 & 2 & $1.05535 \mathrm{e}-01$ & -25 & & & $u=12$ & & imp: $n=1$ & $\$ c .2 . f l p . a$ \\
\hline 33 & 3 & $1.05667 e-01$ & $\# 32$ & & & $u=12$ & & imp: $n=1$ & $\$ c .2 . \mathrm{mlp} . \mathrm{a}$ \\
\hline 34 & 0 & & -16 & -23 & 24 & $u=13$ & $\mathrm{fill}=14$ & $i m p: n=1$ & $\$ c .2 . d w 11 . b$ \\
\hline 35 & 4 & $8.74120 e-02$ & $\# 34$ & & & $u=13$ & & imp: $n=1$ & $\$ c \cdot 2$. surr.drm.b \\
\hline 36 & 2 & $1.05535 \mathrm{e}-01$ & -26 & & & $\mathrm{u}=14$ & & imp: $n=1$ & $\$ c .2 . f l p . b$ \\
\hline 37 & 3 & $1.05667 e-01$ & $\# 36$ & & & $u=14$ & & imp: $n=1$ & $\$ c .2 \cdot \mathrm{mlp} \cdot \mathrm{b}$ \\
\hline 38 & 0 & & -19 & -23 & 24 & $u=15$ & fil1 $=16$ & imp: $n=1$ & $\$ c .2 . d w 11 . c$ \\
\hline 39 & 4 & $8.74120 \mathrm{e}-02$ & \#38 & & & $u=15$ & & imp: $n=1$ & $\$ c .2$. surr.drm.c \\
\hline 40 & 2 & $1.05535 e-01$ & -27 & & & $u=16$ & & $i m p: n=1$ & $\$ c .2 . f l p . c$ \\
\hline 41 & 3 & $1.05667 e-01$ & $\# 40$ & & & $u=16$ & & imp: $n=1$ & $\$ c .2 . \mathrm{mlp} . \mathrm{c}$ \\
\hline
\end{tabular}




\section{Figure A.5 - (Continue Case tesfaa 1)}

\begin{tabular}{|c|c|c|c|c|c|c|c|}
\hline 1 & so & 2406.65000 & & & & $\mathbf{s . \infty b}$ & \\
\hline 2 * & $\mathbf{p}$ & -0.00000 & 1.00000 & 0.00000 & 0.00000 & \$ s.pln.a & \\
\hline $3 *$ & $\mathrm{p}$ & -0.86603 & -0.50000 & 0.00000 & -30.08312 & $\$ s . p \ln . b$ & \\
\hline $4 *$ & $\mathrm{p}$ & 0.86603 & -0.50000 & 0.00000 & -60.16625 & \$ s.pln.c & \\
\hline 5 & $\mathrm{pz}$ & 174.94250 & & & $\$$ & s.teir3.teir2 & \\
\hline 6 & $\mathrm{pz}$ & 86.51875 & & & $\$$ & s.teir2.drum & \\
\hline 7 & $\mathrm{pz}$ & -1.90500 & & & $\$$ & s.drum.pad & \\
\hline 8 & $c / z$ & 0.00000 & 0.00000 & 28.72689 & $\$$ & s.dwo.a & \\
\hline 9 & $\mathrm{pz}$ & 84.44814 & & & $\$$ & s.drm.1d.top & \\
\hline 10 & $\mathrm{pz}$ & -0.15189 & & & $\$$ & s.drm.bs.bot & \\
\hline 11 & $c / z$ & 0.00000 & 0.00000 & 28.57500 & $\$$ & s.dwi.a & - \\
\hline 12 & $\mathrm{pz}$ & 84.29625 & & & $\$$ & s.drm.ld.bot & \\
\hline 13 & $\mathrm{pz}$ & 0.00000 & & & $\$$ & s.drm.bs.top & \\
\hline 14 & $\mathrm{~s}$ & 28.57500 & 0.00000 & 84.29625 & 13.00000 & \$ s.dlp.a & \\
\hline 15 & $c / z$ & 0.00000 & 60.16625 & 28.72689 & $\$$ & s.dwo.b & \\
\hline 16 & $c / z$ & 0.00000 & 60.16625 & 28.57500 & $\$$ & s.dwi.b & \\
\hline 17 & $\mathbf{s}$ & -14.28750 & 84.91293 & 84.29625 & 13.00000 & \$ s.dlp.b & \\
\hline 18 & $c / z$ & -52.10550 & 30.08312 & 28.72689 & $\$$ & s.dwo.c & \\
\hline 19 & $c / z$ & $-\overline{5} 2.10550$ & 30.08312 & 28.57500 & $\$$ & s.dwi.c & \\
\hline 20 & $\mathbf{s}$ & -66.39300 & 5.33645 & 84.29625 & 13.00000 & \$ s.dlp.c & \\
\hline 21 & $\mathrm{pz}$ & 172.87189 & & & $\$$ & s.2.drm.12.top & \\
\hline 22 & $\mathrm{pz}$ & 88.27186 & & & $\$$ & s.2.dm.bs.bot & \\
\hline 23 & $\mathrm{pz}$ & 172.72000 & & & $\$$ & s.2.dm.ld.bot & \\
\hline 24 & $\mathrm{pz}$ & 88.42375 & & & $\$$ & s.2.dm.bs.top & \\
\hline 25 & $s$ & 28.57500 & 0.00000 & 88.42375 & 13.00000 & $\$$ s.2.dlp.a & \\
\hline 26 & $\mathbf{s}$ & -14.28750 & 84.91293 & 88.42375 & 13.00000 & s s.2.dlp.b & \\
\hline 27 & $\mathbf{s}$ & -66.39300 & 5.33645 & 88.42375 & 13.00000 & $\$$ s.2.dlp.c & \\
\hline 28 & $\mathrm{pz}$ & -32.38500 & & & $\$$ & s.pad.soil & \\
\hline
\end{tabular}


Figure A.6 - (Continue Case tasax 1 )

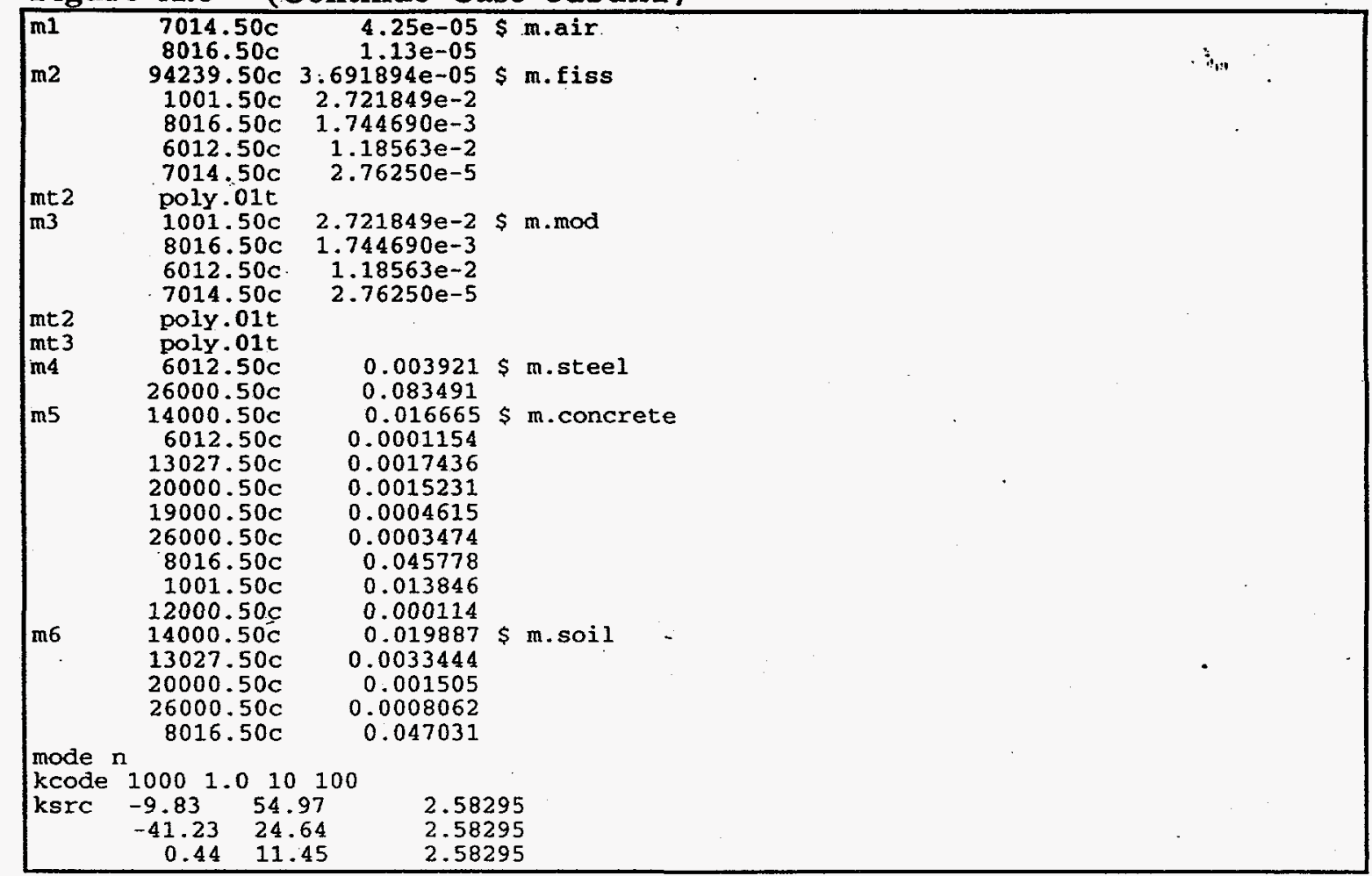


Figure A.6 - MCNP4A Input for Tri-Pitch Array of drums containing Fissile/Moderator Mixture Occupying bottom of Drum with $\mathrm{H} / \mathrm{Pu}$ set for Dry Conditions (Case tdsax1).

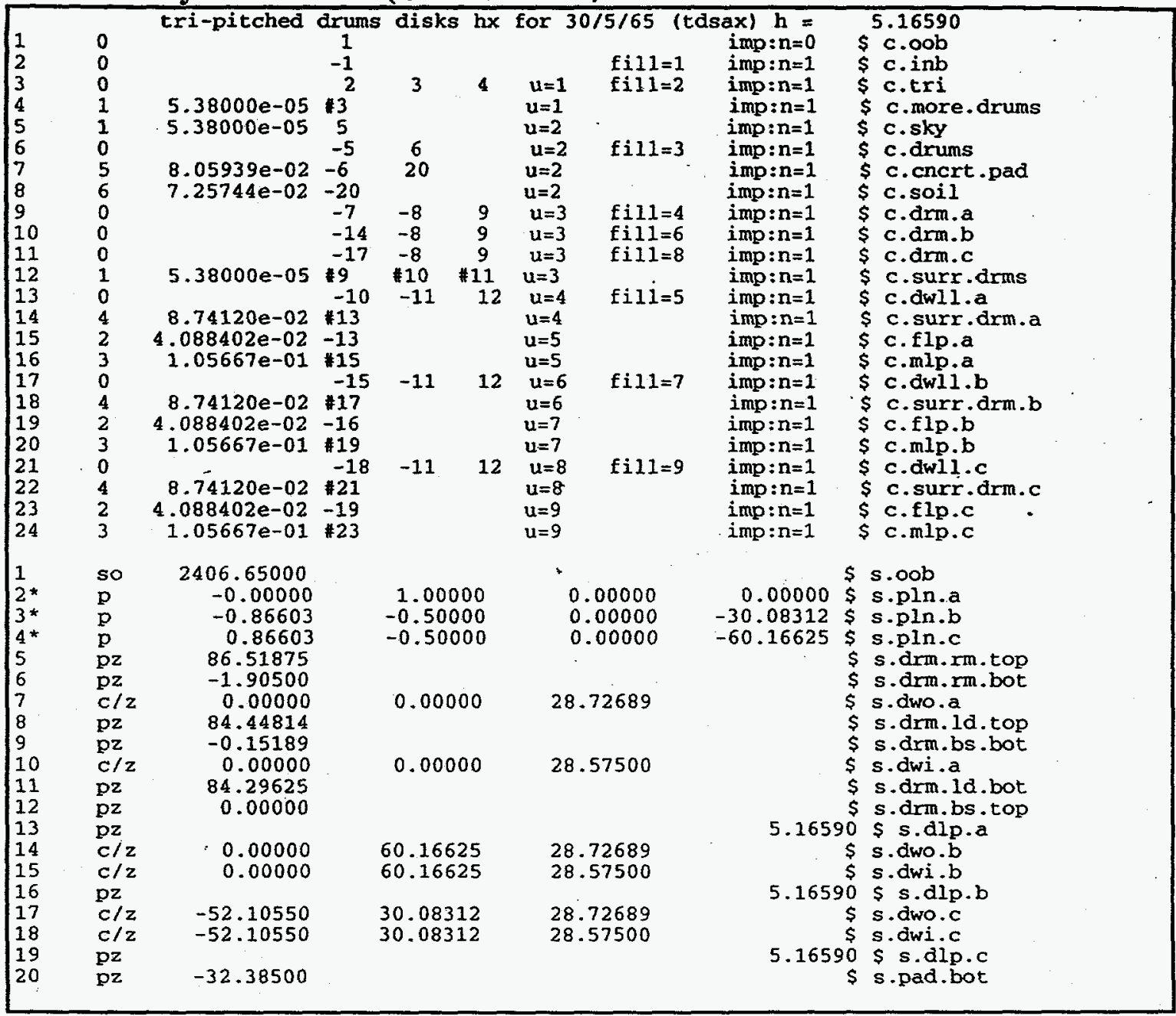


4.62E-12). This configuration was analyzed and included (cases TESFAA[1-8]) for comparison of this analysis to past NCSEs.

This analysis considered two sets of 3 drums stacked two high arranged in an infinite planar array, with each drum containing 2 plastic bottles placed as close as possible to bottles in the adjacent drums (cases TESGA[1-8]). The two bottles worth of fissile material and moderator were modeled as a spherical section of approximately 2 liters with a radius of $13 \mathrm{~cm}$. Lumps were positioned at the base of the drums because of the previous results (see Table 5 that demonstrates that lumps collocated at the base of drum are more reactive than lumps collocated at the middle plane of drum.).

Each bottle contained a mixture of fissile material and moderator. The amount of fissile material was varied to test the effects of exceeding the WAC inventory limits (i.e., $195 \mathrm{~g}$ PU-239 per drum). Moderator was assumed 30/5/65 percent volume mixture of

polyethylene, water, and air, respectively (Pu-239 volume was neglected). This moderator mixture was used to bound the moderating properties of the low density wood fiber used to make swipes. The remainder of the drum was filled with the moderator mixture $(30 / 5 / 65$ $\%$ volume mixture of polyethylene, water, and air, respectively). Drums were placed in a triangular pitched array separated by the lid diameter of the drum. Spectral reflection on a triangular cell was used to model an infinitè planar array (See Figure A.1).

Table 10 - Comparison of K-effective $+/$ - 1 Standard Deviation for Stacked 6 Drums Configurations with Two 1-Liter Bottles containing Pu-239 and Dry Polyethylene/Water/Air Mixture.

\begin{tabular}{|c|c|c|c|}
\hline Cases & TESFAA[1-8] & TESGA[1-8] & TELBD[1-8] \\
\hline Top Drum Fissile Loc & bottom & bottom & Single Stacked Array \\
\hline Bottom Drum Fissile Loc & top & bottom & bottom \\
\hline Lump Radius (cm) & 13 & 13 & 13 \\
\hline Lump Volume (cm $* * 3)$ & 2103 & 2103 & 2103 \\
\hline $195 \mathrm{~g} \mathrm{Pu}-239$ & $0.89903+/-0.00290$ & $0.79387+/-0.00202$ & $0.79461+/-0.00207$ \\
\hline $242 \mathrm{~g} \mathrm{Pu}-239$ & $0.90814+/-0.00292$ & $0.80633+/-0.00238$ & $0.80859+/-0.00208$ \\
\hline $300 \mathrm{~g} \mathrm{Pu}-239$ & $0.92220+/-0.00308$ & $0.81909+/-0.00193$ & $0.82011+/-0.00194$ \\
\hline $390 \mathrm{~g} \mathrm{Pu}-239$ & $0.93802+/-0.00308$ & $0.83332+/-0.00234$ & $0.83237+/-0.00198$ \\
\hline $510 \mathrm{~g} \mathrm{Pu}-239$ & $0.95051+/-0.00293$ & $0.84225+/-0.00196$ & $0.84795+/-0.00219$ \\
\hline $728 \mathrm{~g} \mathrm{Pu}-239$ & $0.96587+/-0.00287$ & $0.87281+/-0.00207$ & $0.87462+/-0.00191$ \\
\hline $970 \mathrm{~g} \mathrm{Pu}-239$ & $0.99598+/-0.00325$ & $0.89286+/-0.00218$ & $0.89448+/-0.00230$ \\
\hline
\end{tabular}

The results in Table 10 (cases TESFAA and TESGA) show the differences when $\mathrm{K}$ effective of stacked drum configurations with realistic separations between fissile material lumps are compared to $\mathrm{K}$-effective of similar drum configurations having fissile lump separations used in past NCSEs. The difference is due to the isolation between fissile material lumps provided by the other material in the drums. Using the old configuration would have significantly reduced the mass that could be tolerated before $\mathrm{K}$-safe was exceeded. However, that reduced mass is greater than the credible 3-drum mass error (242 g Pu-242 per drum) identified by the frequency study (Ref. 4). The stacked configuration used in this NCSE, TESFAA[1-8], demonstrated masses as high as $970 \mathrm{~g} \mathrm{Pu}-239$ could be tolerated.

The results of Table 10 (cases TESGA and TELBP) also demonstrate that stacking of drums is not a criticality concern provided container inventories are maintained at the $W A C$ 
Figure A.7 - MCNP4A Input for Flooded Tri-Pitch Array of drums containing Fissile/Moderator Mixture Occupying bottom of Drum with H/Pu set for Dry Conditions (Case tdsx1).

3

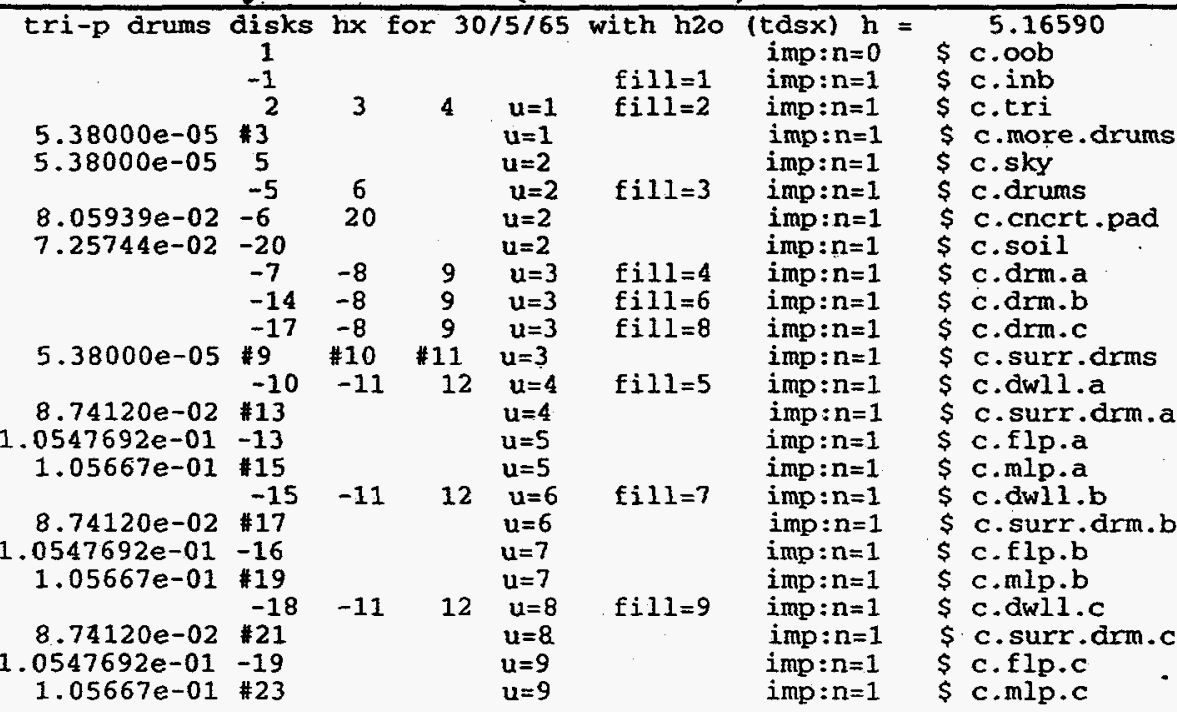

2406.65000

$-0.00000$

$-0.86603$

0.86603

86.51875

$-1.90500$

0.00000

84.44814

$-0.15189$

0.00000

84.29625

0.00000

0.00000

0.00000

60.16625

60.16625

1.00000

$-0.50000$

$-0.50000$

0.00000

28.72689

0.00000

28.57500

$-52.10550$

30.08312

30.08312

28.72689

28.57500

28.72689

28.57500
$\$ 5.00 b$

0.00000 s.pln.a

-30.08312 \$ s.pin.b

-60.16625 S s.pln.

$\$$ s.drm.rm.top

$\$$ s.drm.rm.bot

$\$$ s.dwo.a

$\$$ s.drm.10.top

$\$$ s.drm.bs.bot

$\$$ s.dwi.a

s s.drm.bs.top

5.16590 \$ s.dlp.a

$\$$ s.dwo.b

$\$$ s.dwi.b

5.16590 \$ s.dlp.b

$\$ s . d w o . c$

$\$$ s.dwi.c

5.16590 \$ s.dlp.c

S s.pad.bot
$\$$ s.drm.10.bot 
Figure A.7 - (Continue Case tdsx1)

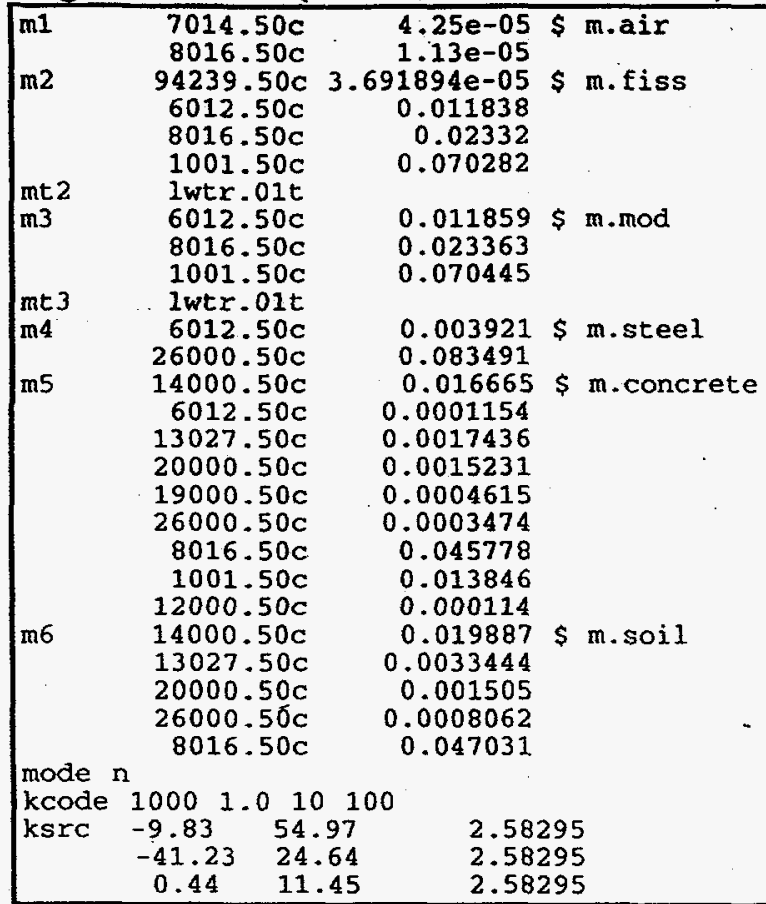


Figure A.8 - MCNP4A Input for Double Planar Array of Drums with $195 \mathrm{~g}$ Pu-239 Lumps Colloacted at the Drum-Drum Interface with H/Pu set for Wet Conditions (Case te2tf1).

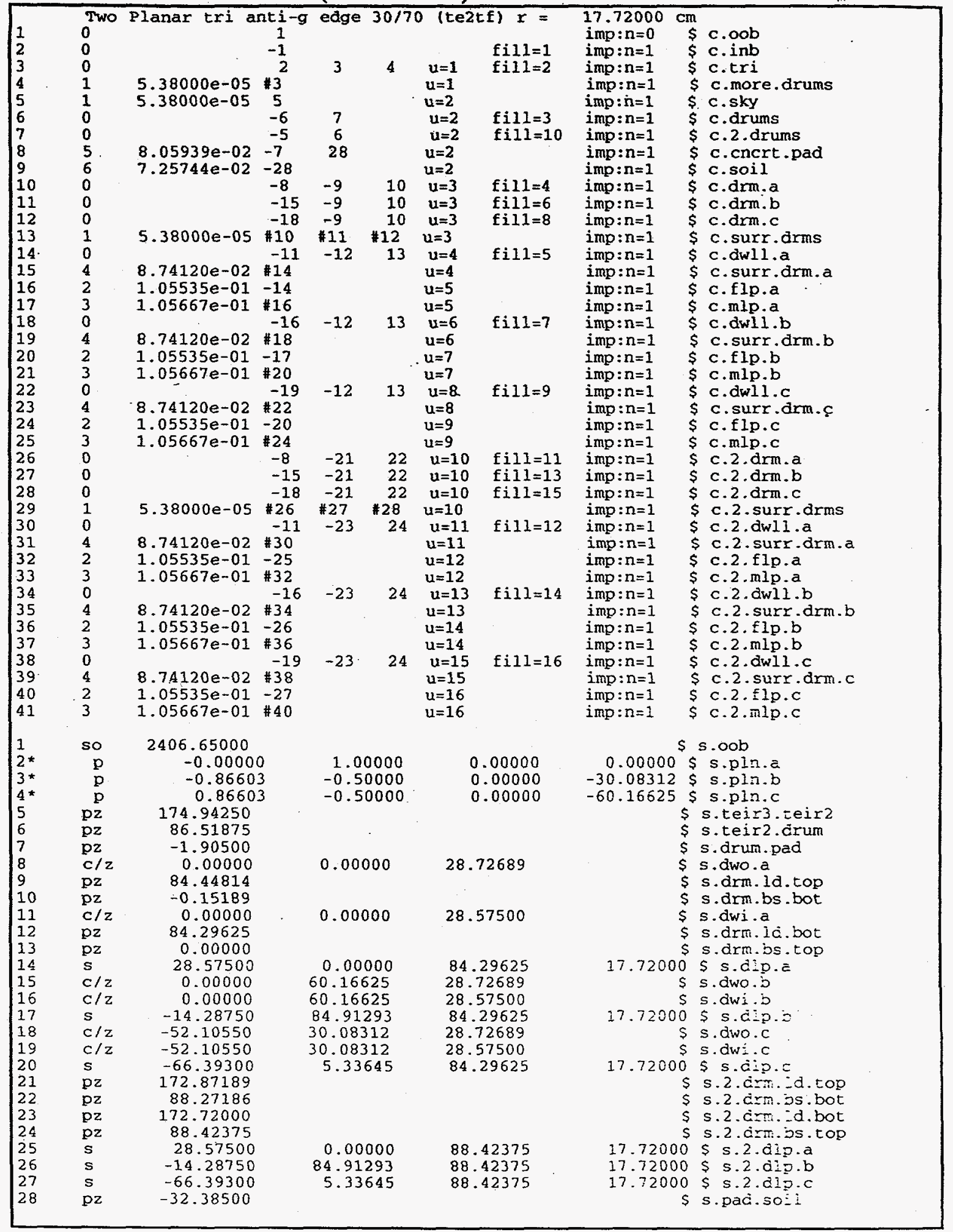


Figure A.8 - (Continue Case te2tf1)

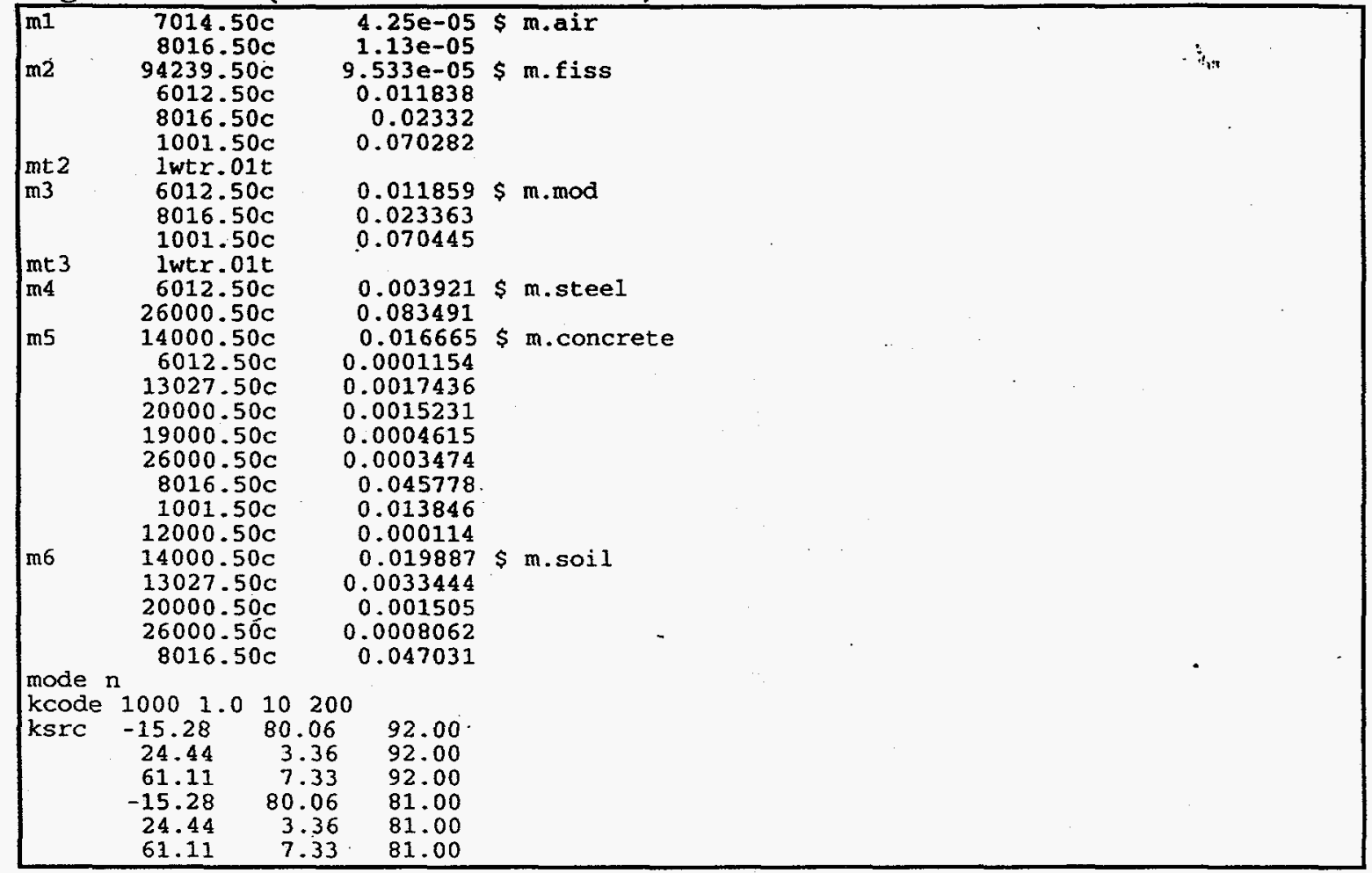




\section{Figure A.9 - MCNP4A Input for Modified case te2tf with correct rolling} rim diameter (Case te2fc1).

\begin{tabular}{|c|c|c|c|c|c|c|c|c|c|}
\hline $\begin{array}{l}1 \\
2 \\
3 \\
4 \\
5 \\
6 \\
7 \\
8 \\
9 \\
10 \\
11 \\
12 \\
13 \\
14 \\
15 \\
16 \\
17 \\
18 \\
19 \\
20 \\
21 \\
22 \\
23 \\
24 \\
25 \\
26 \\
27 \\
28 \\
29 \\
30 \\
31 \\
32 \\
33 \\
34 \\
35 \\
36 \\
37 \\
38 \\
39 \\
40 \\
41\end{array}$ & $\begin{array}{l}0 \\
0 \\
0 \\
1 \\
1 \\
0 \\
0 \\
5 \\
6 \\
0 \\
0 \\
0 \\
1 \\
0 \\
4 \\
2 \\
3 \\
0 \\
4 \\
2 \\
3 \\
0 \\
4 \\
2 \\
3 \\
0 \\
0 \\
0 \\
1 \\
0 \\
4 \\
2 \\
3 \\
0 \\
4 \\
2 \\
3 \\
0 \\
4 \\
2 \\
3\end{array}$ & $\begin{array}{l}5.38000 \mathrm{e}-05 \\
8.74120 \mathrm{e}-02 \\
1.05535 \mathrm{e}-01 \\
1.05667 \mathrm{e}-01 \\
8.74120 \mathrm{e}-02 \\
1.05535 \mathrm{e}-01 \\
1.05667 \mathrm{e}-01 \\
8.74120 \mathrm{e}-02 \\
1.05535 \mathrm{e}-01 \\
1.05667 \mathrm{e}-01\end{array}$ & $\begin{array}{l}\text { tri } \\
1 \\
-1 \\
2 \\
\# 3 \\
5 \\
-6 \\
-5 \\
-7 \\
-28 \\
-8 \\
-15 \\
-18 \\
\# 10 \\
-11 \\
\# 14 \\
-14 \\
\# 16 \\
-16 \\
\# 18 \\
-17 \\
\# 20 \\
-19 \\
\# 22 \\
-20 \\
\# 24 \\
-8 \\
-15 \\
-18 \\
\# 26 \\
-11 \\
\# 30 \\
-25 \\
\# 32 \\
-16 \\
\# 34 \\
-26 \\
\# 36 \\
-19 \\
\# 38 \\
-27 \\
\# 40\end{array}$ & $\begin{array}{c}\text { anti- } \\
3 \\
7 \\
6 \\
28 \\
-9 \\
-9 \\
-9 \\
\# 11 \\
-12 \\
\\
-12 \\
\\
-12 \\
\\
-21 \\
-21 \\
-21 \\
\# 27 \\
-23 \\
\\
-23 \\
-23 \\
\\
\\
\\
\\
\end{array}$ & $\begin{array}{r}10 \\
10 \\
10 \\
12 \\
13\end{array}$ & $\begin{array}{l}u=1 \\
u=1 \\
u=2 \\
u=2 \\
u=2 \\
u=2 \\
u=2 \\
u=3 \\
u=3 \\
u=3 \\
u=3 \\
u=4 \\
u=4 \\
u=5 \\
u=5 \\
u=6 \\
u=6 \\
u=7 \\
u=7 \\
u=8 \\
u=8 \\
u=9 \\
u=9 \\
u=10 \\
u=10 \\
u=10 \\
u=10 \\
u=11 \\
u=11 \\
u=12 \\
u=12 \\
u=13 \\
u=13 \\
u=14 \\
u=14 \\
u=15 \\
u=15 \\
u=16 \\
u=16\end{array}$ & $\begin{array}{l}\text { corr. } \\
\text { fill }=1 \\
\text { fill }=2 \\
\text { fill }=3 \\
\text { fill }=10\end{array}$ & $\begin{array}{c}\text { rim (te } 2 \text { fc) } \\
\text { imp: } n=0 \\
\text { imp: } n=1 \\
\text { imp: } n=1 \\
\text { imp: } n=1 \\
\text { imp: } n=1 \\
\text { imp: } n=1 \\
\text { imp: } n=1 \\
\text { imp: } n=1 \\
\text { imp: } n=1 \\
\text { imp: } n=1 \\
\text { imp: } n=1 \\
\text { imp: } n=1 \\
\text { imp: } n=1 \\
\text { imp: } n=1 \\
\text { imp: } n=1 \\
\text { imp: } n=1 \\
\text { imp: } n=1 \\
\text { imp: } n=1 \\
\text { imp: } n=1 \\
\text { imp: } n=1 \\
\text { imp: } n=1 \\
\text { imp: } n=1 \\
\text { imp: }: n=1 \\
\text { imp: } n=1 \\
\text { imp: } n=1 \\
\text { imp: } n=1 \\
\text { imp: } n=1 \\
\text { imp: } n=1 \\
\text { imp: } n=1 \\
\text { imp: } n=1 \\
\text { imp: } n=1 \\
\text { imp: } n=1 \\
\text { imp: } n=1 \\
\text { imp: } n=1 \\
\text { imp: } n=1 \\
\text { imp: } n=1 \\
\text { imp: } n=1 \\
\text { imp: } n=1 \\
\text { imp: } n=1 \\
\text { imp: } n=1 \\
\text { imp: } n=1\end{array}$ & 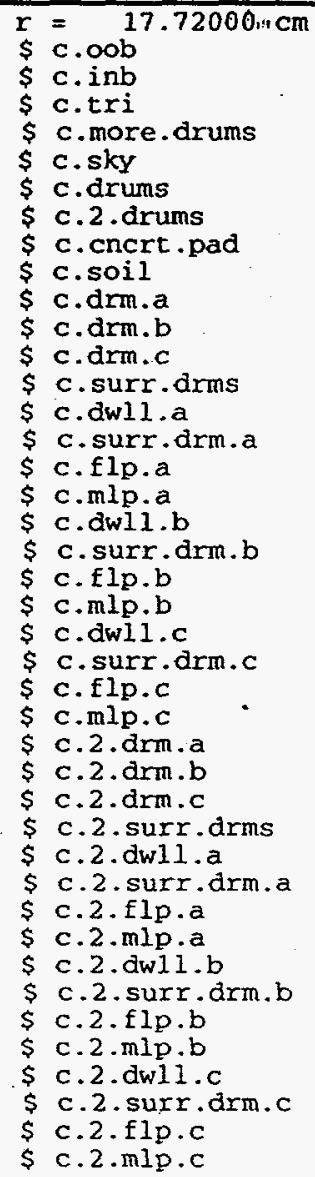 \\
\hline $\begin{array}{l}1 \\
2 * \\
3 * \\
4 * \\
5 \\
6 \\
7 \\
8 \\
9 \\
10 \\
11 \\
12 \\
13 \\
14 \\
15 \\
16 \\
17 \\
18 \\
19 \\
20 \\
21 \\
22 \\
23 \\
24 \\
25 \\
26 \\
27 \\
28\end{array}$ & $\begin{array}{l}\mathrm{so} \\
\mathrm{p} \\
\mathrm{p} \\
\mathrm{p} \\
\mathrm{pz} \\
\mathrm{pz} \\
\mathrm{pz} \\
\mathrm{c} / \mathrm{z} \\
\mathrm{pz} \\
\mathrm{pz} \\
\mathrm{c} / \mathrm{z} \\
\mathrm{pz} \\
\mathrm{pz} \\
\mathrm{s} \\
\mathrm{c} / z \\
\mathrm{c} / \mathrm{z} \\
\mathrm{s} \\
\mathrm{c} / \mathrm{z} \\
\mathrm{C} / \mathrm{z} \\
\mathrm{s} \\
\mathrm{pz} \\
\mathrm{pz} \\
\mathrm{pz} \\
\mathrm{pz} \\
\mathrm{s} \\
\mathrm{s} \\
\mathrm{s} \\
\mathrm{pz}\end{array}$ & $\begin{array}{r}2422.52500 \\
-0.00000 \\
-0.86603 \\
0.86603 \\
174.94250 \\
86.51875 \\
-1.90500 \\
0.00000 \\
84.44814 \\
-0.15189 \\
0.00000 \\
84.29625 \\
0.00000 \\
28.57500 \\
0.00000 \\
0.00000 \\
-14.28750 \\
-52.44920 \\
-52.44920 \\
-66.73670 \\
172.87189 \\
88.27186 \\
172.72000 \\
88.42375 \\
28.57500 \\
-14.28750 \\
-66.73670 \\
-32.38500\end{array}$ & & $\begin{array}{r}0.00 \\
60.56 \\
60.56 \\
85.30 \\
30.281 \\
30.281 \\
5.53\end{array}$ & $\begin{array}{l}1000 \\
312 \\
312 \\
980 \\
156 \\
156 \\
489\end{array}$ & $\begin{array}{r}84.2 \\
28.7 \\
28.5 \\
84.2 \\
28.7 \\
28.5 \\
84.2\end{array}$ & $\begin{array}{l}7500 \\
29625 \\
2689 \\
57500 \\
29625 \\
2689 \\
7500 \\
29625\end{array}$ & $\begin{array}{r}0.00000 \$ \\
0.28156 \$ \\
0.56312 \$ \\
\$ \\
\$ \\
\$ \\
\$ \\
\$ \\
\$ \\
\$ \\
\$ \\
\$ \\
17.72000 \\
\$ \\
\$ \\
17.72000 \\
\$ \\
\$ \\
17.72000 \\
\$ \\
\$ \\
\$ \\
17.72000 \\
17.72000 \\
17.72000 \\
\$\end{array}$ & 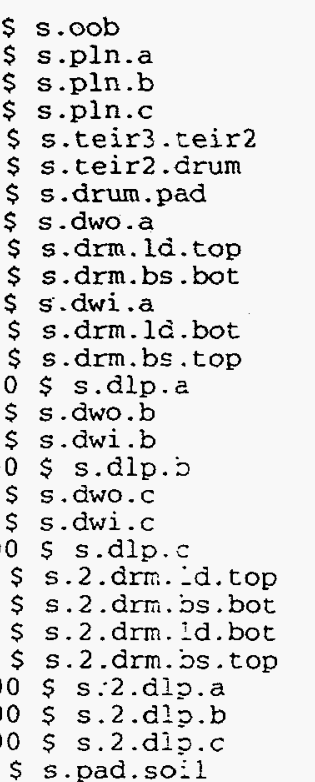 \\
\hline
\end{tabular}


$\cdot$

Figure A.9 - (Continue Case te2fc1)

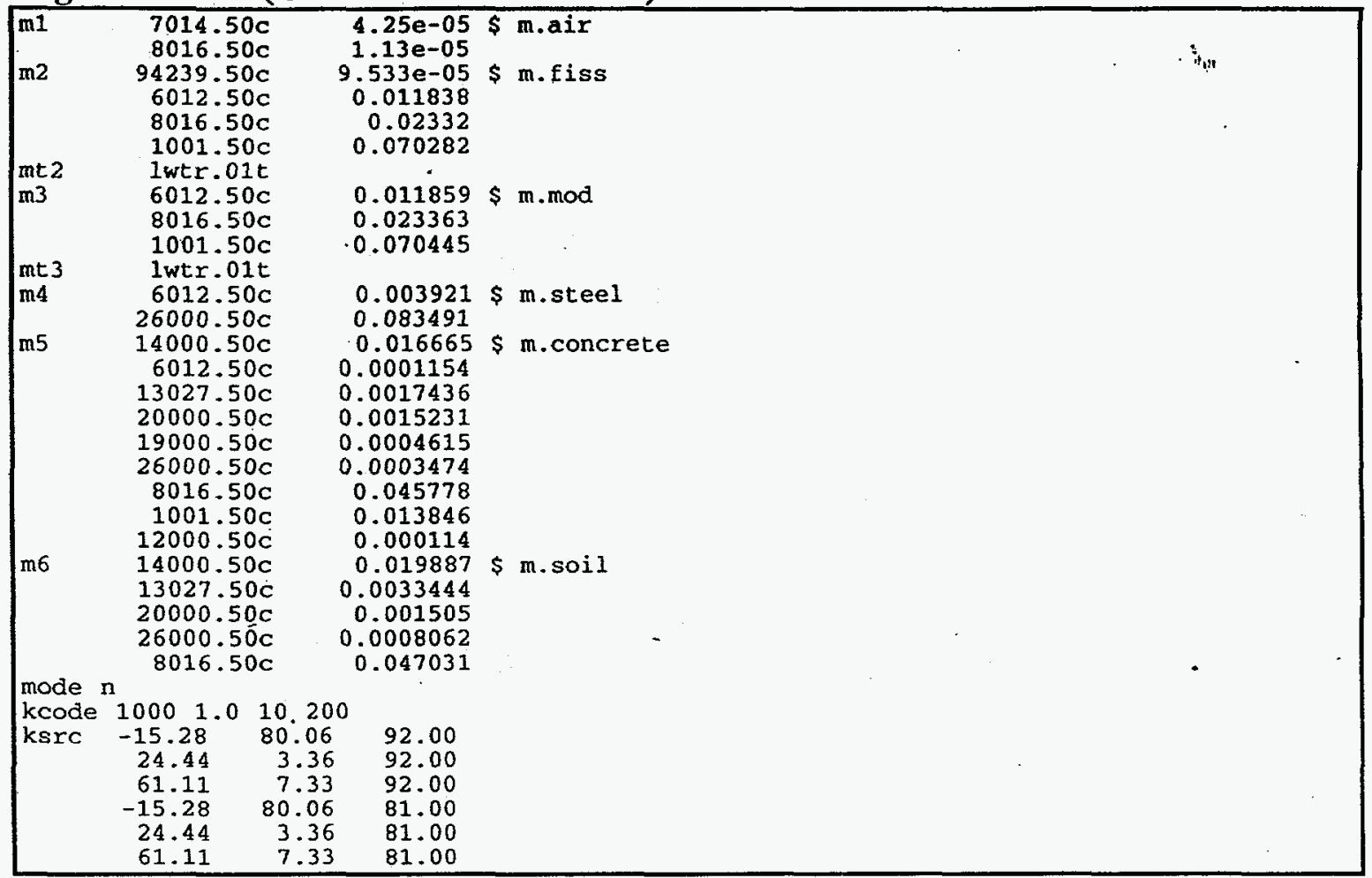


Figure A.10 - MCNP4A Input for Modified case te2fc with rolloing rims overlapping (Case te2fo1).

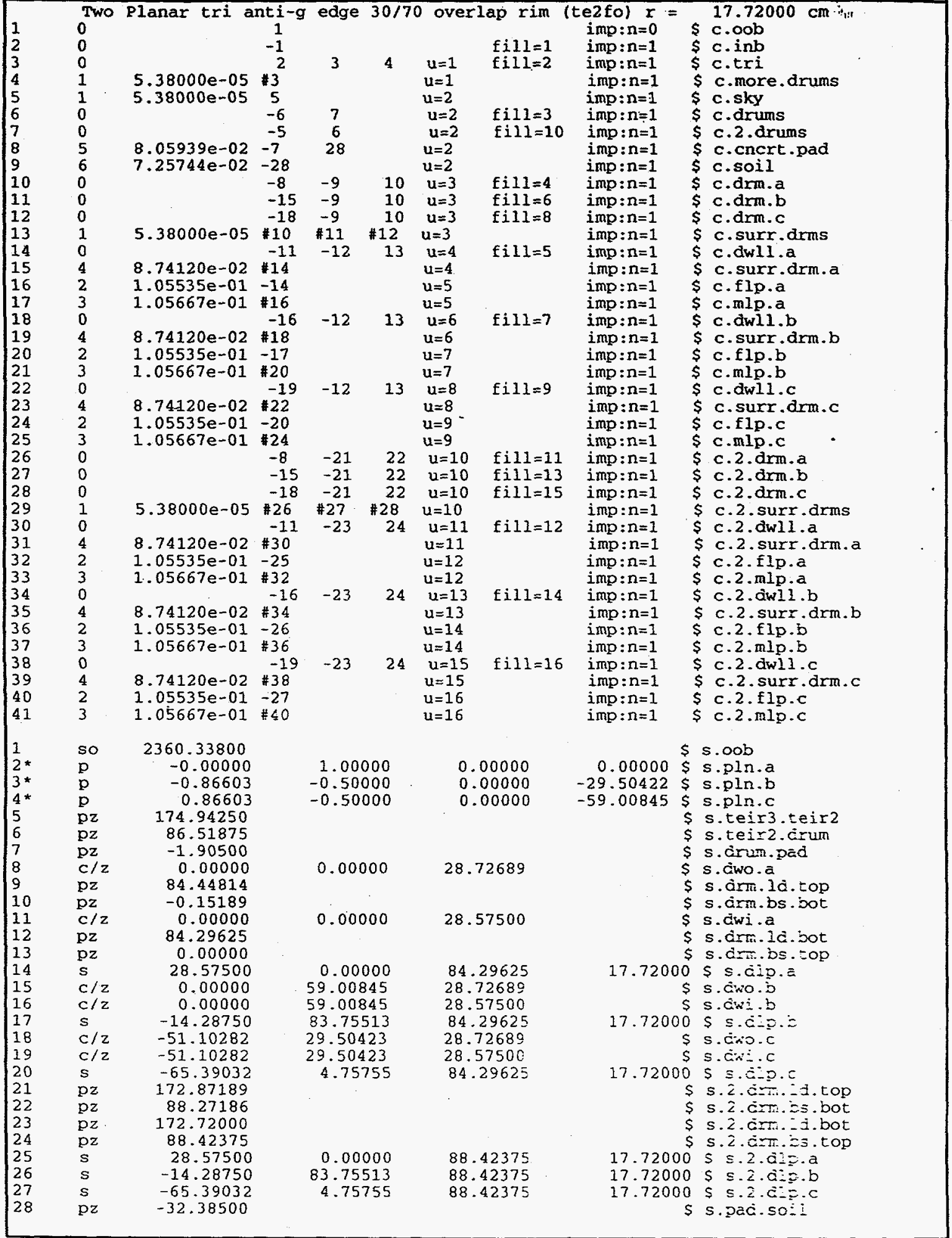


Figure A.10 - (Continue Case te2fo1)

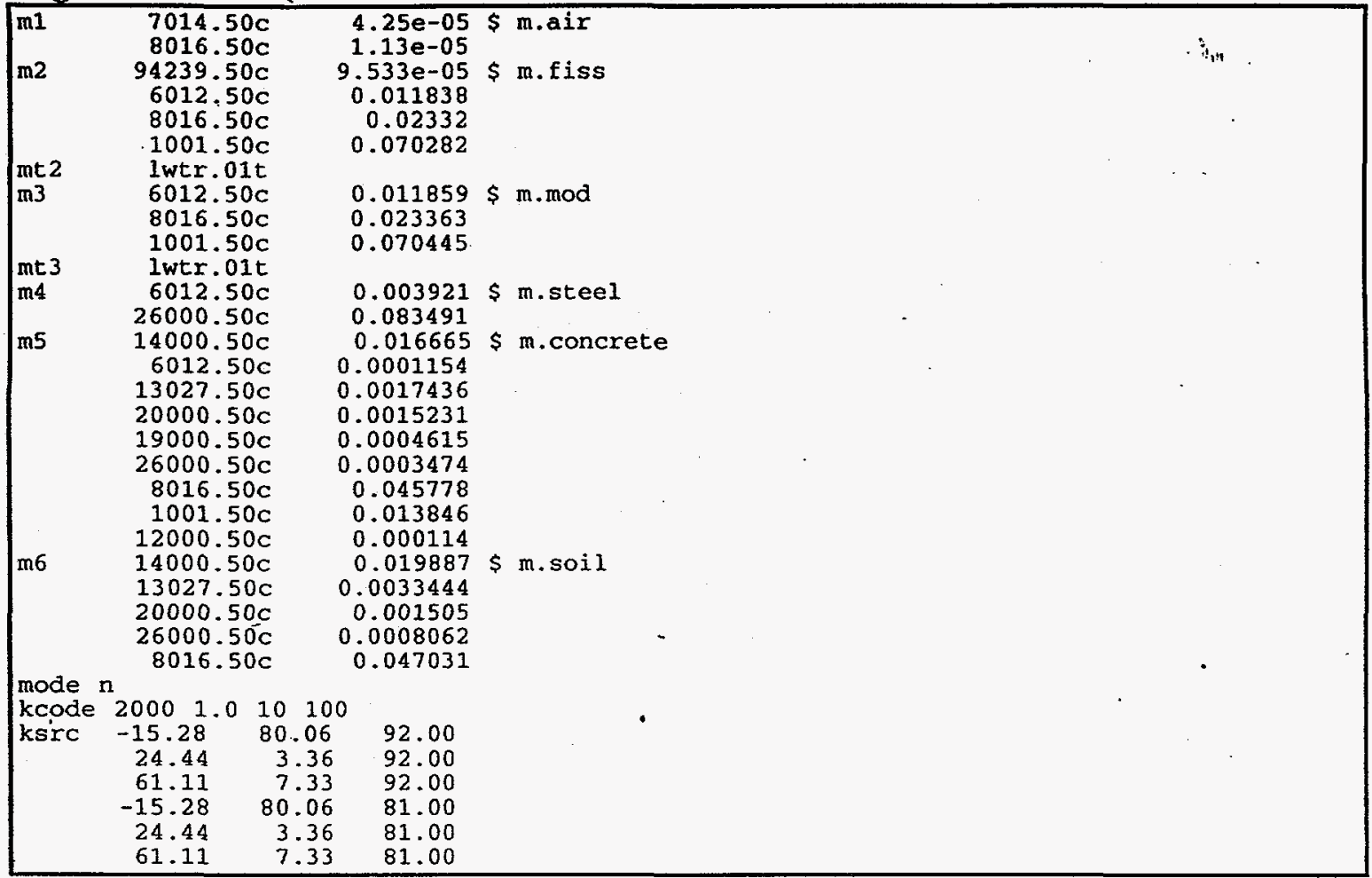


Figure A.11 - MCNP4A Input for Modified case tels with Triangular Pitch array of Drum with Three Edge Located Fissile Lumps (Case tels01).

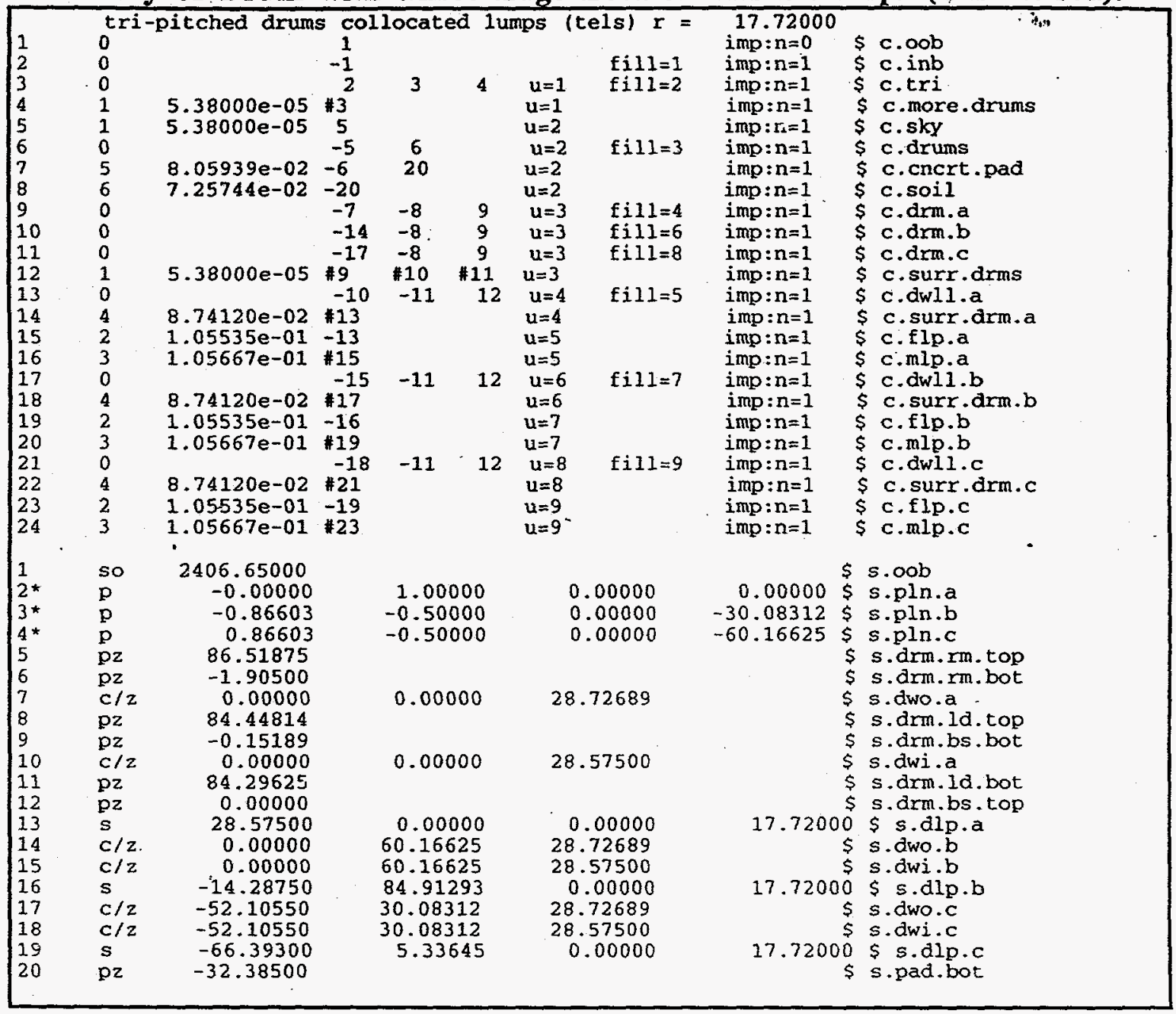


Figure A.11 - (Continue Case tels01)

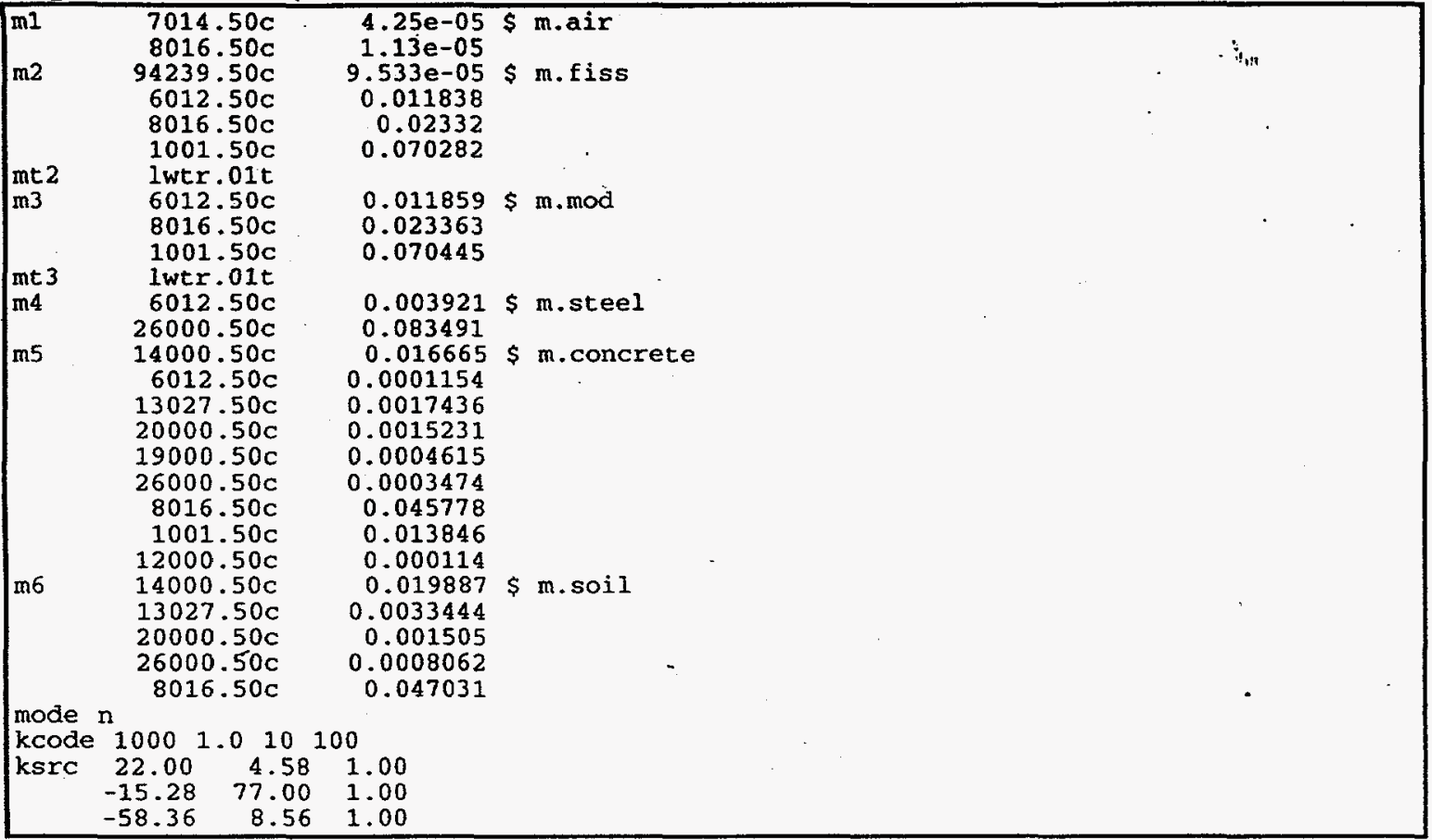


Figure A.12 - MCNP4A Input for Modified case tels with Square Pitch array of Drum with Two Edge Located Fissile Lumps (Case e2ls1).

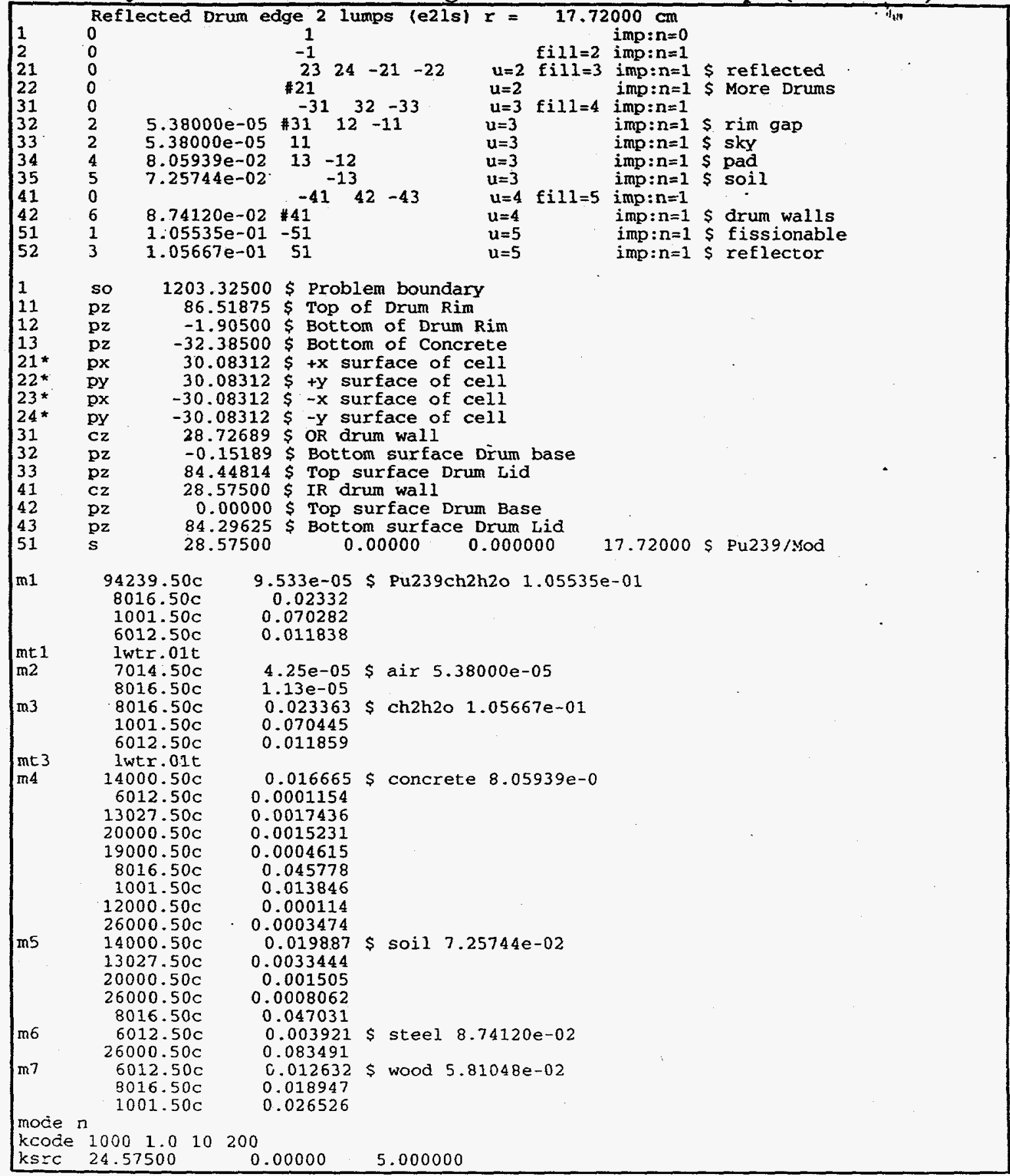


Figure A.13 - MCNP4A Input for Modified case tels with Square Pitch array of Drum with Four Edge Located Fissile Lumps (Case e4Is1).

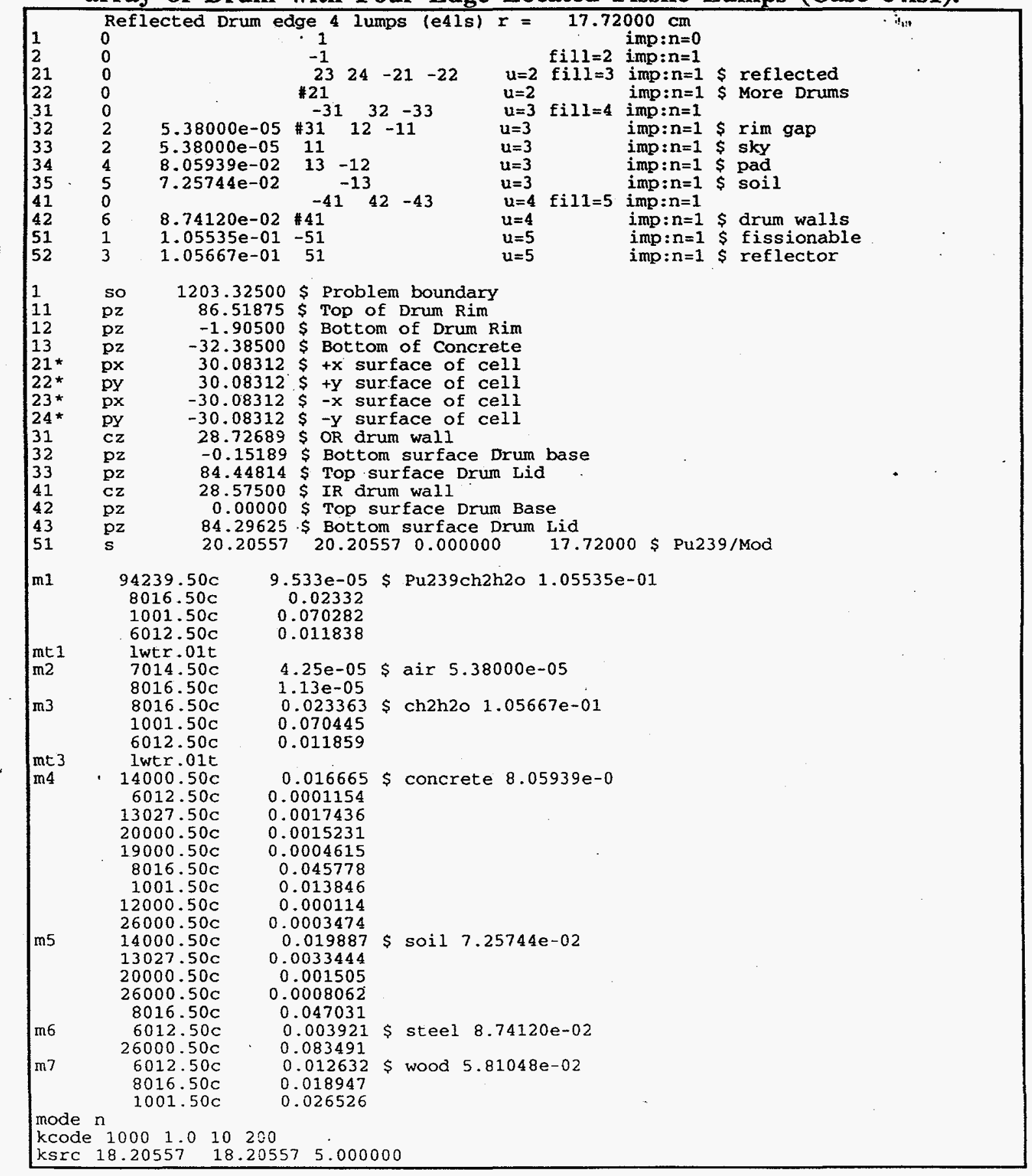


Figure A.14 - MCNP4A Input for Double Planar Array of Drums with Wetted $195 \mathrm{~g}$ Pu-239 Lumps Located at the bottom of the Drums (Case tesgw 1).

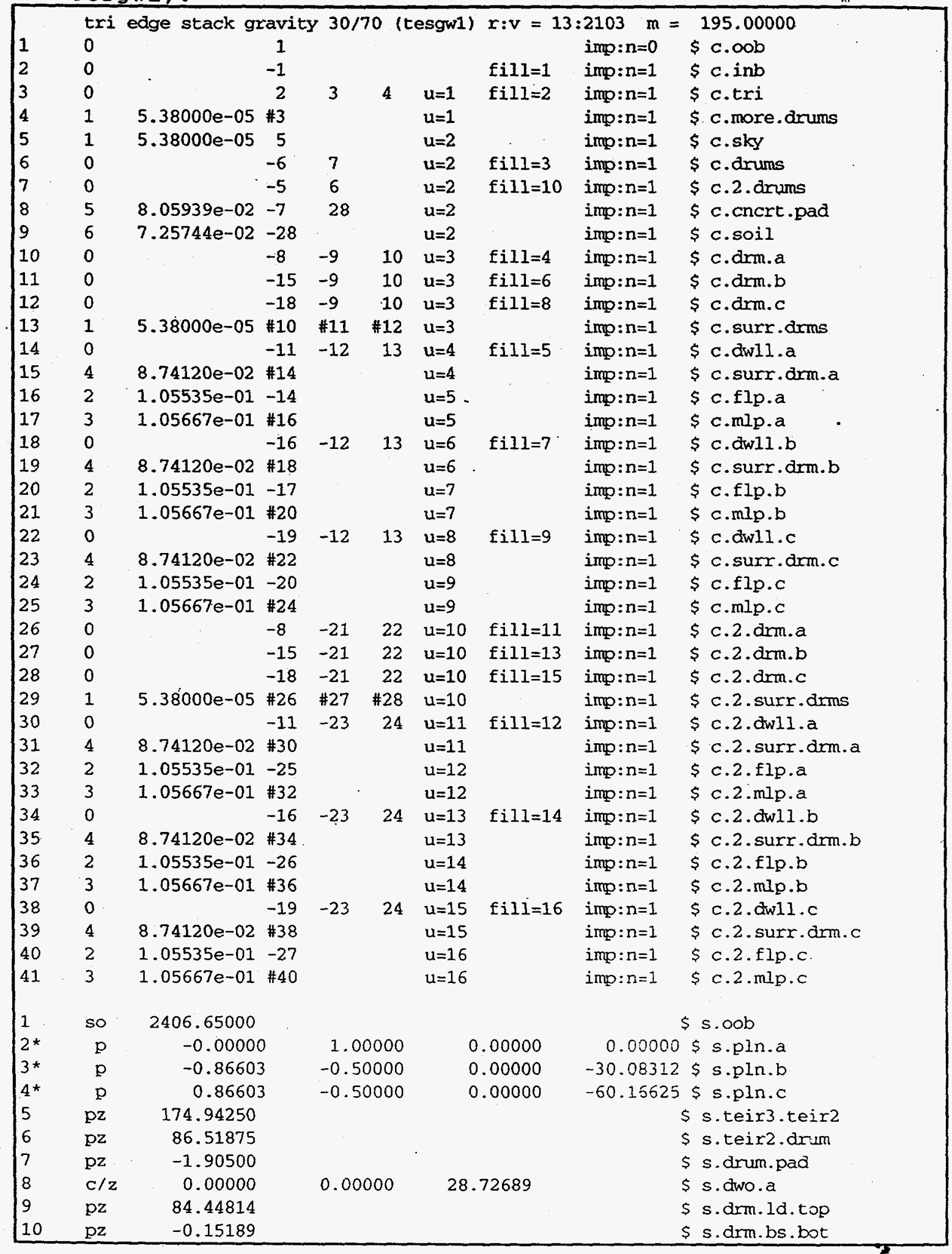


$-\cdots z$

.....

Criticality Safety Envelope for Receipt, Handling, and Storage of Transuranic Waste 6 Nov 97

Figure A.14 - (Continue Case tesgw1)

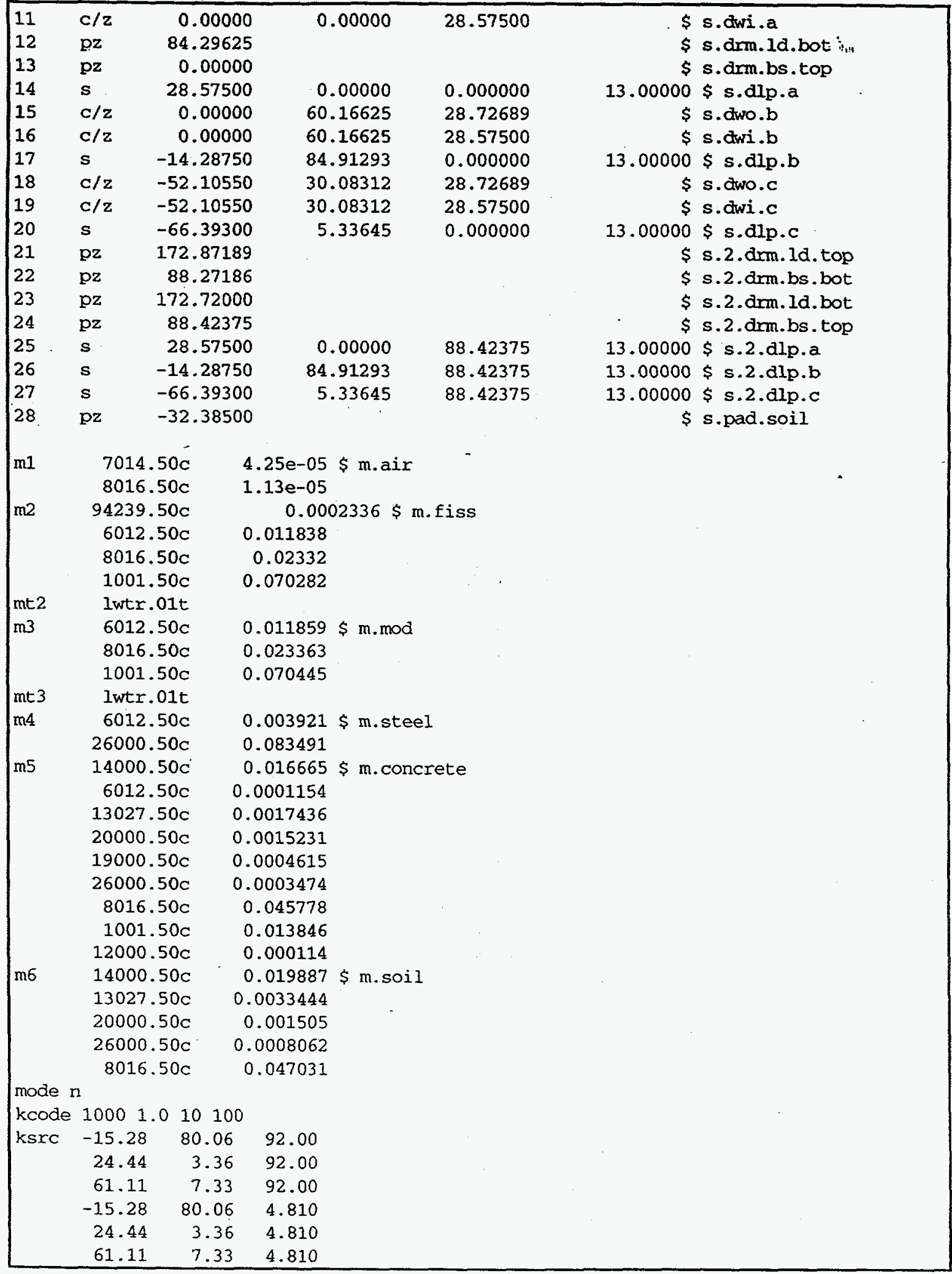




\subsection{APPENDIX B - HEPA FILTER CHARACTERISTICS}

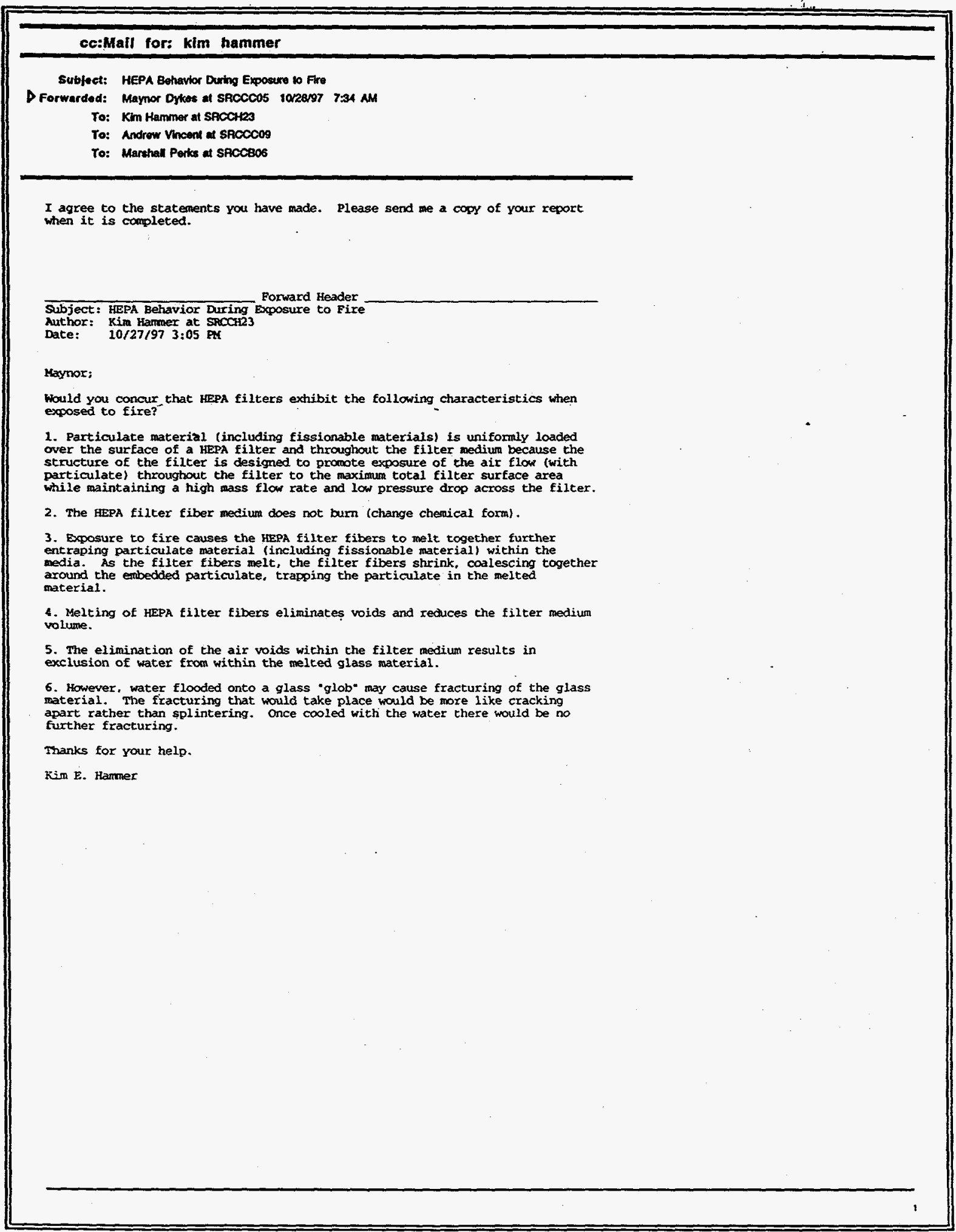

